\title{
The Perceived Role Competencies and Qualifications of Newly Hired Novice and Experienced Nurse Educators in Prelicensure Registered Nurse Programs: A Regional Study
}

\author{
Denice H. Kirchoff \\ West Virginia University
}

Follow this and additional works at: https://researchrepository.wvu.edu/etd

\author{
Recommended Citation \\ Kirchoff, Denice H., "The Perceived Role Competencies and Qualifications of Newly Hired Novice and \\ Experienced Nurse Educators in Prelicensure Registered Nurse Programs: A Regional Study" (2010). \\ Graduate Theses, Dissertations, and Problem Reports. 3536. \\ https://researchrepository.wvu.edu/etd/3536
}

This Dissertation is protected by copyright and/or related rights. It has been brought to you by the The Research Repository @ WVU with permission from the rights-holder(s). You are free to use this Dissertation in any way that is permitted by the copyright and related rights legislation that applies to your use. For other uses you must obtain permission from the rights-holder(s) directly, unless additional rights are indicated by a Creative Commons license in the record and/ or on the work itself. This Dissertation has been accepted for inclusion in WVU Graduate Theses, Dissertations, and Problem Reports collection by an authorized administrator of The Research Repository @ WVU.

For more information, please contact researchrepository@mail.wvu.edu. 
The Perceived Role Competencies and Qualifications of Newly Hired Novice and Experienced

Nurse Educators in Prelicensure Registered Nurse Programs: A Regional Study

\section{Denice H. Kirchoff}

Dissertation submitted to the College of Human Resources and Education at West Virginia University

in partial fulfillment of the requirements

for the degree of

Doctor of Education

in

Educational Leadership Studies

Approved by

Ernest Goeres, Ph.D.

Sharon Boni, Ph.D.

Paul Chapman, Ph.D.

Cynthia Persily, Ph.D.

Richard T. Walls, Ph.D

Department of Educational Leadership Studies

Morgantown, West Virginia

2010

Keywords: Novice; Experienced; Nurse Educator; Competencies; Qualifications

Copyright 2010 Denice H. Kirchoff 


\begin{abstract}
The Perceived Role Competencies and Qualifications of Newly Hired Novice and Experienced Nurse Educators in Prelicensure Registered Nurse Programs: A Regional Study
\end{abstract}

\author{
Denice H. Kirchoff
}

The health care profession is faced with a well publicized shortage of registered nurses. This shortage is accompanied by a declining number of nurse educators who are needed to prepare individuals entering the field. Factors recognized to be related to the educator shortage are the heavy workload and academic demands that immediately confront the new educator. Faculty members have reported feeling overwhelmed and uncertain of their decision to enter academia. Moreover, nurse educators enter into the profession with varying educational backgrounds which pose challenges to their respective nursing program to develop their entry level needs.

The purpose of the study was to determine the perceived qualifications and competencies of nurse educators as they entered into new faculty positions. A sample of 69 newly hired faculty located in six states participated in the study. A comparison of perceived competencies and qualifications of novice nurse educators (one year or less of teaching experience) and experienced nurse educators (greater than one year of teaching experience) was examined. The competencies and qualifications of nurse educators with two types of degree specializations were also explored.

Statistical analyses suggested no significant difference in perceived competency levels for educators with and without teaching experience. Data analyses also revealed no significant difference in perceived competency levels for educators with differing degree specializations. Findings suggest that a thorough assessment of the competencies and qualifications of new faculty be initiated to best support them in their new role. Once completed, nursing programs will be prepared to assist new faculty in meeting their individual needs and further develop the competencies held by the new educator. As a result, new nurse educators will be more likely to remain in the profession as they receive the appropriate guidance needed toward preparing the increased number of registered nurses to alleviate our nation's health care crisis. 


\section{PERCEIVED COMPETENCIES OF NURSE EDUCATORS}

\section{Acknowledgements}

First and foremost, I owe this accomplishment to my mother. Without her, this would not have been possible. Thank you for helping me in any way you could and for caring for Nicholas while I was consumed in my projects. Your help did not ever go unnoticed or unappreciated.

To my father, for always being there with your quiet and gentle strength. Thanks for always worrying about me. You have taught me the value of working hard all of my life.

To my son, Nicholas, thank you for your patience and understanding when you so often heard the words "I have to do my college work." I hope that my determination and perseverance will influence you to work hard in life and to not be afraid to pursue your dreams.

To my brother, for supporting me, and for the countless times I needed your writing expertise. I only hope to someday possess your writing abilities.

To my neighbors, the Harpers, and especially the Danhires, for all the times you were there to take care of my son. You are my second family.

To Penny, for keeping me on track, for your help whenever I needed it, and for your friendship. I am so glad our paths have crossed and I know our friendship will last a lifetime.

To Lisa, for always being there to listen, and for sharing your friendship since nursing school.

To Dr. Goeres, my advisor and my committee chair, for always being there to answer my questions and to lessen my fears. I appreciate all of your guidance and support. I have learned how to be a better teacher from your example.

To Dr. Sharon Boni, for all of your words of encouragement especially when I doubted myself. I couldn't ask for a better mentor and role model than you. You have inspired me in so many ways.

To Dr. Walls, for your time and attention to detail in this process. Your guidance was greatly appreciated.

To Dr. Persily, and my entire committee, for your thoughtful responses, expertise, and insight into this process. 


\section{Table of Contents}

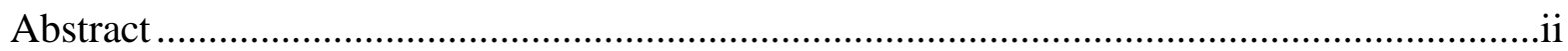

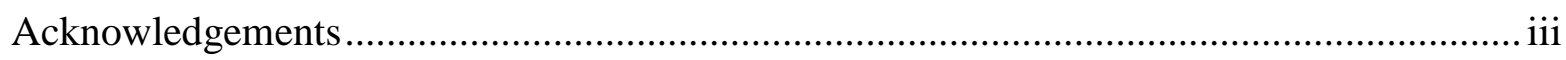

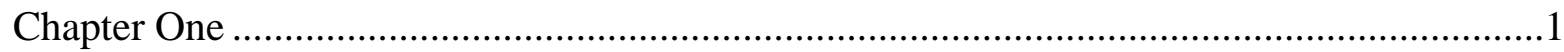

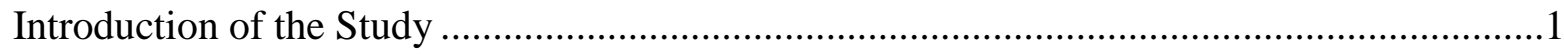

Statement of the Problem ................................................................................. 8

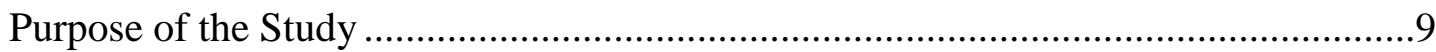

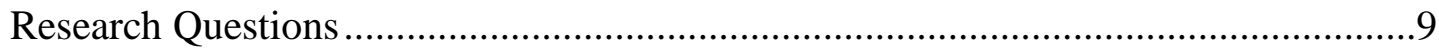

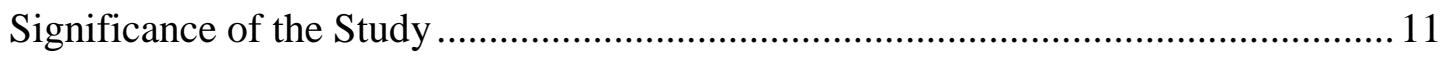

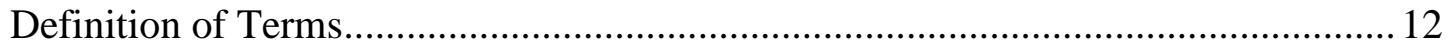

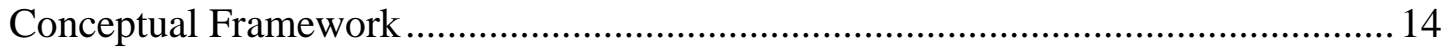

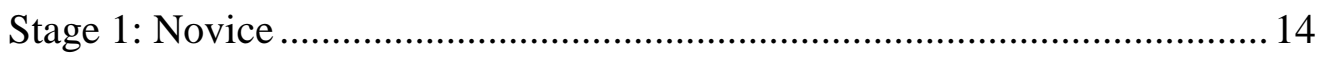

Stage 2: Advanced Beginner................................................................. 15

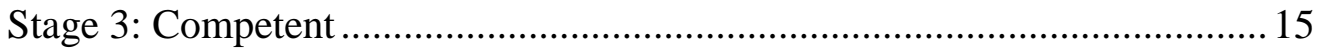

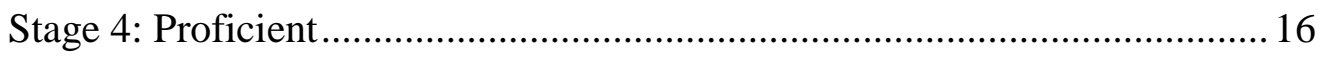

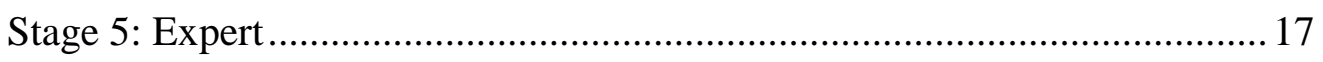

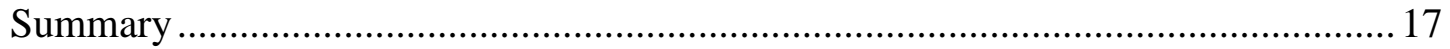

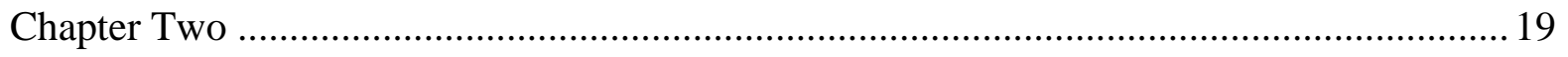

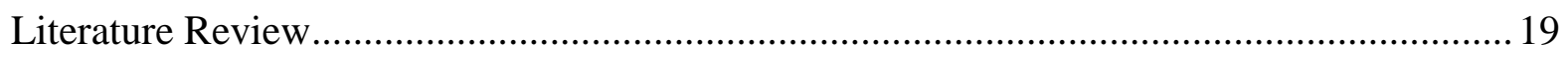

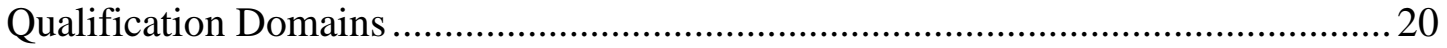

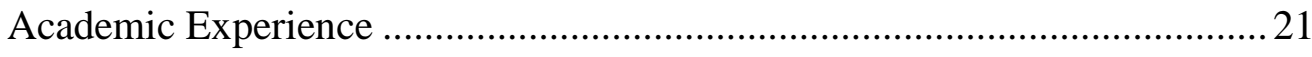

Education Qualifications: Master of Science in Nursing with an

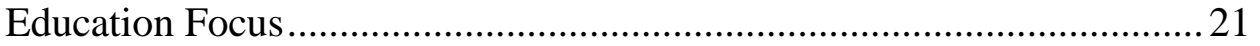

Education Qualifications: Master of Science in Nursing with an Advanced Practice Focus .............................................................. 23

Education Qualifications: Doctoral Preparation ...................................... 24

Clinical Practice Qualifications ............................................................ 25

Collaborator and Leadership Qualifications .......................................... 27

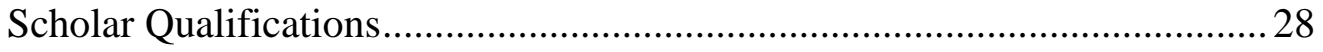

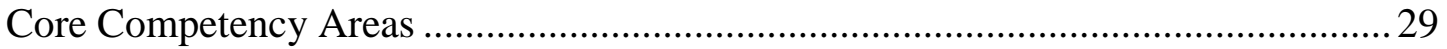




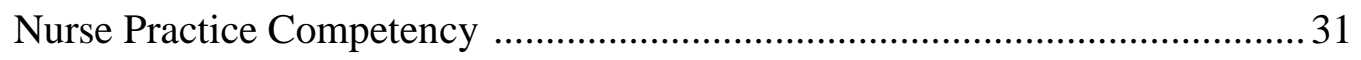

Facilitate Learning Competency …........................................................... 33

Facilitate Learner Development and Socialization Competency …................... 35

Use Assessment and Evaluation Strategies Competency ................................ 37

Design Curriculum and Evaluate Program Outcomes Competency …............... 38

Function Within the Educational Environment Competency ...........................40

Leader and Collaborator Role Competency ................................................. 42

Scholar Role Competency................................................................... 43

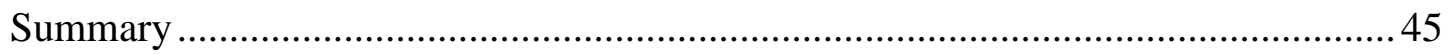

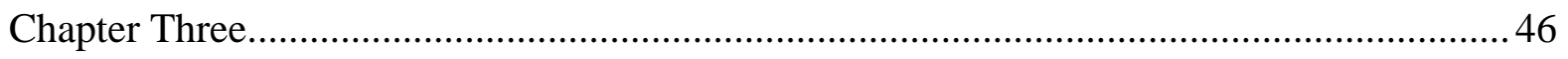

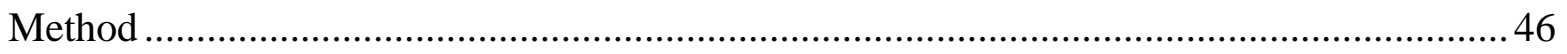

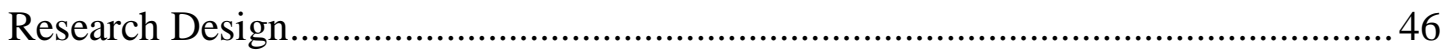

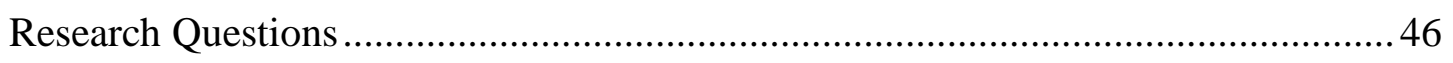

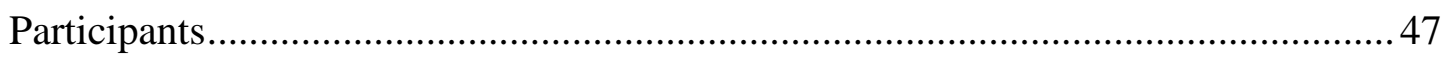

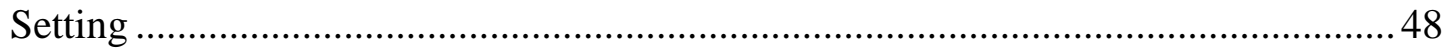

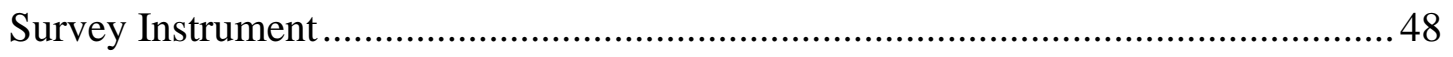

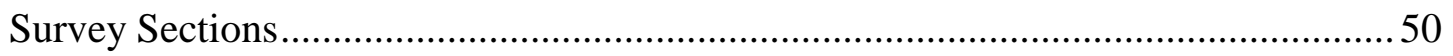

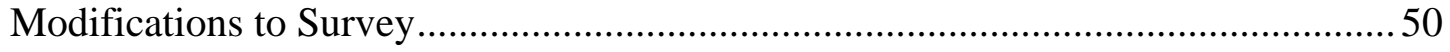

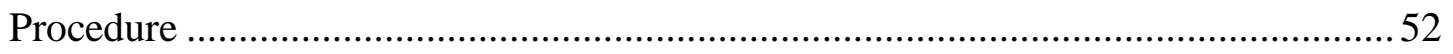

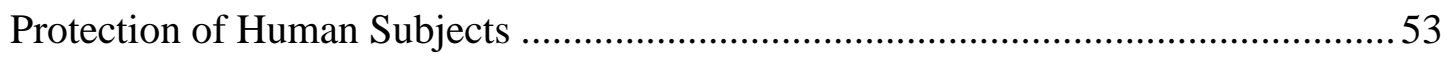

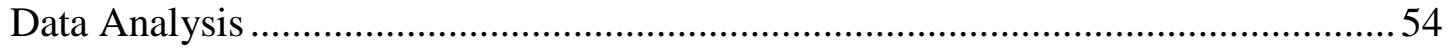

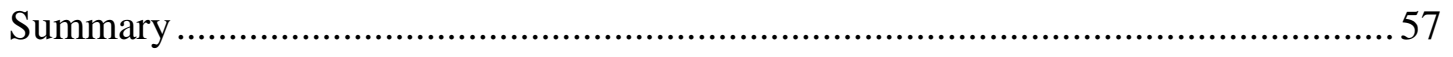

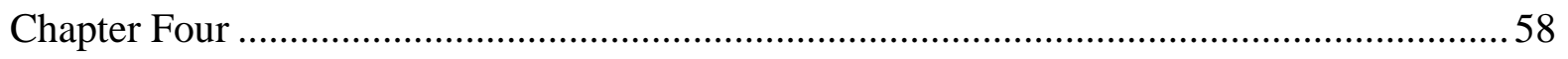

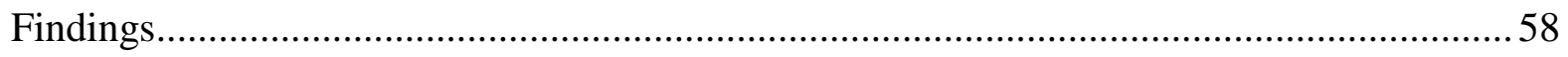

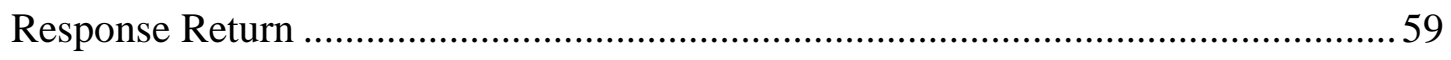

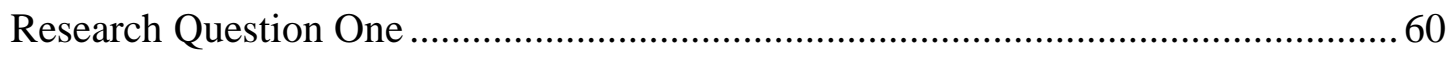

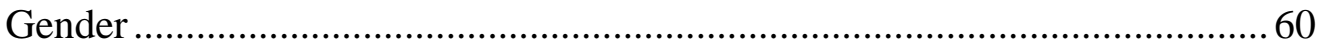

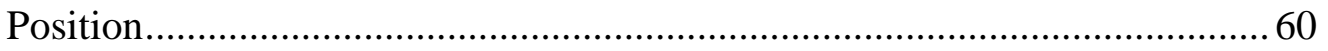

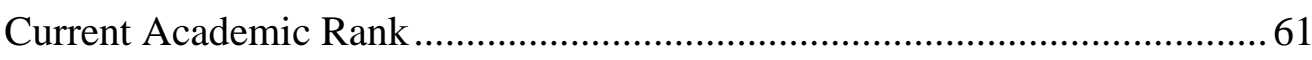

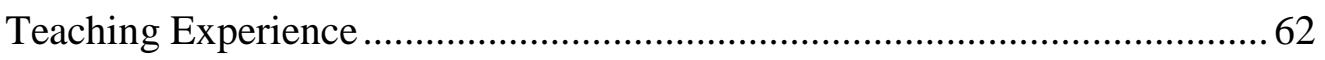

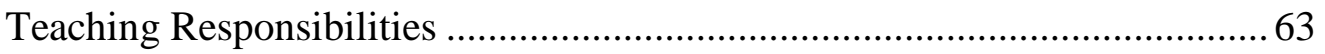




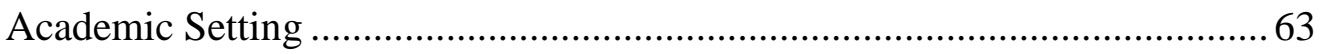

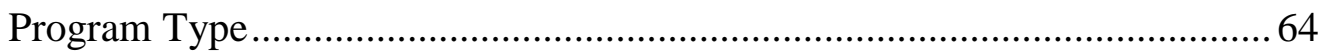

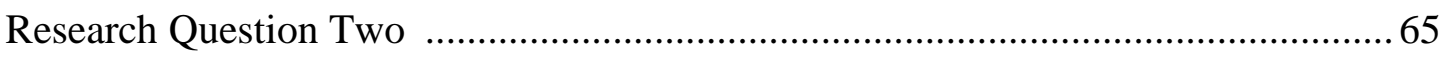

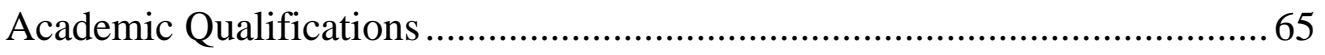

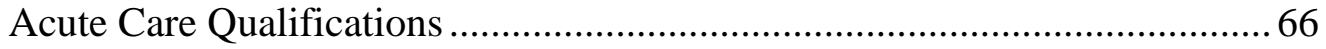

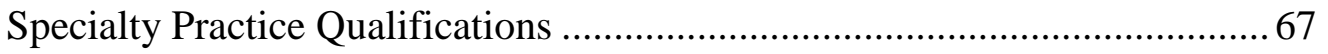

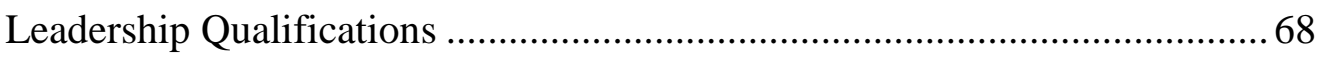

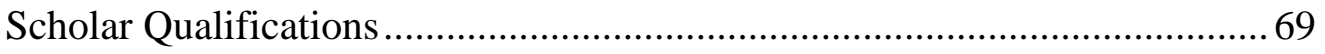

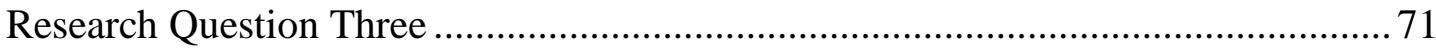

Self-perceived Competency Differences: Novice vs. Experienced Faculty ... 71

Perceived Proficiency Levels: Facilitate Learning .................................... 75

Perceived Proficiency Levels: Facilitate Learner Development and

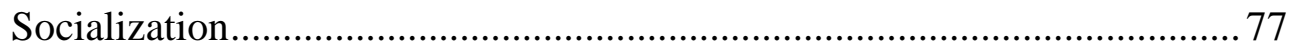

Perceived Proficiency Levels: Use Assessment and Evaluation Strategies.... 79

Perceived Proficiency Levels: Design Curriculum and Evaluate Program

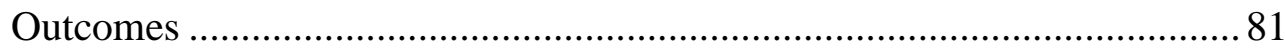

Perceived Proficiency Levels: Function Within the Educational

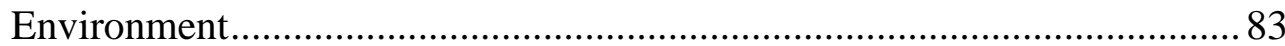

Perceived Proficiency Levels: Leader and Collaborator Role ....................... 85

Perceived Proficiency Levels: Scholar Role............................................... 86

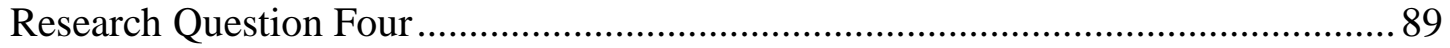

Competency Differences: Degree Types ................................................ 89

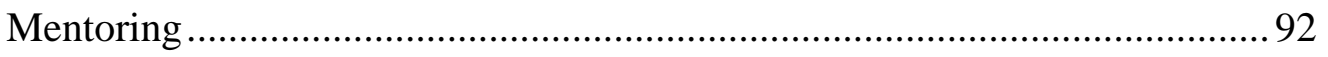

Additional Comments ....................................................................... 95

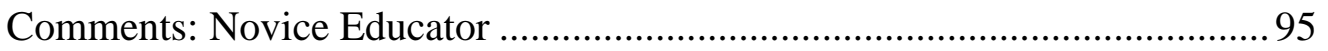

Comments: Experienced Educator ........................................................ 96

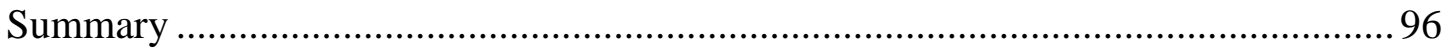

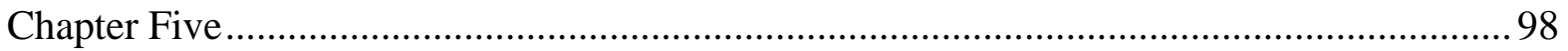

Summary, Conclusions, and Recommendations...................................................... 98

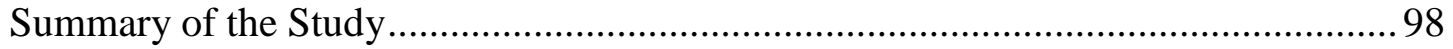

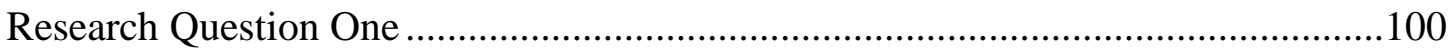




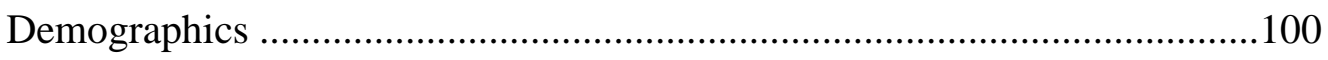

Current Academic Rank ................................................................................. 100

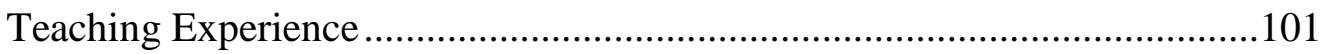

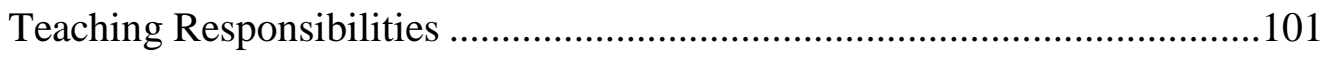

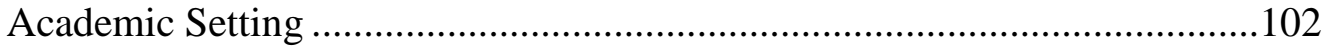

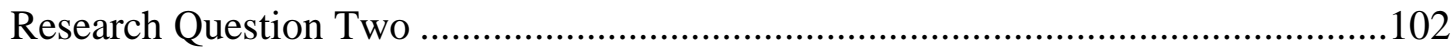

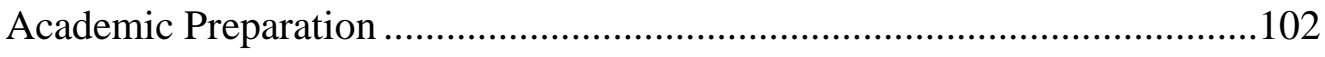

Acute Care and Specialty Practice Qualifications .....................................104

Leader and Collaborator Qualifications ....................................................105

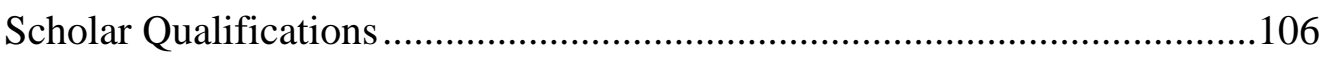

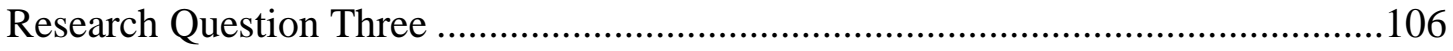

Novice versus Experienced Educators Self-rating of Competencies .............106

Deficiencies Reported by Novice and Experienced Educators .....................107

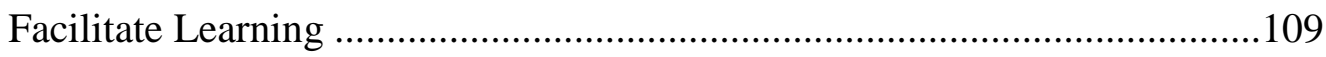

Facilitate Learner Development and Socialization ...................................111

Use Assessment and Evaluation Strategies ..............................................112

Design Curriculum and Evaluate Program Outcomes ................................114

Function Within the Educational Environment.........................................115

Leader and Collaborator Role Competency .............................................117

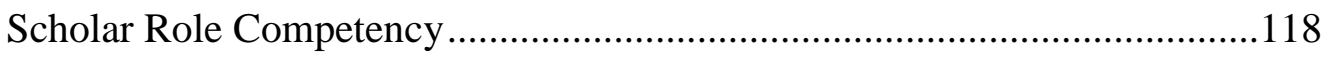

Research Question Four .............................................................................. 119

Advanced Practice versus Nursing Education Focus.................................119

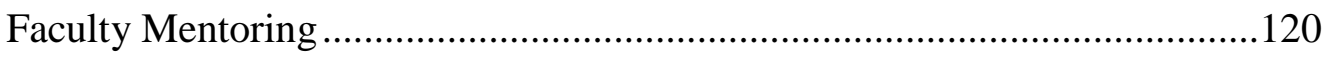

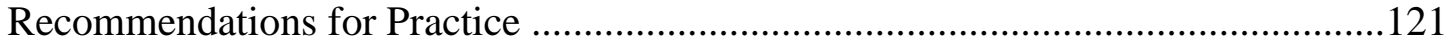

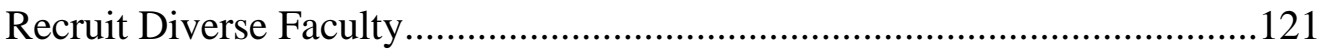

Reduce Workload Complexity .......................................................... 121

Individualize Faculty Needs ............................................................... 122

Develop Formal Mentoring Programs .....................................................122

Provide Competency Overview .........................................................123

Encourage Scholarly Research and Writing ............................................ 123

Engage in Program and Curriculum Development .....................................124 
Review Assessment and Evaluation Procedures ........................................124

Implement Professional Development for Teaching Strategies ...................125

Educate about Departmental and University Responsibilities ......................125

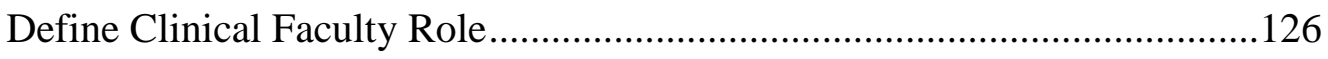

Promote Professional Involvement Opportunities ......................................126

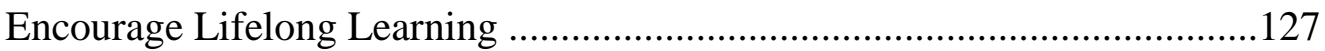

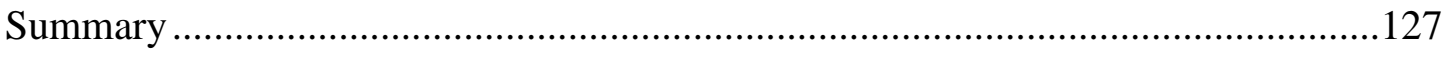

Recommendations for Future Research ....................................................... 127

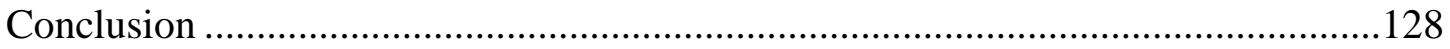

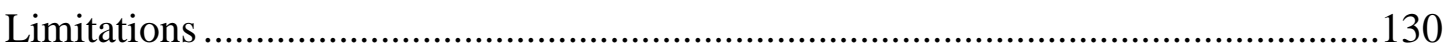

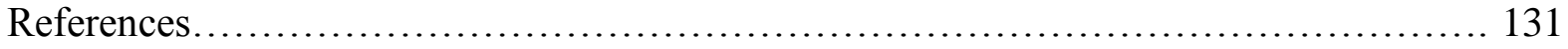

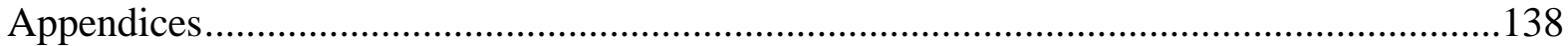

Appendix A: Nurse Educator Inventory Poindexter Survey (2009) ........................138

Appendix B: Initial Letter to Deans and Administrators .........................................143

Appendix C: Permission for Use of Survey...................................................... 144

Appendix D: Letter to Deans with Survey Link ................................................. 145

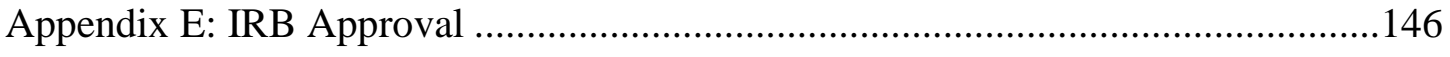

Appendix F: Letter to Participants ................................................................... 147

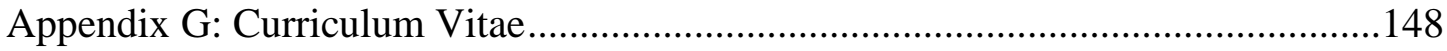




\section{PERCEIVED COMPETENCIES OF NURSE EDUCATORS}

\section{List of Tables}

Table 1 Summary of Research Questions 1-2, Survey Items, and Data Analysis............ 54

Table 2 Summary of Research Question 3, Survey Items, and Data Analysis.......................55

Table 3 Summary of Research Question 4, Survey Items, and Data Analysis ......................56

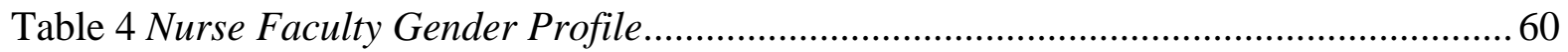

Table 5 Nurse Faculty Academic Position ........................................................................... 61

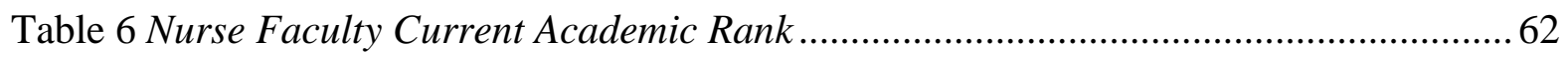

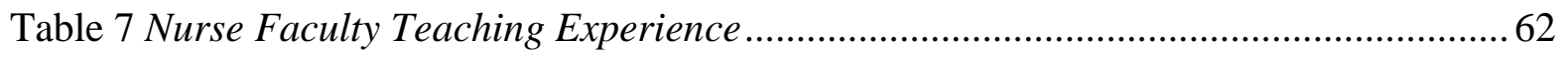

Table 8 Nurse Faculty Teaching Responsibilities .......................................................... 63

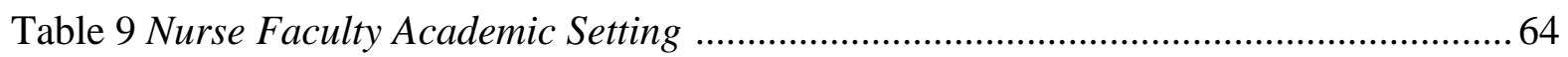

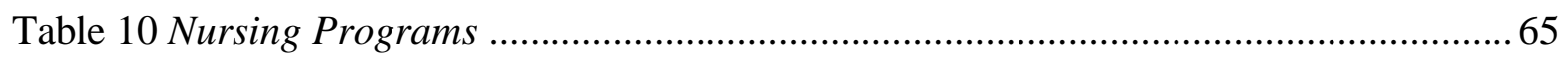

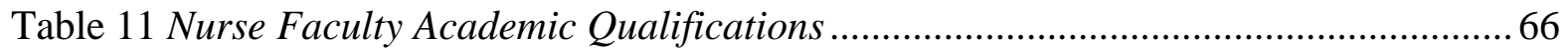

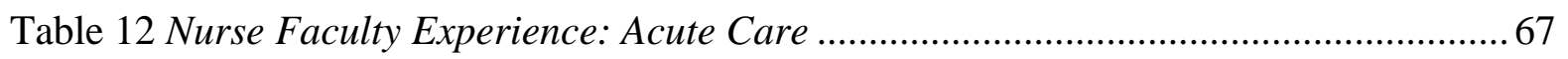

Table 13 Nurse Faculty Experience: Specialty Practice ...................................................6 67

Table 14 Nurse Faculty Experience: Clinical Practice, Advanced Practice, and

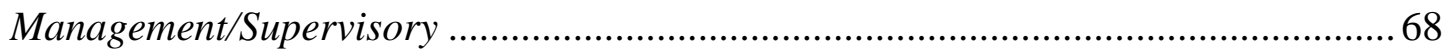

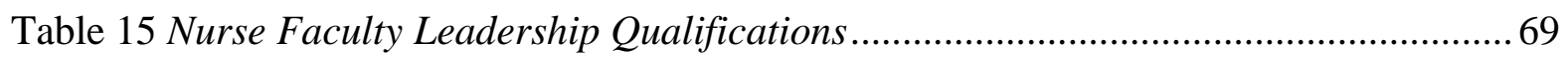

Table 16 Nurse Faculty Scholar Qualifications ............................................................... 70

Table 17 Differences in Perceived Competencies: Novice versus Experienced Nurse

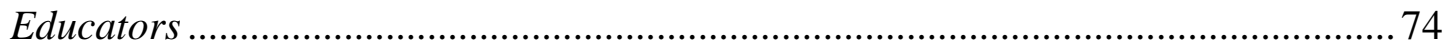

Table 18 Proficiency Ratings to Facilitate Learning ......................................................... 76

Table 19 Proficiency Ratings to Facilitate Learner Development and Socialization ............ 78

Table 20 Proficiency Ratings to Use Assessment and Evaluation Strategies....................... 80

Table 21 Proficiency Ratings to Design Curriculum and Evaluate Program Outcomes ....... 82

Table 22 Proficiency Ratings to Function Within the Educational Environment .................. 84

Table 23 Proficiency Ratings to Demonstrate Leader and Collaborator

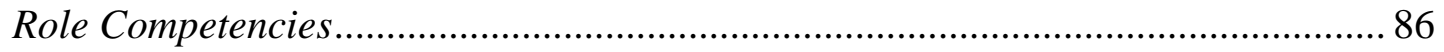

Table 24 Proficiency Ratings to Demonstrate Scholar Role Competencies .......................... 87

Table 25 Differences in Nurse Educator Competencies by Degree Type ............................. 91

Table 26 Mentoring Program Participation ................................................................... 92

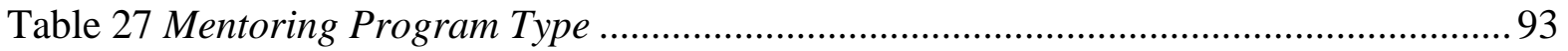


Table 28 Mentoring Program Delivery ........................................................................ 93

Table 29 Nursing Faculty Mentors ........................................................................... 94

Table 30 Competencies Addressed through Mentoring Programs..................................... 94

List of Figures

Figure 1 NLN (2005) and Poindexter (2008) Competency Comparison ............................ 20

Figure 2 Faculty Deficiency Comparison: Facilitate Learning Competency .......................109

Figure 3 Faculty Deficiency Comparison: Facilitate Learner Development

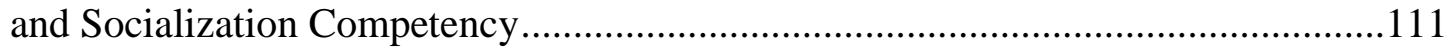

Figure 4 Faculty Deficiency Comparison: Use Assessment and Evaluation Strategies

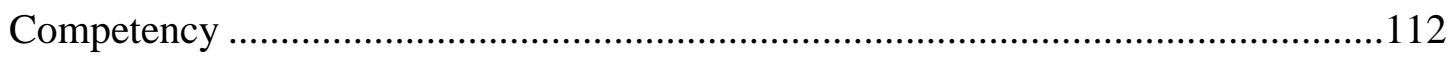

Figure 5 Faculty Deficiency Comparison: Design Curriculum and Evaluate

Program Outcomes Competency ................................................................... 114

Figure 6 Faculty Deficiency Comparison: Function Within the Educational

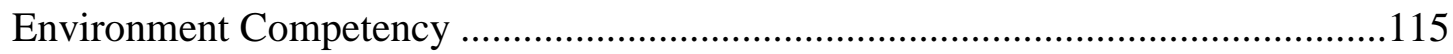

Figure 7 Faculty Deficiency Comparison: Exhibit Leader and Collaborator Competency ...117

Figure 8 Faculty Deficiency Comparison: Demonstrate Scholar Role Competency 


\section{PERCEIVED COMPETENCIES OF NURSE EDUCATORS}

\section{Chapter One}

The United States is currently experiencing a serious shortage of registered professional nurses. According to the American Association of Colleges of Nursing (AACN, 2008a), there are currently 400,000 registered nurse positions needed in the United States. This number is expected to increase to as high as 500,000 by 2025 as baby boomers age and the need for healthcare in this country continues to grow (AACN, 2008a). Moreover, while industry information regarding the nursing shortage logically places emphasis on the need for more registered professional nurses, an equally important issue is the need for an increased number of qualified nurse educators who are required to educate individuals who desire to enter the profession (AACN, 2008b; Falk, 2007; NLN, 2002; NLN, 2005a; Valiga, 2003). Recent statistics indicate that in the 2008-2009 academic year, nursing schools in the United States had to reject the admission of 49,948 qualified applicants needed for the future nursing workforce due to the insufficient numbers of qualified nurse educators (AACN, 2008b).

The statistics regarding the lack of qualified nurse educators have been evident in the literature and have been attributed to the difficulty with recruiting and retaining new faculty. According to the American Association of Colleges of Nursing, a total of 767 faculty vacancies were identified at 344 nursing schools with baccalaureate and/or graduate programs across the country (AACN, 2008b). The National League for Nursing (NLN) also indicated that vacant faculty positions were attributed to retirement and that 36.5 percent of faculty left their positions because of this reason (NLN, 2005a). The AACN reported that the average age of nurse educators for professors, associate professors, and assistant professors was 58.9, 55.2, and 50.1 years respectively, which indicates that the educator shortage will remain a real concern for many years into the future (AACN, 2008b). Similarly, it has been estimated that 75 percent of 


\section{PERCEIVED COMPETENCIES OF NURSE EDUCATORS}

the current faculty population will retire by 2019. Because of these statistics, the shortage of nurses and nurse educators has been rightfully recognized as a national "crisis" (NLN, 2002, p.1; Foxall, Megel, Grigsby, \& Billings, 2009).

The adjustment into academia for nursing educators has been complicated because faculty members are prepared differently for their educator roles. According to the National League for Nursing (NLN), many nurse educators do not possess the skills necessary to function effectively in the teaching environment (NLN, 2006). Depending on the educational background of new faculty, some nurse educators may possess efficient clinical skills while others may possess a broader scope of knowledge regarding classroom and pedagogical skills. A thorough assessment of the baseline knowledge and abilities of new faculty designed to determine the specific areas in which newly hired novice educators possess strengths and shortcomings may help nursing programs devote attention to these areas. This would not only facilitate a new faculty member's transition into the academic setting, but also further develop competence in the clinical and classroom settings.

Because of the issues contributing to the shortage of nurse educators, including the proper methods to be used during the professional development of newly hired educators, a solid understanding of their qualifications and competencies is needed. The NLN has initiated several strategies to bring increased awareness to the profession regarding these issues. The NLN has also offered suggestions intended to meet these challenges and has recognized the need for the profession to develop the evidence-base needed to enhance the development and refinement of the educator role (NLN, 2002).

The first initiative was announced in 2002 through the publication of the position statement entitled "The Preparation of Nurse Educators" (NLN, 2002). Within this statement, the 


\section{PERCEIVED COMPETENCIES OF NURSE EDUCATORS}

NLN Board of Governors discussed the impact of the nurse educator "crisis" (p. 1) and brought attention to the necessity of recruiting seasoned registered nurses who have demonstrated the requisite skills and interest in teaching. The organization also addressed the need for increased opportunities for graduate programs to assist and support development opportunities for the educator role.

The NLN articulated its views regarding the type of educational preparation required for an individual desirous of pursuing a career in nursing education. The two most commonly known educational pathways that can potentially be chosen by nurse educators seeking an advanced degree to teach nursing included a Master's degree with an education focus or a clinical advanced practice focus. Regardless of the pathway, a Master's degree is the minimum requirement necessary to teach full-time in nursing education (Ellis \& Hartley, 2008). However, according to the NLN (2002):

The academic community should not assume that individuals are qualified to teach simply because they hold a particular credential (i.e., master's degree or doctorate) and have expertise in a particular area (whether that be nursing, statistics, or any other field). (p. 3)

The Master's degree with an advanced practice focus encompasses several clinical specialties and includes the roles of the clinical nurse specialist, nurse practitioner, nurse midwife, and nurse anesthetist (ANA, 1996). Master's degree programs that prepare an individual for this type of specialization place attention on the study of a particular clinical focus. This requires an individual to obtain a certain number of hours of direct clinical experience within a preferred area of specialization (Ellis \& Hartley, 2008; NLN, 2006; Thrall, 2005). The NLN (2002) acknowledged the importance and advantages of a formal background in a clinical 


\section{PERCEIVED COMPETENCIES OF NURSE EDUCATORS}

advanced practice specialty. The NLN noted that nurse educators with advanced practice experience often possess the required knowledge to teach in the clinical domain of nursing education and provide an important contribution to nursing education. However, the NLN (2002) conveyed that this type of specialization does not sufficiently prepare an individual to conduct the pedagogical approaches necessary to adequately prepare students enrolled in nursing entry level educational programs.

Conversely, the Master's degree with a nursing education focus prepares an individual to specialize and subsequently teach in nursing education. This specialization encompasses methods that foster the development of the knowledge and skills necessary to teach in an academic setting and ultimately achieve success in the educator role (NLN, 2002). The NLN (2002) recommends this pathway as the best route to pursue for purposes of achieving the level of preparation required of the nurse educator. Despite this view, there have been reports which have indicated that regardless of the type of educational preparation, individuals entering into the teaching role experience a rather difficult learning transition upon entrance into the academic environment (Siler \& Kleiner, 2001; Sienty, 1988; Young, 1999).

In short, differing educational backgrounds and clinical qualifications exist among nurse faculty (NLN, 2002) and because of the declining supply of nurse educators, recruiting nurse educators solely with an education specialization is not realistically possible. In turn, recruiting faculty who possess a master's degree that emphasizes either an advanced practice or a teaching specialization is more viable (Anderson, 2008). Nursing programs should acknowledge these differences, carefully examine newly hired faculty strengths and shortcomings, and define a path for new faculty members that will foster the development of their unique approaches toward 


\section{PERCEIVED COMPETENCIES OF NURSE EDUCATORS}

fulfilling the educator role. As a result, their role and transition into the academic setting can be further supported and developed by the nursing programs in which they are employed.

In 2005, the NLN took on a second initiative to develop and publish the Nurse Educator Core Competencies which were identified in "The Scope of Practice for Academic Nurse Educators" (NLN, 2005b). These competencies were developed by a faculty task force that consisted of a group of expert nurse educators located throughout the country (Halstead, 2007). After extensive review of the literature and research regarding the roles of the nurse educator, eight core competencies were established. The competencies were created to provide an outline defining the required knowledge and skills necessary to achieve successful fulfillment in the nurse educator role (Halstead, 2007). The competencies were also intended to serve as a direction for graduate curricula to better prepare individuals for a career in nursing education as well as to guide nurse faculty toward demonstrating excellence in the role by achieving national certification as a nurse educator.

The eight core competencies include: (a) facilitate learning, (b) facilitate learner development and socialization, (c) use assessment and evaluation strategies, (d) participate in curriculum design and evaluation of program outcomes, (e) function as a change agent and leader, (f) pursue continuous quality improvement in the nurse educator role, (g) engage in scholarship, and (h) function within the educational environment (NLN, 2005b; Billings \& Halstead, 2009; Halstead, 2007). Moreover, each of the identified competencies contains task statements that specifically identify the skills needed to achieve a particular competency.

The development of the competencies has contributed to providing a clear framework to guide the profession of nursing education (Halstead, 2007). The competencies are also useful for offering a direction for developing new nurse faculty. Therefore, it is important for nursing 


\section{PERCEIVED COMPETENCIES OF NURSE EDUCATORS}

programs to carefully examine the competencies held by their new faculty. Nursing programs hiring new faculty should not assume that because faculty members have been educated in a certain area that they understand and have the ability to function efficiently in the role. New nurse educators should communicate their own perceptions regarding their competency levels because there may be differences in the expectations of new faculty by senior faculty as compared to how new faculty see themselves (Siler \& Kleiner, 2001; Young, 1999).

The third initiative of the National League for Nursing was noted in the NLN's 2006 Position Statement entitled, "Mentoring of Nurse Faculty." This organization acknowledged the need for nursing programs to initiate effective faculty development programs in an effort to retain newly hired faculty. The position statement also indicated that mentoring was not only important to enhance the development of the newly hired educator in their role, but also had the effect of establishing a welcoming environment for the individual (NLN, 2006).

Effective faculty development and mentoring should begin with an acknowledgment of the individual differences in entry level qualifications as well as with an assessment of the knowledge and skills of incoming faculty (Blauvelt \& Spath, 2008). By first examining the qualifications and competencies of new faculty, nursing programs can gather the information required to begin to individualize the needs of new faculty, build upon their strengths, and remedy their shortcomings. Lewallen, Crane, Letvak, Jones, and $\mathrm{Hu}$ (2003) noted that "failure to identify the individual needs of new faculty may also contribute to stress" (p. 258) for new faculty, a problem that has been apparent in newly hired educators in the nursing profession. Moreover, Baker (2007) concluded that "nurse educators, during their first full-time teaching year, should feel they are being nurtured and provided with the tools they need to be successful in academia"(p. 238). 


\section{PERCEIVED COMPETENCIES OF NURSE EDUCATORS}

To date, there is limited quantitative research that assesses the entry level qualifications of newly hired nurse educators as well as their knowledge of the core competencies for nurse educators. Much of the literature has uncovered assessments of novice educators' experiences through qualitative methodologies (Siler \& Kleiner, 2001; Young, 1999; McDonald, 2004; Sienty, 1988; Horat, 2008; Lewallen, et al., 2003). Some of this research also included information pertaining to the experienced educators as well.

The quantitative research presented by Poindexter (2008) addressed the core competencies and qualifications of novice nurse educators and was used to develop this study. Poindexter's (2008) dissertation research at Western Michigan University provided an analysis of entry-level qualifications and competencies of novice faculty teaching in prelicensure registered nurse programs. This national study used a survey to determine deans and administrators' perceptions of their preferred entry-level competencies of novice nurse educators. The results of the study indicated that deans and administrators had high expectations of the qualifications and competencies of their new faculty.

The study further defined what qualifications and competencies were necessary to obtain an educator position in several types of academic institutions. Poindexter (2008) stated the results of the study added input toward developing new avenues for improving the preparation of nurse educators. In addition, Poindexter (2008) noted that her study would be of value in enhancing the development of nurse educators upon entering into this role. In her recommendations for future research, Poindexter (2008) stated that similar studies could be conducted using newly hired novice nurse educators' own perceptions of their competencies which could offer further information toward the education and career development of nurse educators. 


\section{PERCEIVED COMPETENCIES OF NURSE EDUCATORS}

\section{Statement of the Problem}

The shortage of nursing faculty has frequently been connected to many factors.

Retirement, poor salaries, and competition with practice roles have been well documented as reasons for the faculty shortage (NLN, 2002; NLN, 2005a; Hessler \& Ritchie, 2006; Brady, 2007). Another contributing factor is the difficult professional adjustment experienced by many new faculty members resulting from the intense demands and workload of their new positions (Thorpe \& Kalischuk, 2003; Kirchoff, 2008; McDonald, 2004; Brady, 2007; NLN 2005a). This contributes greatly to a sense of uncertainty regarding their career choice and is directly responsible for the premature departure of many nurse educators from their chosen profession (Sienty, 1988; Siler \& Kleiner, 2001).

Upon entering into their role, nurse educators must balance the demands of a practice profession which requires teaching in both clinical and classroom settings. Newly hired nurse faculty are confronted with the expectations of performing and possessing knowledge in both of these domains while simultaneously transitioning into the academic world, which demands continued demonstrations of meritorious scholarship, research, and service (Baker, 2007; NLN 2006; Blauvelt \& Spath, 2008; Siler \& Kleiner, 2001). These complex expectations have been reported to create role strain, stress, and frustration for new faculty that could hinder their ability to successfully meet these challenges. It is thus imperative that these issues be recognized and addressed by nursing education programs so that proper support can be provided to the new faculty member during this difficult transition period (Blauvelt and Spath, 2008; McDonald, 2004; NLN, 2006). 


\section{PERCEIVED COMPETENCIES OF NURSE EDUCATORS}

\section{Purpose of the Study}

The purpose of the study was to identify the perceived competencies of newly hired nurse educators during their entry into a full-time teaching position in a prelicensure registered nursing accredited program. This study also examined how novice and experienced nurse educators perceive themselves as being prepared for the faculty role. According to Neese (2003), selfexamination is important to the teacher role when entering into the profession. Identifying perceived proficiency qualifications and competency levels will identify the strengths and shortcomings of newly hired educators; therefore, allowing mentoring initiatives to be developed according to individual needs. The nurse educator shortage requires strategies that assist with nurturing and retaining newly hired nurse educators. Again, individualizing mentoring efforts will contribute toward retaining qualified educators.

\section{Research Questions}

The following research questions were designed for the purpose of this study:

1. What is the demographic profile (gender, academic position, rank, teaching experience, teaching responsibilities, type of academic setting) of newly hired nurse educators who teach in prelicensure registered nurse programs?

2. What qualifications (education, clinical practice, collaborator and leadership, and scholar) do newly hired nurse educators possess who teach in prelicensure registered nurse programs?

3. How do newly hired nurse educators rate themselves on their knowledge and skills to fulfill nurse educator competencies (facilitate learning, facilitate learner development and socialization, use assessment and evaluation strategies, design curriculum and evaluate 


\section{PERCEIVED COMPETENCIES OF NURSE EDUCATORS}

program outcomes, function within the educational environment, exhibit leader and collaborator role competencies, and demonstrate scholar role competencies)?

4. Do nurse educators with a graduate degree focus in advanced practice differ from nurse educators with a nursing education degree focus in their perceived competencies to (a) facilitate learning, (b) facilitate learner development and socialization, (c) use assessment and evaluation strategies, (d) design curriculum and evaluate program outcomes, (e) function within the educational environment, (f) exhibit leader and collaborator role competencies, and (g) demonstrate scholar role competencies?

Specifically, this study addresses information that relates to each section of the survey, "Nurse Educator Competency and Qualification Inventory" (Poindexter, 2009). The research questions that were aligned to the survey included:

\section{Research Question One}

a. What is the academic experience of newly hired nurse educators who teach in prelicensure registered nurse programs?

\section{Research Question Two}

b. What are the educational qualifications of newly hired nurse educators who teach in prelicensure registered nurse programs?

c. What are the clinical practice qualifications of newly hired nurse educators who teach in prelicensure registered nurse programs?

d. What are the collaborator and leadership qualifications of newly hired nurse educators who teach in prelicensure registered nurse programs? 
e. What are the scholar qualifications of newly hired nurse educators who teach in prelicensure registered nurse programs?

\section{Research Questions Three and Four}

f. What are the nurse practice competencies of newly hired nurse educators who teach in prelicensure registered nurse programs?

g. What is the newly hired nurse educator's level of proficiency to facilitate learning in prelicensure registered nurse programs?

h. What is the newly hired nurse educator's level of proficiency to facilitate learner development and socialization in prelicensure registered nurse programs?

i. What is the newly hired nurse educator's level of proficiency to use assessment and evaluation strategies in prelicensure registered nurse programs?

j. What is the newly hired nurse educator's level of proficiency to design curriculum and evaluate program outcomes in prelicensure registered nurse programs?

k. What is the newly hired nurse educator's level of proficiency to function within the educational environment in prelicensure registered nurse programs?

1. What is the newly hired nurse educator's level of proficiency to exhibit leader and collaborator role competencies in prelicensure registered nurse programs?

m. What is the newly hired nurse educator's level of proficiency to demonstrate scholar role competencies in prelicensure registered nurse programs?

\section{Significance of the Study}

The results of this study could assist the profession of nursing by providing empirical evidence that will indicate the perceived entry-level qualifications and competencies held by novice and experienced educators during their first year of hire. The results of this study can be 


\section{PERCEIVED COMPETENCIES OF NURSE EDUCATORS}

used as a concrete direction to appropriately assist with the growth and development of nurse faculty as they enter into new positions (Poindexter, 2008). Furthermore, faculty development and mentoring programs could be designed and implemented according to the newly hired educators' own perceptions rather than the views of their senior faculty or administrators.

This study also provides valuable insight into the qualifications and competencies of newly hired educators by using their own views. The findings of this study can provide the nursing education profession with a baseline of information regarding the qualifications and competencies of new faculty and could be used throughout the careers of novice and experienced nurse educators as they develop their expertise in the field. Moreover, the results of this study may provide information to assist with strengthening graduate level education programs designed to prepare individuals for the nurse educator role. Information obtained may also be valuable for nurse educators as they prepare themselves to assume positions within academic settings best suited to their individual competencies and qualifications.

Overall, it is critical that a baseline of knowledge regarding the perceived qualifications and competencies of novice and experienced educators be established. As a result, the initiatives set forth by the NLN concerning the nurse educator shortage, preparation of nurse educators, and mentoring of nurse faculty can be supported with empirical data which will specifically identify the knowledge and skills of novice and experienced nurse educators.

\section{Definition of Terms}

Experienced Nurse Educator: A nurse educator with greater than one year of previous teaching experience, and is assuming a new position in an academic setting (Poindexter, 2008). Master of Science in Nursing degree with Advanced Practice focus (MSN AP): A Master's degree which concentrates on the diagnosis and treatment of clients within a specified clinical 


\section{PERCEIVED COMPETENCIES OF NURSE EDUCATORS}

environment. These include: nurse practitioners, clinical nurse specialists, nurse anesthetists, or nurse midwives (NLN, 2002).

Master of Science in Nursing degree with a Nursing Education Focus (MSN Ed.): A Master's degree with a focus on the preparation of an individual to teach nursing students in an academic environment (NLN, 2002).

Novice Nurse Educator: A nurse educator with one year or less of previous teaching experience and is assuming a new position in an academic setting (Poindexter, 2008).

Nurse Educator Competencies: Demonstrated knowledge, skills, and values essential to fulfill the nurse educator role requirements in the profession of nursing education (Poindexter, 2008). Nurse Educator Qualifications: The educational degrees achieved by the nurse educator as well as experience in nursing education, advanced practice specializations, experience in practice as a registered nurse, and scholarly and leadership work completed (Poindexter, 2008).

Prelicensure Nursing Program: An associate, diploma, or bachelor degree-nursing program that prepares students to become licensed as a registered nurse (Poindexter, 2008).

Proficiency Levels (Benner, 1984)

- No Experience: No previous knowledge or practical experience with stated competency; requires continuous guidance - considered a novice within a given area or field.

- Advanced Beginner: Some previous knowledge or practical experience with stated competency; requires frequent guidance.

- Competent: Sufficient knowledge, able to perform confidently with little guidance

- Proficient: Holistic understanding of competency; past experiences guide decisions.

- Expert: Highly skilled; deep understanding of competency; provides guidance to others. 


\section{PERCEIVED COMPETENCIES OF NURSE EDUCATORS}

\section{Conceptual Framework}

This study will be guided by the framework of Patricia Benner's "From Novice to Expert" (1984) to assist in defining the level of proficiency of the novice nurse educator as they enter into practice. Benner's framework (1984) was developed from the Dreyfus Model of Skill Acquisition and described the experiences of how an individual transitions through stages as they gain knowledge and practical experience. These stages are referred to as levels of proficiency and include the following categories: novice, advanced beginner, competent, proficient, and expert (Benner, 1984). Further, Benner (1984) used the levels of proficiency to gain insight into the experiences of practicing nurses as they develop in their role. These same principles can be applied to the novice educator as they transition into and professionally develop in the academic setting. Benner examined the experiences of nurses who enter into practice as novices, gain knowledge through practice over time, and evolve into experts. Through interviews and observations she documented these experiences, and interpreted the data which was compared and validated by research team members. A brief description of the four stages is described in Poindexter's (2008) framework.

Stage 1: Novice. This stage of proficiency examines individuals when they first enter into practice. During this stage the individual has no experience with the situation at hand. In order for the individual to begin to develop, only objective data are given to them. Benner (1984) uses an example of a novice nurse who is taught about the weight and vital signs of a patient. The novice nurse can identify such information, and use it to provide care according to the task at hand. Application to situations where a change in vital signs may occur is difficult for the unseasoned nurse to understand. Similarly, the novice nurse educator may be provided with a faculty and student handbook, but the novice educator will have little knowledge as to how to 


\section{PERCEIVED COMPETENCIES OF NURSE EDUCATORS}

apply the data regarding specific student situations that reflect information in the handbook. Benner states that this "rule-governed behavior typical of the novice is extremely limited and inflexible" (Benner, 1984, p.21). This is because the novice has no experience from which to guide behavior; therefore, by providing a set of rules, there is a form of data that can be used to provide appropriate care.

Stage 2: Advanced beginner. At this stage of proficiency, the nurse has acquired some experience from which to begin to "demonstrate acceptable performance" (Benner, 1984, p. 22). Here the nurse may have worked with a particular type of patient and through experience the individual learns and is able to transfer this knowledge to other similar situations. At this stage, all of the experiences learned from the individual are treated as equal experiences and the advanced beginner has difficulty distinguishing or prioritizing the data. When applying this to the nurse educator, a new faculty member may be given departmental committee assignments and understands the importance of attending scheduled meetings. The novice nurse educator, however, will not be able to identify the committee that is the most valuable in reflecting the outcomes of the nursing program. To the novice, all committees are viewed as equally important. Benner notes that within the stages of novice and advanced beginner, the individual is gaining knowledge and attempting to remember the rules of the situation. According to Benner (1984), this is a lot to grasp for these individuals and at these stages there is not any more an individual can do but absorb the data.

Stage 3: Competent. Benner (1984) stated that to develop into a competent professional, an individual should be practicing in the field for at least two to three years. Within this stage, the nurse begins to outline and define long term outcomes and is able to provide care for multiple types of patients. The nurse is able to analyze, apply information, and implement care in various 


\section{PERCEIVED COMPETENCIES OF NURSE EDUCATORS}

clinical situations. The component that is lacking is the efficiency with which the individual can apply the task to the situation. For the competent nurse educator, an individual may be able to demonstrate the proper development of course objectives and formulate an examination based on the objectives, but time management skills to complete the task may be problematic. Similarly, the nurse educator may possess an understanding of classroom lecture content, but lack the ability to transfer the knowledge to students within the time frame designated for classroom learning. Lastly, as the nurse educator reaches this stage, he or she is able to begin to balance the demands placed upon them and prioritize their responsibilities.

Stage 4: Proficient. Within this stage, the clinical nurse is able to realize the entire picture of the situation because of the experience that has been gained in the previous stages. The nurse is now able to holistically understand the meaning of the situation. Proficiency is usually achieved after the nurse has had experience in a given setting for three to five years (Benner, 1984). In addition, the nurse is able to develop an understanding of approaching and implementing care safely to patients. During unfamiliar situations, the nurse may regress to previous stages, but is able to make appropriate decisions based on these experiences. In addition, when provided explanations regarding clinical situations, the nurse is able to analyze and even contradict the point of views suggested by others.

For the nurse educator, the faculty member now has the ability to offer various perspectives on a situation because of experience gained in the field. Educators have now developed their own teaching style, and may or may not accept alternative strategies to benefit student progress. Educators are also able to identify problems with students and provide solutions to resolve these problems. In cases where the educator may have to learn a new 


\section{PERCEIVED COMPETENCIES OF NURSE EDUCATORS}

concept, such as with technology in the classroom, the educator may regress to the previous stages and adapt by learning the rules of using these advances.

Stage 5: Expert. Within this stage, the clinical registered nurse does not have to depend on others to understand the situation. The nurse is able to comprehend various situations and initiate the care required. The nurse is able to focus on the problem and already has developed an understanding of the problem by examining all of the possible causes involved.

The nurse educator is also able to approach problems and offer solutions to those problems because of the deep understanding of the nature of the problem. For example, if a student is confused about whether or not to withdraw from nursing and is having academic difficulties, the nurse educator is able to confidently advise the student regarding this decision and offer possible alternatives. More importantly, the educator will be able to help the student determine and understand the reasons for the academic deficiencies.

Overall, this study is framed by this model and is used to determine novice and experienced educators' perceptions of their own level of proficiency according to the competencies for nurse educators. Novice faculty identified the level of proficiency that applied to them as they entered into a new practice setting in academia. By understanding the stages of this framework, senior nurse faculty can provide greater assistance to newly hired educators toward progression of higher stages of competence achievement.

\section{Summary}

Because of the differing educational backgrounds of newly hired faculty, the required knowledge involved to successfully achieve fulfillment of the nurse educator competencies, and the importance of developing the careers of newly hired faculty, it is clear that research is needed to identify how well new faculty members perceive their entry level qualifications and 


\section{PERCEIVED COMPETENCIES OF NURSE EDUCATORS}

competencies. The expectations for success in the faculty role are especially high because of the shortage of nurse educators as well as the demands faced by novice and experienced educators to quickly acquire the knowledge and skills to guide students in achieving and implementing safe nursing care (Siler \& Kleiner, 2001). Meeting this challenge can often be difficult for newly hired faculty members, regardless of their teaching experience, because of differing expectations, qualifications, and competencies with which they enter into new positions (Seiler \& Kleiner, 2001).

At present, studies have not been conducted to identify newly hired nurse educators perceived proficiency level within a given competency area when entering academia. The focus of this study will be to examine the perceptions of novice and experienced faculty during their first year of employment in order to determine their entry-level qualifications and competencies. Exploring the nurse educator's knowledge of the competencies can contribute significantly toward identifying the appropriate strategies necessary to facilitate the growth of new educators and to provide a basis for senior faculty to assist new faculty in further developing their insufficiencies. Ultimately, senior nurse faculty can place a concerted effort to nurture newly hired faculty toward a successful path in nursing education. 


\section{PERCEIVED COMPETENCIES OF NURSE EDUCATORS}

\section{Chapter Two}

\section{Literature Review}

Chapter two presents a literature review regarding novice nurse faculty competencies and qualifications. A number of cited investigations also included competencies and qualifications of experienced nurse educators that furthered the literature review's scope. Limited research has been conducted regarding the entry-level competencies and qualifications of newly hired nurse educators (Poindexter, 2008). Thus, this review focuses on the common core competencies published by NLN (2005) and Poindexter (2008). In addition, this literature review discusses Poindexter's (2008) three competencies and four qualification domains that are exclusive to her research. The study's four research questions organize this review.

The NLN's (2005b) initial research produced the following eight core competencies focused on the teaching and advising role of the nurse educator. The eight competency areas are as follows: (a) facilitate learning, (b) facilitate learner development and socialization, (c) use assessment and evaluation strategies, (d) participate in curriculum design and evaluation of program outcomes, (e) function as change agent and leader, (f) pursue continuous quality improvement in nurse educator role, $(\mathrm{g})$ engage in scholarship, and $(\mathrm{h})$ function within the educational environment.

While the NLN efforts have contributed significantly to identifying overall competencies of nurse educators, the focus was not specific to the novice nurse educator (Poindexter, 2008). Acknowledging NLN's initial core competencies, Poindexter (2008) concurred with five of the eight NLN's competency recommendations, which are referenced as Common Competencies as seen in Figure 1. In addition, Poindexter identified three competencies specific to the novice nurse educator, which are: (a) leader and collaborator role, (b) scholar role, and (c) and nurse 
practice. Furthermore, Poindexter (2008) indicated that four qualification domains were necessary to consider when a practicing nurse enters the academic environment. The qualifications are: (a) educational qualification, (b) clinical practice qualification, (c) collaborator and leadership qualification, and (d) scholar qualification. Poindexter (2008) also references academic experiences specific to the novice educator's competency development.

Figure 1. NLN (2005) and Poindexter (2008) Competency Comparison.

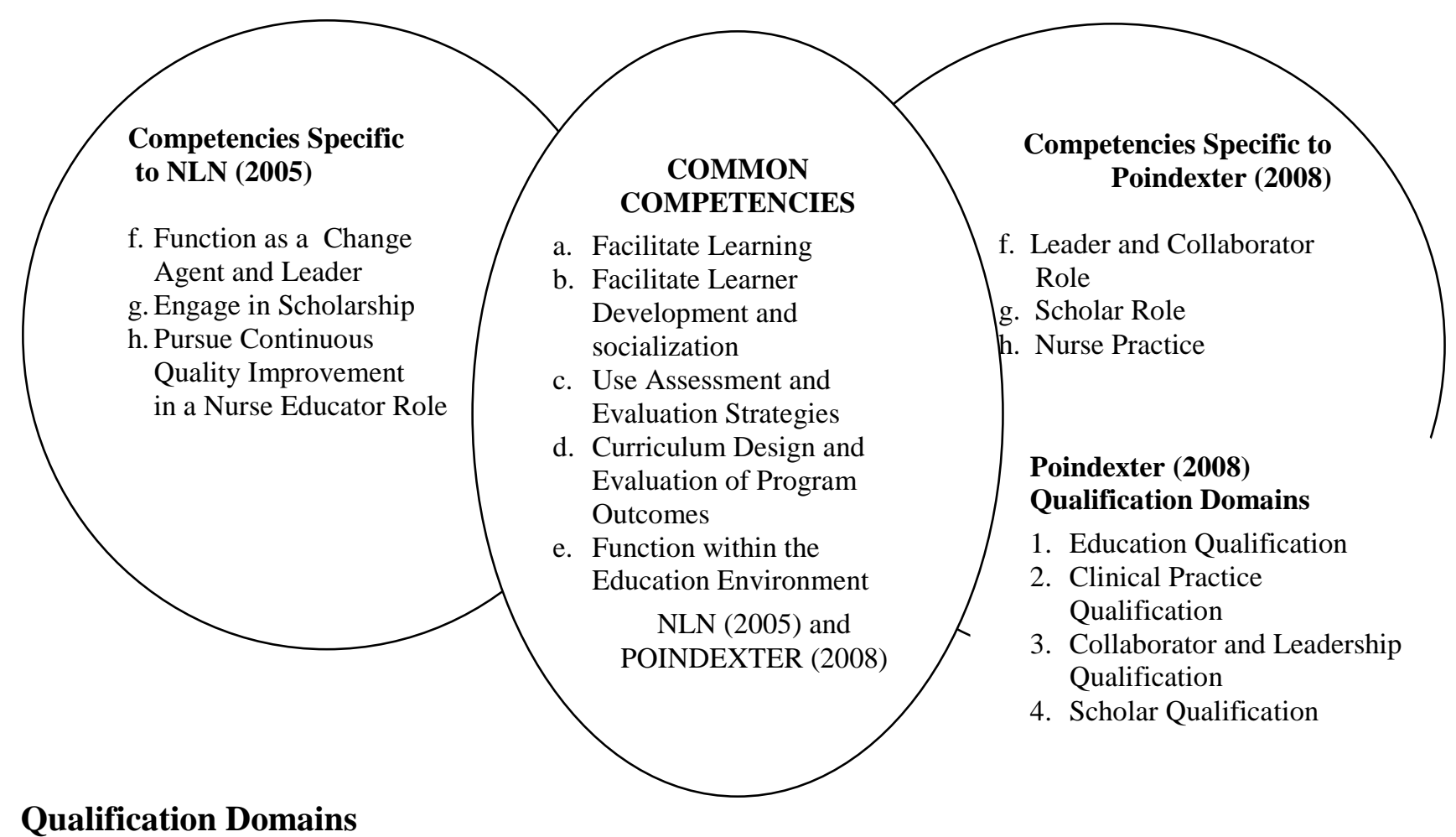

Research indicates that there are certain qualifications a nurse educator should possess when pursuing a position in nursing education. According to Poindexter's (2008), the qualifications that required attention during the recruiting and hiring of nurse educators included the four qualification domains identified in Figure 1. These qualifications were associated with the professional achievements and the body-of-knowledge that a nurse educator has contributed to the nursing profession. The distinction between qualification domains and competency areas were evident throughout Poindexter's (2008) research and survey instrument (Appendix A). 


\section{PERCEIVED COMPETENCIES OF NURSE EDUCATORS}

Academic experience. Poindexter's (2008) investigation reported five specific indicators that were referenced as the nurse-educator's academic experience. These were the nurse educator's held position, academic rank, and number of years as a nursing professional. Furthermore, primary teaching responsibilities and type of academic setting influenced the appropriate experience for teaching in a prelicensure registered nursing program. In addition to general academic experience, measuring the education qualifications required an identification of the specific degree type the nurse educator possesses at the master's and doctoral level.

\section{Education qualifications: Master of Science in Nursing with an education focus.}

Earning a Master's in Nursing with an education focus references the degree associated with successfully delivering in-class instruction, advising, and measuring student performance (Ellis and Hartley, 2008; NLN, 2002). The degree includes a wide range of programs that include a Master of Science in Nursing (MSN), a Master of Nursing (M.N.), and a Master of Science (M.S.) with a major in nursing or a Master of Arts (M.A.) degree with an emphasis in nursing (Dracup, 2005). Curricula emphasis in nursing education specifically focuses on preparing an individual to teach nursing students in an academic and clinical setting.

Master's programs with a teaching emphasis also prepare the future educator to apply the NLN core competency areas within the academic setting where students are studying to become registered nurses (Villanova University, 2009; Billings \& Halstead, 2009). Moreover, preparation for the role of the nurse educator extends beyond developing an understanding of the core competencies for nurse educators (NLN, 2005b; Billings, 2003). Teaching preparation additionally includes but is not limited to understanding nursing content, knowing how to appropriately develop learning objectives, using teaching strategies to foster student learning, 


\section{PERCEIVED COMPETENCIES OF NURSE EDUCATORS}

providing evidence-based practice opportunities for students, using information technology, and pursuing lifelong learning (NLN, 2005b; Halstead, 2007).

Course content within a Master of Science program with a focus in nursing education involves developing an understanding of services, polices, and the rights and responsibilities of faculty within an academic setting as well. Furthermore, this encompasses aspects of research, scholarship, publishing, and presenting at professional conferences (Billings \& Halstead, 2009).

The academic requirements most suitable for the role of teaching in nursing has been discussed and debated in the nursing literature for several years (NLN, 2002; Zungolo, 2004; Young, 1999). Poindexter (2008) found that the Master of Science in Nursing with an education focus was the highest preferred teaching degree as rated by the perceptions of deans and administrators nationally. Community college deans preferred this degree 65 percent of the time. Liberal arts institution deans and administrators preferred the Master of Science degree in nursing $(41 \%)$. Poindexter also reported that 59 percent of deans and administrators from research institutions required a Master of Science degree with a focus on nursing education to obtain a faculty position.

Neese's (2003) personal experiences as a new nurse educator prepared with a Master of Science degree in nursing and an education focus proved to be very beneficial for the role. This author acknowledged that this degree specialization enhanced the understanding of the responsibilities associated with the position and provided an opportunity to learn more about the expectations within the role. Similarly, McDonald (2004) found that novice nurse educators felt that they would have benefitted more in their new academic positions by having a graduate degree with an education or teaching focus. 


\section{PERCEIVED COMPETENCIES OF NURSE EDUCATORS}

Sienty (1988) conducted a descriptive study with a 2-point cross-sectional design to determine the experience and extent of role strain of 31-novice nurse faculty during their first and second academic semester. A questionnaire measured job-related stressors of the new faculty. Personal interviews were used to further determine aspects of new faculty role strain. Although nursing faculty members were educationally prepared for the role with a Master of Science degree in Nursing, many felt that role strain would occur during their first year of teaching regardless of the academic preparation. Moreover, participants reported role strain would be increased without educational teaching preparation for the role. Over half of the participants indicated teaching preparation should be a requirement in nursing education.

\section{Education qualifications: Master of Science in Nursing with an advanced practice}

focus. This type of Master's degree in nursing emphasizes a specific clinical specialization area and is referenced as a Master of Science in nursing degree with a focus on advanced practice nursing. Those awarded this degree are referenced as advanced practice nurses and possess a strong background in clinical practice (ANA, 1996).

Advanced practice focus in a Master's program also allows an individual to teach within a nursing education program. However, there is a significant difference in the program's educational core. This degree emphasizes a clinically-specialized graduate degree as opposed to the teaching, learning, and assessment methods emphasized in a Master's in Nursing with an education focus (ANA, 1996; Dracup, 2005).

Young (1999) conducted a qualitative examination on the experience of 17 new nurse educators across the United States. It was found that new nurse educators often relied on their experiences as a registered nurse to handle difficult situations rather than on their academic preparation. Many of the participants had to learn first from their mistakes in teaching before 


\section{PERCEIVED COMPETENCIES OF NURSE EDUCATORS}

developing an understanding how approach a situation appropriately. Moreover, even with teacher preparation in graduate school, some new faculty did not feel prepared to teach in the academic setting. Additional findings in the study revealed that faculty mentoring was not provided for some of the participants and faculty had to learn their responsibilities on an informal basis.

Education qualifications: Doctoral preparation. The doctoral degree can include, but is not limited, to a Doctorate of Philosophy (Ph.D.), Doctorate of Nursing Science (DNS), Doctorate of Nursing Practice (DNP), or a Doctorate of Education (Ed. D), Although a newly hired educator may possess a doctoral degree, the AACN reported that enrollment in all doctoral programs increased only by 0.9 percent from the 2007-2008 academic year (AACN, 2008b). In addition, the AACN stated that 313 applicants attempting to enter into doctoral programs were not admitted because of the shortage of appropriate faculty to chair, teach, and serve on doctoral committees (AACN, 2008b).

Recently, the overall interest in doctoral enrollment has grown and evidence of the history of declines has changed. The AACN's press release in 2009 indicated that enrollment has increased by 20.5 percent. This upward trend has followed a six-year period of declines in graduation from these programs (AACN, 2009). Based on these statistics, it is likely that the profession will encounter an increased number of doctoral prepared educators in the future.

Various viewpoints exist regarding whether or not nurse faculty should possess a doctoral degree when entering into the field. Bartels (2007) noted that holding a Master's degree as the educator's only credential lacks the ability to expand nursing science through research and scholarly activities. In addition, Bartels (2007) stated: 


\section{PERCEIVED COMPETENCIES OF NURSE EDUCATORS}

Doctoral prepared nursing faculty hold the sole credential needed to provide entry to and full recognition of the academy. The nursing profession, even in a time of faculty shortage cannot afford to accept less if it is to ensure the preparation of nurses who are capable of addressing the complexities of the current and future health care environment. (p. 155)

Interestingly, Bartels' (2007) noted that despite having the doctoral credential, many faculty remain unprepared to meet the expectations associated with the nursing faculty role.

Poindexter (2008) found that deans and administrators preferred a doctoral degree for teaching if the nursing program was within in a research institution. Community college administrators reported that doctoral degrees were not required to enter into practice as a nurse educator. Liberal arts deans and administrators felt that either the Ph.D. or the MSN with advanced practice degree were equally acceptable as the preferred entry- level degree. The most frequently reported degree that was found to be "not required" by all of the institutions was the Doctoral of Nursing Science (Poindexter, 2008).

Clinical practice qualifications. According to Poindexter's (2008) research, there are certain clinical practice qualifications that should be considered for a nurse educator to obtain a position in nursing education. These areas included years of nursing experience in acute care, specialty practice, or management and administration. In addition, current positions held in clinical and advanced practice were also identified as important to qualify an individual to be considered for hire into a nursing education program (Poindexter 2008).

Research conducted on nurse educators with experience in clinical practice has revealed that despite having years of nursing practice experience, many educators have difficulty meeting the requirements associated with the teaching role (Young, 1999; McDonald, 2004). Anderson 


\section{PERCEIVED COMPETENCIES OF NURSE EDUCATORS}

(2008) conducted a qualitative analysis of the role transition of clinically experienced nurses that entered into the field of nursing education. The population sample included 10 nurse practitioners and 8 clinical nurse specialists from 14 institutions located in four states in the upper Midwest of the United States. The participants had 13 to 25 years of experience in nursing practice and possessed clinical experience in critical care, pediatric, gerontologic, and community nursing. Participants did not have formal preparation in teaching within an academic setting. Semi-structured interviews of the participants revealed that newly hired educators were overwhelmed with the responsibilities associated with their role. It was difficult for them to transfer their advanced level of expertise to the beginner level of the nursing student. The newly hired faculty members used their experience as a nurse to assist them with problem solving.

Overall, the participants provided details of the difficult transition into the academic setting. Newly hired faculty identified the importance of having clinical experience when teaching nursing students to provide safe client care in the practice setting. Many of the participants that currently remained in the clinical practice setting in addition to teaching had to decrease their time in practice to accommodate the demands of their role in academia (Anderson, 2008).

Kirchoff (2008) interviewed two tenured faculty members and two tenure-track faculty in an associate degree program regarding their experiences upon entering into their teaching positions. One faculty member indicated that she was from an advanced practice background. Despite this, the same faculty member revealed the need for a mentor in the clinical setting to help to "kind of get to know the lay of the land" (p.15). "It is very scary to be in a hospital with 8 or 10 students, not having been there before" (Kirchoff, 2008, p.15). 


\section{PERCEIVED COMPETENCIES OF NURSE EDUCATORS}

Participants reported that it would be helpful if a mentor could assist in developing teaching strategies in the clinical setting and inform the new faculty member regarding the dayto-day clinical operations. Faculty indicated that it would be beneficial if someone would attend a clinical conference and help the newly hired educator develop teaching strategies and problemsolving approaches to situations that may have occurred during the clinical day. Overall, regardless of teaching or practice experience, faculty members needed assistance with teaching students in the clinical and classroom setting (Kirchoff, 2008). Despite their need for consistent guidance, Kirchoff's study revealed that new faculty members were not provided with support and supervision of a mentor.

Poindexter (2008) found that deans and administrators nationally felt that community college faculty need to "function within a broad scope of practice as a nurse generalist in addition to their specialty area of practice" (p.169). Deans and administrators from liberal arts institutions expected that the incoming nurse educator possess a minimum of two to three years of acute care clinical practice experience. It was preferred that new faculty have a least four to five years of experience in a specialty practice area. Applicants that held current practice positions were also preferred by deans and administrators in liberal arts institutions. Research institutions required the new educator to have a minimum of two or three years of acute care clinical practice experience and one year of specialty practice. Preference was also given to the applicant with four or more years of acute care experience and more than five years of specialty practice experience within research schools (Poindexter, 2008).

Collaborator and leadership qualifications. Among the many roles that nurse educators need to hold, the nurse educator should possess the ability to exhibit leadership and collaborator qualities to educate and train nursing students as they enter in the practice setting 


\section{PERCEIVED COMPETENCIES OF NURSE EDUCATORS}

(Halstead, 2007). "Leadership abilities need to be demonstrated by all nurses, including nurse educators, to ensure that nursing advances as a profession and positively impacts health care delivery systems of the future" (Halstead, 2007, p. 117).

To achieve a nurse educator position, an individual should maintain active memberships and leadership positions within nursing organizations (Poindexter, 2008). They must collaborate and develop relationships with other health care professionals and faculty members to foster student learning (Halstead, 2007). Leadership skills are required to advocate for increased strategies and opportunities to address political, economic, and social forces that can impact the nursing and health care fields (Halstead, 2007, Poindexter, 2008).

While demonstrating leadership skills is important, Dozier (2007) found that even accomplished classroom teachers lacked the training necessary to develop educational leadership skills regarding policy. In a study conducted by the Center for Teacher Leadership, Dozier (2007) sampled 300 exemplary teachers that generated 179 respondents from 37 different states. Results indicated that even accomplished teachers lacked the training necessary to develop their leadership and educational policy skills. Dozier concluded that educators lack the skills they need because often there are few opportunities provided for them to develop this skill. This research demonstrated the importance of developing leadership skills of new teachers, which could be applied to newly hired nurse educators. However, in order to develop leadership, the presence of these skills and abilities must be first determined in order to gain growth and development within this area.

Scholar qualifications. The nurse educator's ability to engage in scholarly activities can occur in a variety of ways. These include conveying knowledge of nursing through presentations at national and regional levels, conducting research in health care and nursing education, 


\section{PERCEIVED COMPETENCIES OF NURSE EDUCATORS}

maintaining a funded area of research, and publishing research in peer reviewed journals (Poindexter, 2008, Halstead, 2007).

The research regarding the incoming qualifications of newly hired educators that relates to specifically to scholarly activities has been limited. Sienty (1988) revealed new faculty members felt they were increasingly being prepared for the scholarly role through formal education. However, balancing and performing the roles expected of them in the academic setting was problematic.

Poindexter (2008) found that research institution deans gave preference to applicants for nurse educators that had published and presented scholarly activities. Poindexter (2008) also noted that deans from community college settings did not require that new faculty have experience in conducting scholarly activities to obtain an entry-level position.

\section{Core Competency Areas}

Competencies identify the knowledge, skills, and abilities that nurse educators need to successfully fulfill their roles (Davis, Stullenbarger, Dearman, \& Kelly, 2005; Billings \& Halstead, 2009). The development of the National League for Nursing's Core Competencies of Nurse Educators was established in 2005 by using various theoretical foundations from nursing science, educational psychology, instructional technology, instructional design, tests and measurements, and evaluation theory (NLN Scope of Practice of Academic Nurse Educators 2005b, p. 11). These competencies include the ability to: (a) facilitate learning, (b) facilitate learner development and socialization, (c) use assessment and evaluation strategies, (d) participate in curriculum design and evaluation of program outcomes, (e) function as a change agent and leader, (f) pursue continuous quality improvement in the nurse educator role, (g)

engage in scholarship, and (h) function within the education environment. The competencies are 


\section{PERCEIVED COMPETENCIES OF NURSE EDUCATORS}

applicable to various nursing education programs including associate degree, bachelor's degree, and master's degree programs.

Within each of the core competencies are elements, referred to as task statements, to further distinguish each competency. These include specific descriptions of items that educators will encounter in their roles. Various factors influence the achievement of the competencies and their respective core elements. Some of these include academic preparation, type of institution, mission of the institution, type of program, and rank of the educator (NLN Scope of Practice for Academic Nurse Educators, 2005b).

Functioning as a competent nurse educator can be accomplished early in the career of nurse educators; however, expanding beyond competent toward expert in the role depends on guidance through mentoring and professional development, doctoral education, and certification in the field (Halstead, 2007; NLN, 2005b). Sienty (1988) emphasized the need for formal and informal support for new nurse educators because many learn their role through "trial and error" (p. 2), an often unproductive and stressful method of achieving progression toward higher levels of competence. Kalb (2008) recommended that these competencies be used by nurse educators to enhance the practice of lifelong learning.

Overall, well-defined statements of expected core competencies and their respective task statements for nurse educator preparation are critical to the structural development of graduate programs of study as well as for the nurse educator to develop and demonstrate excellence in the role (Davis, et al., 2005; Halstead, 2007). In a time when the number of nurse educators is growing short and performance expectations are increasing, these competencies serve as the structure from which the nursing education needs to begin to adequately prepare nurse educators in their role (Halstead, 2007). 


\section{PERCEIVED COMPETENCIES OF NURSE EDUCATORS}

Nurse practice competency. Nurse practice competencies are measurable tasks, which include the ability to implement and evaluate evidence; practice in a specialized clinical area; and provide guidance to patients and family members (Poindexter 2008). In addition to serving patients and family members, the nurse practice competencies require the nurse educator to collaborate with health care teams, function within an acute care environment, and incorporate ethical decision-making. Emphasis should also be placed on serving as a professional role model with an insight toward cultural competence in the provision of nursing care (Poindexter, 2008).

The literature regarding clinical competence and its influence on successfully fulfilling the nurse educator role has been inconsistent in its findings. Siler and Kleiner (2001) conducted a phenomenological study to discover the meaning of the newly hired nurse faculty experience. Twelve participants (6 experienced and 6 non-experienced faculty members) from five states were included in the study. The participants represented employment from institutions with diverse missions. All of the participants were experienced nurses. It was found that clinical expertise did not prepare them for their positions as nurse educators. The study revealed that the newly hired educators' ability to provide competent nursing care to patients in a hospital setting did not provide them with the assistance needed to adjust to academia. When faced with this transition, it was a much different experience than they first thought.

According to Siler and Kleiner (2001), one participant said, "it's an entirely different culture than anything I've ever been exposed to. There...is a different culture and different language and different expectations that you don't encounter in the hospital setting or the business world" (p. 399). In addition, most of the newly hired faculty members were concerned about meeting acceptable performance standards in teaching, scholarship, and service. Newly hired faculty often evaluated their ability to successfully perform based on how well the students 


\section{PERCEIVED COMPETENCIES OF NURSE EDUCATORS}

performed. During the first academic year, the participants' self-rating of their teaching performance was high and low. One participant stated she would feel mortified when she was unable to answer questions posed by students (Siler and Kleiner, 2001). Overall, the study results indicated that functioning as a nurse and even being considered an expert in the field of nursing practice does not indicate the ability to transition easily into the faculty role (Siler \& Kleiner, 2001).

McDonald (2004) studied the experiences of new teachers in her dissertation research. She recalled her first teaching experience:

I am a nurse. I am not a teacher. It is March. I am standing at the front of a class of 50 nursing students. My heart is racing. I am pale and clammy, my hands shake enough that I have firmly planted them in my pockets. I am about to teach a theory class to the unsuspecting group. It will be my first formal classroom teaching experience. The topic is shock and I begin the class by offering words to this effect: Today we are going to look at shock. Here I am - your case-study. (p.1)

McDonald's (2004) qualitative study resulted in similar new faculty experiences as her own. Eight new nurse educators were interviewed during their first semester of teaching. The participants had an average of over 20 years of experience as a practicing nurse. The participants had some form of teaching experience either to patients, families, or the community. It was discovered that participants had difficulty understanding and defining their role as faculty. Additionally, policies and procedures of the university and department were left unclear for them to function comfortably in their new roles (McDonald 2004).

Dempsey (2007) examined the role transition from nurse clinician to classroom lecturer for the newly hired educator. Semi-structured interviews were used to gather data to represent 


\section{PERCEIVED COMPETENCIES OF NURSE EDUCATORS}

the feelings of the newly hired educator as they transitioned into the classroom setting. Six participants were involved in the study and had six to 18 years of clinical practice experience. Results indicated that all six of the participants reported the initial feelings described as "frightened, daunted, and stressed" (Dempsey, 2007, p.4). One participant noted, "I was absolutely petrified standing up in a classroom as a newly qualified tutor and lecturer" (Dempsey, 2007, p.4). Dempsey (2007) also noted that the participants did not know what to expect and even felt a "degree of pressure both from themselves and from their colleagues to instinctively know how to do their job" (p.4).

Young (1999) reported that participants in her study often relied on their clinical background to assist them with teaching. Some of the participants used specific examples from their nursing practice to enhance their teaching effectiveness. One participant relied on her experiences in educating other nurses in the practice setting to assist with teaching effectively to students.

Facilitate learning competency. Facilitating student learning involves a complex activity that requires the nurse educator to develop an understanding of how students learn (Billings \& Halstead, 2009). By effectively attending to student learning, faculty can further develop their own approach toward teaching effectiveness within the discipline (Bartels, 2007).

Successfully achieving the skills within the "facilitate learning" competency has been an evolving process over several decades and remains a challenge for new and experienced educators (Didham, 2003). Because of changes in student demographics and the trends associated with providing health care to our nation, the nursing education profession is struggling to keep up with effectively delivering classroom content (Didham, 2003). Faculty must develop 


\section{PERCEIVED COMPETENCIES OF NURSE EDUCATORS}

teaching strategies that meet the current standard of care for students to provide safe nursing care (Suplee \& Gardner, 2009).

In the past, nursing educators presented and emphasized classroom content which students needed to learn. The content-driven process was delivered by relying on a traditional lecture approach to foster student learning that reflected the way in which the faculty member was taught (Zungolo, 2004; Tanner, 2002; Ironside, 2004; Didham, 2003). However, changing society's health care needs has forced additional content to the classroom and clinical settings. Thus, the competency of facilitating student learning remains very challenging for novice and experienced faculty (Tanner, 2002).

It has been well documented that nurse educators can no longer teach as they were traditionally taught and now must develop methods that are most suitable to today's generation of students (Zungolo, 2004; Billings \& Halstead, 2009; Didham, 2003). The transition from teaching the conventional way to actively involving students in the learning process is difficult. Zungolo (2004) stated that faculty not prepared by a Master's in Nursing Education program, "lack formal knowledge regarding teaching and curriculum" (p. 19). These individuals "continue to teach in the same manner as they were taught, often with an eye toward teaching the extensive content taught in their specialty program" (Zungolo, 2004, p. 19).

Ironside (2004) advocated that facilitating student learning must be reexamined to include creative ways that cover the content necessary for students to comfortably enter into practice. Ironside noted that educators are generally concerned with their teaching practices, especially when increased pressure is evident to continually add up-to-date content to suit the health care needs of the industry. Research indicates that newly hired faculty members have the same concerns (Siler \& Kleiner, 2001). 


\section{PERCEIVED COMPETENCIES OF NURSE EDUCATORS}

Siler and Kleiner (2001) conducted a phenomenological study to determine the experiences of new nurse faculty. A sample size of 12 participants was interviewed during their first academic year as a new educator. It was reported that although the participants received formal education for preparation in the classroom setting, it was not enough to enable them to comfortably conduct lectures. Novice faculty often felt that they had to learn on their own and had increasing questions as they gained experience within their first year. One participant found the workload of teaching two courses was “overwhelming” (p. 402). As a result, Siler and Kleiner (2001) stated the importance of nursing programs to encourage and support newly hired faculty throughout their initial year of hire.

Facilitate learner development and socialization competency. According the National League for Nursing (2002), it is essential that nurse educators possess knowledge to "advance the total development and professional socialization of the learner" (NLN, 2002, p. 2). Facilitating learner development and socialization requires that nurse educators demonstrate an understanding of the students' educational needs. This includes demonstrating knowledge in the learning styles of adult, multicultural, physically challenged, and at risk students (NLN Competencies, 2005b). This process also involves an understanding of how to assist and prepare students for the role of the registered nurse, as well as support students in meeting their professional goals. Incorporating the use of cognitive, psychomotor, and affective domains of content enhances the students' understanding of the development in their role as they prepare to enter into the health care arena (NLN, 2005b).

Limited knowledge exists regarding the most appropriate method to use to develop an environment that fosters professional development and enhances the socialization of the student (Halstead, 2007). This complex activity should be developed by experienced and new educators. 


\section{PERCEIVED COMPETENCIES OF NURSE EDUCATORS}

Smith and Garteig (2003) implemented and evaluated a teaching strategy that was designed to foster the professional growth of the student as well as enhance collegiality of both first and fourth year nursing students. The activity used was a linked assignment that actively involved nursing students by guiding their learning as they communicated with each other. Through active discussion and personal reflection, the students shared their perceptions and experiences of the image of nursing. The first and fourth year student interactions promoted their socialization skills and professional growth. The first year students benefitted from this activity because they could see themselves as becoming qualified and competent in their roles. The fourth year students felt a renewed "sense of professional worth and pride" (p. 229).

Espeland and Shanta (2001) addressed the importance of preparing students for the profession through empowerment. According to Espeland and Shanta, faculty should provide students with the ability to develop their own learning and offer strategies that will allow learners to gain confidence and autonomy. Faculty should frequently interact with students to develop a relationship of mutual respect and to foster thinking skills. Clear communication is essential to create an atmosphere where students can express views without feeling intimidated.

Autonomy was also noted as a factor that should be encouraged to facilitate the professional growth of student. Faculty should provide avenues to increase the student's problem solving skills in the classroom and clinical setting. Increasing the autonomy of students will enhance the confidence of students (Espeland and Shanta, 2001).

Accountability also fostered the development of students. Espeland and Shanta (2001) stated that faculty who accept excuses from students lessens their accountability. Students should also regularly attend clinical and classroom activities and be held responsible for their 


\section{PERCEIVED COMPETENCIES OF NURSE EDUCATORS}

attendance. All of these activities provided methods for students to participate in their own learning and ultimately empowered and engaged them in their own professional growth.

Use assessment and evaluation strategies competency. This competency area encompasses the nurse educator's ability to assess and evaluate methods used to meet established learning objectives. It also includes assessing student learning in the cognitive, affective and psychomotor domains, applying evidence-based assessment within the academic environment, developing test blueprints that reflect course objectives, and interpreting test analysis data to improve the teaching/learning process (Poindexter, 2008; Halstead, 2007; NLN, 2005b). In nursing education, assessment and evaluation occur in the clinical and classroom settings.

Evidence regarding the ability of the new educator to understand and implement this process is lacking in the literature, but reports have indicated that this area should be addressed with new faculty. Neese (2003) noted that among the many things that new educators learn, one essential component was to possess the ability to foster student learning through the identification of student responses to teaching. Having effective skills to assess and evaluate these responses was not only necessary, but required (Neese, 2003). Likewise, Hessler and Ritchie (2006) offered several suggestions on how to best assist new faculty with the transition into teaching. These authors revealed that testing and evaluation was an area of concern for new faculty. One approach offered to alleviate these concerns was for faculty mentors to encourage new faculty to observe testing procedures and provide practice opportunities for grading of students. In doing so, these authors felt that new faculty would become more confident in this area and stress and role strain would be reduced.

Consistent with new faculty reports on assessment and evaluation, Kirchoff (2008) found that assessment and evaluation was an area where new faculty reported uncertainty. Two tenured 


\section{PERCEIVED COMPETENCIES OF NURSE EDUCATORS}

faculty members and two tenure-track faculty reflected on their knowledge upon entrance into the faculty role. Faculty members felt they had lacked the skills needed to conduct a class and use assessment and evaluation strategies. Participants indicated that the department operated under the assumption that everyone was capable. One participant stated that there was no formal mentoring on how to prepare for a lecture. One participant stated, "I was basically given the old lecture and I ran with it" (p.18). It was also recommended by the participants in the study that new faculty be given specific information on how to prepare a lecture and develop an examination. One faculty stated:

I am from a practice background and I have not had any prior educational class preparation at all. So, I have nothing in regard to test construction or test item writing. I have not had any educational preparation for this at all. (p. 20)

Blauvelt and Spath (2008) stated their mentoring program, which consisted of curriculum building, classroom management, and test construction, proved to be beneficial to the new educator. These authors initiated mentoring of these concepts based on the assessment of the academic background and experience of the new nurse educator. Once this was established, faculty mentors were able to build upon the knowledge of the new educator in these areas.

Poindexter (2008) found that in liberal arts institutions deans and chairs ranked knowledge of assessment and evaluation fourth in the core competencies when hiring new faculty. Community college deans and chairs ranked assessment and evaluation as sixth out of eight core competencies. Research institution administrators ranked assessment and evaluation last for non-tenure track positions and sixth for tenure track positions.

Design curriculum and evaluate program outcomes competency. Knowledge of curriculum is considered an important aspect to understand in preparation for the role of nurse 


\section{PERCEIVED COMPETENCIES OF NURSE EDUCATORS}

educator (Billings \& Halstead, 2009; Neese, 2003; Zungolo, 2004). Until now, there is no existing evidence that clearly identifies the underlying knowledge of curriculum development of nurse educators as they enter into the role. Yet nursing faculty must have the ability to develop curriculum models that will "optimally prepare graduates with the knowledge and skills to provide patient-centered care” (Billings \& Halstead, 2009, p. 132).

Nursing programs have been challenged with the task of rethinking and restructuring curriculums to meet the needs of a rapidly changing health care environment (Tanner, 2002; Billings \& Halstead, 2009). In order to for this to be accomplished, nursing faculty must use their scientific knowledge base, clinical competence, and creativity as they engage in this process (Billings \& Halstead, 2009, p. 134).

New faculty members entering the profession have the potential to add innovative perspectives to the process of curriculum development and facilitate the educational needs of students. However, they must first possess an understanding of the components of curriculum development. Reports in the literature indicate new faculty lack the necessary knowledge regarding aspects of program curriculum and design. Sienty (1988) found new faculty members were not provided with information pertaining to program curriculum. This resulted in increased role strain especially when advising students. New faculty members were often fearful they would provide misinformation to students.

Hessler and Ritchie (2006) acknowledged that the educational background of new faculty may influence their curriculum knowledge. These authors indicated that faculty prepared in graduate education with an advanced practice focus may not possess an understanding of curriculum. Therefore, these authors felt it was necessary to provide new faculty with a comprehensive review of program curriculum. 


\section{PERCEIVED COMPETENCIES OF NURSE EDUCATORS}

Likewise, Goldenberg, Andrusyszyn, and Iwasiw (2004) indicated new educators often lack knowledge in curriculum development because these concepts may not have been included in the faculty member's graduate academic program. It was reported that faculty members must often rely on professional development or direct experience to gain knowledge in this area (Goldenberg, et al., 2004). Therefore, these authors conducted a study of two approaches used to teach curriculum development in a graduate nursing education course. The approaches involved active engagement of curriculum design in groups as well as through Bensusan's Escalator Model (as cited in Goldenberg et al., 2004). Through this experience, it was stated that students began developing a curriculum by first determining their understanding of the process and then brainstorming how to accomplish the process. By first identifying their underlying knowledge of the topic, the students were able to share ideas and develop program goals. The result of the study indicated that both methods used were successful because of active and direct participation in learning the process of curriculum development.

Overall, determining the foundation of knowledge of the novice educator's ability to develop and design curriculum as well as the degree in which the new educator was educationally prepared for this task was necessary to foster an understanding of curriculum (Goldenberg, et al., 2004). Likewise, involving students in the process of active learning was beneficial in achieving positive student outcomes regarding curriculum development and design.

Function within the educational environment competency. The ability for the newly hired nurse educator to function within the educational environment includes having an understanding of issues that affect higher education and developing connections with the academic community that influence nursing education. This also involves demonstrating an understanding student and colleague values and beliefs. It encompasses professionalism, respect, 


\section{PERCEIVED COMPETENCIES OF NURSE EDUCATORS}

and building a climate that fosters student development (NLN, 2006). Moreover, it includes the ability to understand the role of the nursing educator in the academic setting (Poindexter, 2008).

Research has indicated that new faculty members often have difficulty adjusting into the academic community. McDonald (2004) found in her qualitative analysis that novice nurse educators were challenged with understanding the daily operations of the nursing department and the institution. Participants stated there was very little assistance and support from senior faculty in determining an understanding of their role and where they fit in the program. One participant stated that "I feel like I am out there treading water by myself" (p 117). Another novice faculty stated "I am finding things out by the seat of my pants (p. 104).

Siler and Kleiner (2001) revealed that although the participants in their study were educationally prepared for the role, the participants reported the "academic setting, its culture, and practices were foreign to them" (p. 399). Results also indicated that newly hired faculty felt seasoned faculty often forgot the experiences they encountered when entering into the role. According to the study, one participant was interested in teaching and thought the academic calendar was an attractive feature of the job. During her first year as an instructor, the participant realized that the calendar was not the only difference compared to a practicing nurse. These reports indicate that the ability to understand the role of the educator and function within the educational environment was difficult for new faculty. Thus, it is important for senior faculty to assist new faculty with this transition, even if new faculty are formally prepared for the role.

Poindexter (2008) found that community college deans and chairs required their newly hired educators to possess the knowledge of an "advanced beginner" in the competency category of functioning within the education environment. Liberal arts institution deans and administrators required "competence' in understanding the intricacies of the educational environment. Research 


\section{PERCEIVED COMPETENCIES OF NURSE EDUCATORS}

university deans and chairs preferred that nurse faculty applicants possess a basic underlying knowledge regarding the ability to function within the educational environment (Poindexter, 2008).

Leader and collaborator role competency. Leader and collaborator role competencies require the educator to function as a role model by conveying and sharing ideas with students and colleagues respectfully and professionally. It encompasses the ability to demonstrate effective public speaking skills and develop partnerships within the health care community for the betterment of students. Among many other characteristics, the nurse educator should promote the advancement of the profession and function when needed as a change agent (Poindexter, 2008; Halstead, 2007).

Research indicating entry-level leadership and collaborator skills of novice nurse educators is minimal. Poindexter (2008) revealed that deans and administrators from research institutions rated leader and collaborator role competencies as the highest-ranking competency necessary when hiring nurse educators. The leader and collaborator role competency ranking by liberal arts and community colleges deans was found to be second to the nurse practice competency (Poindexter, 2008).

Poindexter's study (2008) also identified the minimal expectations of newly hired nurse educators to speak in public, convey ideas, and demonstrate clinical leadership skills. Forty-two percent of deans and administrators indicated that newly hired nurse educators should be "competent" and 34 percent indicated that they should be "proficient" in leadership skills for non-tenure earning positions. Fifty-two percent of deans and administrators expected newly hired faculty to be "competent" and 43 percent of administrators indicated "proficient" when entering into tenured positions. Expectations regarding the ability to speak publically ranged between 
"advanced beginner" and "competent" for non-tenure earning positions. Expectations increased to "competent" and "proficient" in the tenure earning positions (Poindexter, 2008).

Scholar role competency. Nurse educators are expected to perform scholarly activities to meet the meritorious requirements of their respective institutions as well as maintain current knowledge of evidence based practices in nursing education (Halstead, 2007). Nurse educators are encouraged to engage in scholarly writing activities and identify aspects of research needed in the field (NLN, 2005b). Becoming competent in scholarly activities can be accomplished by all academic educators (NLN, 2005b). However, the extent to which this is performed by the new educator is lacking in the literature and no studies in nursing research offer specific insight regarding the entry level knowledge of scholarly activities of new nurse educators upon hire into the academic setting.

Poindexter (2008) found that the preferred levels of scholar competency of new nurse educators according to the perceptions of deans and administrators were different among academic institutions. Deans and administrators of community colleges required lower levels of scholarly competence in contrast to liberal arts or research institutions. Moreover, Poindexter (2008) indicated that administrators from research institutions preferred a higher level of scholarly competence in their novice nurse educators. Overall, the rank ordering of this competency was last among all eight of the core competencies in liberal arts and community colleges (Poindexter, 2008).

Blauvelt and Spath (2008) applied Boyer's (1990) model of scholarship to enhance the development of new educators in this area. These authors acknowledged the importance of understanding scholarship as seasoned nursing faculty mentor novice faculty. Partnerships of new and seasoned faculty contributed to the interpretation of new meanings and concepts that 


\section{PERCEIVED COMPETENCIES OF NURSE EDUCATORS}

were essential to the faculty role. Blauvelt and Spath (2008) revealed that development in this area was critical during the nursing educator shortage in order to continue to contribute to evidence-based research; however, it was first necessary to create an awareness of the learning needs of the new faculty member (Blauvelt \& Spath, 2008).

Alteen, Didham, and Stratton (2009) discussed the impact of nursing scholarship in their nursing department as it transitioned from a diploma program to a bachelor degree program. This program addressed scholarship by first conducting a needs assessment of their faculty during the program's transition. One issue that emerged from the needs assessment was the "need to explore their growth as novice academics while making the transition into a university environment as well as defining an approach to develop a clearer understanding of themselves as teachers and scholars" (Alteen, et al., 2009, p. 268). The faculty conducted interactive workshops which enabled them to address and reflect upon these issues. During the workshops, the authors stated that Boyer's model of scholarship was introduced and faculty identified their own perceptions of scholarship.

Ultimately, faculty developed activities and projects of interest following the provided guidelines for developing a personal scholarship plan. In addition, faculty members from other disciplines were invited to share perspectives on scholarly activities. It was found that although the disciplines varied, the interests in scholarship were similar. Over a ten-year period, this retrospective examination was found to enhance the growth and development of faculty members in scholarship throughout the institution (Alteen, et al., 2009).

McVeigh, Moyle, Forrester, Chaboyer, Patterson, and St. John (2002), also described the importance of scholarship through engaging in scholarly writing as a group. In this study, the authors used a case study approach to discuss the development of a publications group within 


\section{PERCEIVED COMPETENCIES OF NURSE EDUCATORS}

their school of nursing. The school of nursing was also experiencing a transitional move from a hospital-based program to a university-based program. This transition brought with it the challenges associated with developing an approach to increase faculty publications and a focus on scholarship and research activities.

To meet these new challenges and expectations, the faculty formed a publication syndicate to help newly hired educators develop their research writing skills. Faculty who participated in this group met to establish the purpose, rules, and guidelines related to proofreading, critiquing, and manuscript authorship. The group met every few weeks and reviewed manuscripts submitted by members. During this period, the syndicate reviewed 11 manuscripts, which were accepted for publication. Five of the eleven publications were presented at national and international conferences. Not only did the group increase the number of publications, members found that the faculty's diverse experience produced increased collaborative writing opportunities and funding for research (McVeigh, et al., 2002).

Overall, it is evident that these approaches to foster scholarly development have been effective. It is important for the nursing education profession to consider engaging in these approaches to better assist in the development of scholarly work. As noted by Alteen et al., (2009) it is necessary to first examine scholarly knowledge that exists among new faculty.

\section{Summary}

Literature review regarding newly hired nurse educator competencies has provided very little quantitative studies. The experience of new faculty members has shown that the professional adjustment into the academic environment has been challenging No literature has exclusively focused on the newly hired nurse educator's level of knowledge regarding each of the core competencies areas. 


\section{PERCEIVED COMPETENCIES OF NURSE EDUCATORS}

\section{Chapter Three}

\section{Method}

\section{Research Design}

A survey questionnaire was used for this quantitative study to identify the perceived qualifications and competencies of newly hired nurse educators employed full-time in a prelicensure accreditated registered nurse program. The survey allowed for an examination of the newly hired educator's perceptions of their own level of qualifications and competences during their first year of employment in a university or hospital based nursing program. The online survey was developed and administered using Survey Monkey Software.

The survey questionnaire was developed as a result of a national study conducted by Poindexter (2008). Her study identified deans and administrators perceptions of what qualifications and competencies novice nurse educators should possess as they enter into the nurse educator role. Poindexter's research was expanded upon in this study by asking novice nurse educators to provide their own perceptions of their qualifications and competencies during their first year of hire.

\section{Research Questions}

The following research questions were designed for the study:

1. What is the demographic profile (gender, academic position, rank, teaching experience, teaching responsibilities, type of academic setting) of newly hired nurse educators who teach in prelicensure registered nurse programs?

2. What qualifications (education, clinical practice, collaborator and leadership, and scholar) do newly hired nurse educators possess who teach in prelicensure registered nurse programs? 
3. How do newly hired nurse educators rate themselves on their knowledge and skills to fulfill nurse educator competencies (facilitate learning, facilitate learner development and socialization, use assessment and evaluation strategies, design curriculum and evaluate program outcomes, function within the educational environment, exhibit leader and collaborator role competencies, and demonstrate scholar role competencies)?

4. Do nurse educators with a graduate degree focus in advanced practice differ from nurse educators with a nursing education degree focus in their perceived competencies to (a) facilitate learning, (b) facilitate learner development and socialization, (c) use assessment and evaluation strategies, (d) design curriculum and evaluate program outcomes, (e) function within the educational environment, (f) exhibit leader and collaborator role competencies, and (g) demonstrate scholar role competencies?

\section{Participants}

Study participants were newly hired nurse educators teaching in prelicensure registered nurse programs located in six states: West Virginia, Virginia, Ohio, Kentucky, Pennsylvania, and Maryland. The selection of newly hired nurse educators was obtained from diploma, associate, and baccalaureate degree prelicensure accreditated registered nursing programs. Program accreditation was identified via state board of nursing web sites.

There were 268 nursing programs in the selected states. Deans and program administrators of each school were first contacted via email that included a description of the study and invited their participation. Permission for contacting the deans was given by the study's chairperson. Program contact information was available for public knowledge on all 


\section{PERCEIVED COMPETENCIES OF NURSE EDUCATORS}

selected state board of nursing web sites. The initial e-mail asked deans or administrators to assist the researcher with gathering a preliminary number of potential participants that met the study's criteria. Administrators were asked to reply to the email by indicating the total number of newly hired full-time faculty in their program for the fall 2009-2010 academic year (Appendix B). Upon reply of the e-mail, a thank-you note was sent to the dean or administrator for responding to the e-mail. A series of two follow-up emails were sent at one-week intervals to those who had not responded to the email inquiry.

One hundred seventy-four responses from the program administrators indicated that new faculty members were hired. Seventy-six deans did not respond or indicated they did not hire new faculty during the designated period. Eighteen of the 268 emails were returned as undeliverable, yielding a 65 percent initial response return for potential study participants. Two hundred three potential participants were identified as new hires by deans and administrators.

\section{Setting}

The type of program in which newly hired nurse educators practiced the teaching role included Community Colleges, Liberal Arts, Research, or Diploma institutions. Programs were nationally accredited and designed to teach prelicensure registered nursing students. It was assumed that participants completed the online survey either at their place of employment or at another convenient location.

\section{Survey Instrument}

The instrument used for the study was a survey entitled "Nurse Educator Competency and Qualification Inventory” (Poindexter, 2009). Permission for its use and revision was given by the developer of the instrument (Appendix C). The survey inventory was developed in response to a nationally conducted research study on nursing administrators perceived entry- 


\section{PERCEIVED COMPETENCIES OF NURSE EDUCATORS}

level competencies and qualifications required of entry-level nurse educators. The results indicated that roles and expected competency levels for an educator included being a competent nurse, teacher, scholar, and collaborator. The expected competencies and qualifications of the educator role were identified through literature reviews completed by the developer.

The developer piloted the survey. Eleven graduate nursing education students in their first internship course, four of which were employed in early entry level teaching positions, reviewed the survey instrument. Each of the students reviewed the survey for ease of completion, clarity of the responses, agreement with the identified qualifications and competencies, length of completion, and appropriateness of the responses. The recommendations were examined and adjustments were made to the survey by the developer (K. Poindexter, personal communication, August 19, 2010).

To review preliminary reliability, Cronbach's alpha was computed to determine internal consistency and correlation of items within each section of the survey. Reliability computations resulted in high alpha coefficients which supported evidence of internal consistency and construct validity of the inventory. The scores indicated high reliability of items grouped within each of the sections, permitting the use of section mean scores for further data analysis (K.

Poindexter, personal communication, August 19, 2010). Cronbach's Alpha results were:

1. Knowledge and Skills in Nursing Practice

2. Facilitates Student Learning

3. Facilitates Learning Development and Socialization

4. Assessment and Evaluation Strategies

5. Curriculum Design and Program Outcomes

6. Function within Educational Environment

7. Leader and Collaborator Role

8. Scholar Role 


\section{PERCEIVED COMPETENCIES OF NURSE EDUCATORS}

\section{Survey Sections}

The instrument consisted of a demographic section, four qualification sub-scales, and eight competence domains. Qualification subscales included academic degree requirements, clinical practice experience, scholar, and collaborative leadership accomplishments. Competence domains were categorized by nurse educator role responsibilities of clinical practice, teaching and advising, collaboration and leadership, and integration of scholarship. Competencies were rated on a Likert-type scale which included the following levels of proficiency: no experience, advanced beginner, competent, proficient, and expert levels.

\section{Modifications to Survey}

Minor modifications were made to Poindexter's survey instrument. Section 1 addressed demographic data regarding newly hired nurse educators' academic experience, which included current position, academic rank, years of full-time teaching experience, teaching responsibilities, and the type of academic setting currently employed. The "position" section of the questionnaire was revised, and the selections of "Not Teaching" and "Adjunct" were eliminated. "Full-time Temporary" and "Gender" indicators were added to this section.

The survey's Section 2 required participants to identify educational qualifications, and newly hired educators were asked to select their level of academic preparation for the role of nurse educator. No revisions were made to this section.

Questionnaire sections 3, 4, and 5 included newly hired educators' clinical practice qualifications, collaborator and leadership qualifications, and scholar qualifications. No revisions were made to these sections. Section 6 included nurse practice competencies. A proficiency level of "No Experience" added to this section. 


\section{PERCEIVED COMPETENCIES OF NURSE EDUCATORS}

Section 7 was entitled "Teaching and Advising," and contained competencies identified by the National League for Nursing (2005) and Poindexter (2008). The competency sections also contained subsections necessary to fulfill each competency area. The competency sections included: (a) facilitate learning, (b) facilitate learner development and socialization, (c) use assessment and evaluation strategies, (d) design curriculum and evaluate program outcomes, (e) function within the educational environment, (f) exhibit leader and collaborator role competencies, and (g) demonstrate scholar role competencies. No revisions were made to this section.

Section 7 asked newly hired educators to indicate perceptions of their level of proficiency for each competency. This was done using a Likert-type scale, which included the categories of (0) no experience, (1) advanced beginner, (2) competent, (3) proficient, and (4) expert. These rankings were identified from the organizing framework of the study that used Benner's Model of Skill Acquisition (Benner, 1984). Benner (1984) described how nurses learn while moving from one level of expertise to the next. This framework included the levels of: (a) novice (b) advanced beginner, (c) competent, (d) proficient, and (e) expert. The same proficiency level was used in the survey instrument and was applied to new nurse educators as they rated themselves in each domain. The proficiency level, "No experience" was added in this section of the survey.

There were five questions added to the survey. These included: (1) Are you currently participating in a mentoring program? (2) If so, have you had a mentor assigned to you? (3) Is the program formal, informal, or both? (4) How is your mentoring program administered? (5) Were the competencies addressed in your mentoring program? Finally, an open-ended question asked for additional comments regarding the participants mentoring experience. 


\section{PERCEIVED COMPETENCIES OF NURSE EDUCATORS}

\section{Procedure}

The nursing programs of the states including and surrounding West Virginia were used for the study. These included Virginia, Maryland, Ohio, Kentucky, and Pennsylvania. The nursing programs within each state were identified using the state's board of nursing web sites as well as National League for Nursing Accrediting Commission (NLNAC) or Commission on Collegiate Nursing Education (CCNE) accreditation identification.

As previously mentioned, prior to the study, the nurse administrators of each program in the selected states were notified via e-mail explaining the study's purpose. Deans and administrators were asked to reply to the e-mail and identified the number of new full-time nurse faculty members that were hired into their program for the 2009-2010 academic year (Appendix C). A second and third follow-up email was sent to each dean who did not respond to the initial email. A thank you note was sent to each responding dean.

Once the total number of newly hired faculty in all states were identified and the Institutional Review Board for the Protection of Human Subjects at West Virginia University approved the study, a email with an electronic link to access the questionnaire was sent to each dean and administrator who identified that they hired new faculty (Appendix D).

The e-mail reiterated the purpose of the study and requested assistance in forwarding the email with the electronic survey link to their newly hired nurse faculty for the 2009-2010 academic year. An attachment to the e-mail also provided the participants with information regarding the purpose of the study and that participation in the study was voluntary. Withdraw was permitted at any time during the study (Appendix E). Additionally, participants were informed that it would take approximately ten minutes to complete the survey. Once the survey was accessed, newly hired nurse educators were asked to provide a self-report of their current 


\section{PERCEIVED COMPETENCIES OF NURSE EDUCATORS}

competencies and qualifications. A second and third e-mail was sent one week apart to deans and administrators. The same procedure was followed and deans were again asked to forward the email with the survey link to their new nurse educators. The electronic link redirected the newly hired nurse educator's browser to access the questionnaire for participation.

The survey instrument was administered during the nurse educators' second semester of hire (eight months) into their academic positions. The survey was electronically administered using survey monkey software. Dillman, Smyth, and Christian's (2009) procedures for internet surveys and the survey monkey user manual (2010) were used as resources for conducting the study. Participants were asked to identify all relevant qualifications pertaining to their professional experience. An open-ended option was available for respondents to submit additional comments or qualifications not identified within the response options. Once the questionnaire was completed, respondents submitted their responses by selecting the "submit button" located at the end of the survey. Response data was analyzed using Statistical Package for the Social Sciences-Personal Computer (SPSS) software and Microsoft Excel software.

\section{Protection of Human Subjects}

The Institutional Review Board approved this research study for the Protection of Human Subjects at West Virginia University (Appendix E). The purpose and intent of the study was explained to the participants in an email attachment (Appendix F). The email allowed access to directly open the survey. Individual responses remained anonymous. Data obtained from the survey remained private and secure because of the multiple layers of security established in the software (Survey Monkey User Manuel, 1999-2010). Access to the survey data was only available to the account holder. There were no foreseeable risks other than inconvenience and time commitment. Survey completion was perceived as implied consent. 


\section{PERCEIVED COMPETENCIES OF NURSE EDUCATORS}

\section{Data Analysis}

Following the return of the surveys, the data were downloaded from the survey monkey software program. SPSS software and Microsoft Excel were used to interpret the data. The data was summarized according to the research questions and survey instrument, "Nurse Educator Competency and Qualification Inventory” shown in Appendix A. Tables were generated to report data for each section of the survey instrument.

Section 1.1-5.0 of the survey included the information regarding the newly hired educator's academic experience and qualifications. These sections related to research question one and two and were analyzed using frequencies and percentages. The dependent variables for these research questions included gender, current academic position, current academic rank, years of full-time teaching experience, teaching responsibilities, type of academic setting, type of nursing program geographic location of nursing program, level of academic preparation, acute care experience, specialty care experience, management experience, leadership experience, and scholar qualifications as seen in Table 1.

Table 1

Summary of Research Questions 1-2, Survey Items, and Data Analyses

\begin{tabular}{lcl}
\hline \multicolumn{1}{c}{ Variables } & Survey Item & Data Analysis \\
\hline Gender & 1.0 & Frequencies and Percents \\
Position & 1.1 & Frequencies and Percents \\
Current Academic Rank & 1.2 & Frequencies and Percents \\
Years of Full-time Teaching Experience & 1.3 & Frequencies and Percents \\
Primary Teaching Responsibilities & 1.4 & Frequencies and Percents \\
Type of Academic Setting & 1.5 & Frequencies and Percents \\
Type of Nursing Program & 1.6 & Frequencies and Percents \\
Participants by State & 1.7 & Frequencies and Percents \\
\hline
\end{tabular}




\section{PERCEIVED COMPETENCIES OF NURSE EDUCATORS}

Table 1

Summary of Research Questions 1-2, Survey Items, and Data Analyses (continued)

\begin{tabular}{lcl}
\hline \multicolumn{1}{c}{ Variables } & Survey Item & Data Analysis \\
\hline Level of Academic Preparation & 2.0 & Frequencies and Percents \\
Acute Care Experience & 3.0 & Frequencies and Percents \\
Specialty Care Experience & 3.0 & Frequencies and Percents \\
Management, Supervisory, clinical and & 3.0 & Frequencies and Percents \\
$\quad$ advanced practice experience & 4.0 & Frequencies and Percents \\
Leadership Experience & 5.0 & Frequencies and Percents \\
Scholar Qualification & &
\end{tabular}

Sections six and seven of the survey related to research question three. The study's participants identified their own proficiency levels for the nurse practice and nurse educator competencies. The dependent variables included "Nurse Practice" and "Nurse Educator Competencies." The self-perceived level of proficiency was ranked by the participants for each variable according to Benner's (1984) framework "From Novice to Expert." The levels of proficiency were: (0) no experience (1) advanced beginner, (2) competent, (3) proficient, and (4) expert. Frequencies and means were computed for this section. In addition, an examination of the differences between nurse practice and nurse educator competencies for the novice and the experienced educator was provided through a statistical analysis of $t$-Tests and means for these groups. Table 2 presents these data.

Table 2

Summary of Research Question 3, Survey Items, and Data Analyses

\begin{tabular}{lll}
\hline $\begin{array}{l}\text { Differences in Competencies between } \\
\text { Novice and Experienced Educators }\end{array}$ & Survey Item & Data Analysis \\
\hline Nurse Practice Competencies & $6.1-6.12$ & Frequencies, \%, $t$-Tests, means \\
Facilitate Learning & 7A1 -7A6 & Frequencies, \%, $t$-Tests, means \\
Facilitate Learner Development & 7B1-7B6 & Frequencies, \%, $t$-Tests, means \\
Assessment and Evaluation & 7C1-7C5 & Frequencies, \%, $t$-Tests, means \\
Curriculum Design & 7D1-7D5 & Frequencies, \%, $t$-Tests, means \\
\hline
\end{tabular}


Table 2

Summary of Research Question 3, Survey Items, and Data Analyses (continued)

\begin{tabular}{lcc}
\hline $\begin{array}{l}\text { Differences in Competencies between } \\
\text { Novice and Experienced Educators }\end{array}$ & Survey Item & Data Analysis \\
\hline $\begin{array}{l}\text { Function within the Educational } \\
\quad \text { Environment }\end{array}$ & $7 \mathrm{E} 1-7 \mathrm{E} 4$ & Frequencies, \%, $t$-Tests, means \\
$\begin{array}{l}\text { Leader and Collaborator Role } \\
\text { Scholar Role }\end{array}$ & $7 \mathrm{~F} 1-7 \mathrm{~F} 3$ & Frequencies, $\%, t$-Tests, means \\
& $7 \mathrm{G} 1-7 \mathrm{G} 7$ & Frequencies, $\%, t$-Tests, means \\
\hline
\end{tabular}

Research question four related to section six and seven of the survey. Newly hired nurse educators again identified their own proficiency levels for the "Nurse Practice" and Nurse Educator Competencies." However, the two types of degree specializations were used as the independent variables. These included the Master's degree with a nursing education focus and a Master's degree with an advanced practice focus. The self-rated level of proficiency was again ranked according to Benner's (1984) framework "From Novice to Expert" for these variables. An analysis of $t$-Tests and means were computed for these groups. Table 3 presents these data. Table 3

Summary of Research Question 4, Survey Items, and Data Analyses

\begin{tabular}{lll}
\hline \multicolumn{1}{c}{ Variables } & Survey Item & Data Analysis \\
\hline Nurse Practice Competencies & $6.1-6.12$ & $t$ - Test and Means \\
Facilitate Student Learning & 7A1-7A6 & $t$ - Test and Means \\
Facilitate Learning Development and & $7 \mathrm{~B} 1-7 \mathrm{~B} 6$ & $t$ - Test and Means \\
Socialization & & \\
Assessment and Evaluation Strategies & $7 \mathrm{C} 1-7 \mathrm{C} 5$ & $t$ - Test and Means \\
Curriculum Design and Evaluation of & $7 \mathrm{D} 1-7 \mathrm{D} 5$ & $t$ - Test and Means \\
Program Outcomes & & $t$ - Test and Means \\
Function within the Educational Environment & $7 \mathrm{E} 1-7 \mathrm{E} 4$ & $t$ - Test and Means \\
Leader and Collaborator Role Competencies & $7 \mathrm{~F} 1-7 \mathrm{~F} 3$ & $t$ - Test and Means \\
Scholar Role Competencies & $7 \mathrm{G} 1-7 \mathrm{G} 7$ & \\
\hline
\end{tabular}




\section{PERCEIVED COMPETENCIES OF NURSE EDUCATORS}

\section{Summary}

This study analyzed the demographic data, qualifications, and competencies of newly hired nurse educators in prelicensure registered nurse programs located in six states. The participants provided a self-report of their qualifications and competencies to teach in an academic setting. Participants rated themselves according to their own level of proficiency to perform the competencies recommended for successfully fulfilling the role of the nurse educator. The web- based survey questionnaire aligned with the study's research questions and used a Likert type rating scale based on the framework of Benner (1984), "From Novice to Expert." The differences in the self-ratings between novice and experienced educators knowledge of the competency areas were provided by a statistical analysis of $t$-Tests and means. Finally, the same statistical analysis was conducted for nurse educators with two types of master's degree specializations. 


\section{PERCEIVED COMPETENCIES OF NURSE EDUCATORS}

\section{Chapter Four}

\section{Findings}

The intent of this chapter is to present the findings of this study. The first section of the chapter discusses the demographic profile of the study's sample, and provides descriptive statistics regarding the profile of newly hired nurse educators located in six states who were teaching in full-time faculty positions for the 2009-2010 academic year. A comparison of novice and experienced nurse faculty is provided to answer research question one.

The next section answers research question two and presents descriptive statistics regarding the qualifications of newly hired nurse educators teaching in academic and clinical settings. A comparison of novice and experienced nurse educators is provided.

The next section presents research findings for question three and provides information that relates to newly hired nurse educators self-rated level of proficiencies for the competency areas. The findings for research question three is illustrated through a statistical analysis consisting of $t$-Tests, means, frequencies, and percentages for novice and experienced nurse educators. The difference between the proficiency ratings for novice and experienced nurse educators is included.

The next section answers research question four and presents the results of the difference in competencies between nurse educators that entered into new faculty positions with two types of academic degree specializations. These included a Master of Science in Nursing degree with a focus on advanced practice and a Master of Science in Nursing degree with a nursing education focus. The findings for research question four are provided by a statistical analysis of $t$-Tests and means. 


\section{PERCEIVED COMPETENCIES OF NURSE EDUCATORS}

Finally, this chapter will present data on the survey's additional questions on faculty mentoring as well as comments from the participants. A summary will conclude this chapter. Specifically, the research questions were:

1. What is the demographic profile (gender, academic position, rank, teaching experience, teaching responsibilities, type of academic setting) of newly hired nurse educators who teach in prelicensure registered nurse programs?

2. What qualifications (education, clinical practice, collaborator and leadership, and scholar) do newly hired nurse educators possess who teach in prelicensure registered nurse programs?

3. How do newly hired nurse educators rate themselves on their knowledge and skills to fulfill nurse educator competencies (facilitate learning, facilitate learner development and socialization, use assessment and evaluation strategies, design curriculum and evaluate program outcomes, function within the educational environment, exhibit leader and collaborator role competencies, and demonstrate scholar role competencies)?

4. Do nurse educators with a graduate degree focus in advanced practice differ from nurse educators with a nursing education degree focus in their perceived competencies to (a) facilitate learning, (b) facilitate learner development and socialization, (c) use assessment and evaluation strategies, (d) design curriculum and evaluate program outcomes, (e) function within the educational environment, (f) exhibit leader and collaborator role competencies, and (g) demonstrate scholar role competencies?

\section{Response Return}

Although there was no way to ensure that all deans distributed the survey to their newlyhired faculty, of the 203 individuals surveyed, sixty-nine completed the questionnaire, a 34 
percent response rate. Ninety-three participants answered Sections 1-5 but not all of Sections 6 or 7 of the survey. Participants were eliminated if the survey was not entirely completed, yielding $69(\mathrm{~N}=69)$ usable surveys.

\section{Research Question One}

Gender. To answer research question one, a description of gender profiles is shown for male and female nurse faculty members that were hired into a new academic position in Table 4. The majority of respondents were female $(n=65 ; 94 \%)$ as compared to males $(n=4 ; 6 \%)$. Table 4 also provides participant data that include a status breakdown for novice versus experienced faculty. Those that were considered to be "novice" consisted of faculty with one year or less of previous teaching experience. The "experienced" faculty members were those with greater than one year of previous teaching experience. Overall, the data indicated that in this sample there were mostly females.

Table 4

Nurse Faculty Gender Profile

\begin{tabular}{lrrrrrr}
\hline \multirow{2}{*}{ Gender } & \multicolumn{2}{c}{ Novice $(n=45)$} & \multicolumn{2}{c}{ Experienced $(n=24)$} & \multicolumn{2}{c}{ Total $(\mathrm{N}=69)$} \\
\cline { 2 - 7 } & $n$ & $\%$ & $n$ & $\%$ & $\mathrm{~N}$ & $\%$ \\
\hline Male & 2 & 4.4 & 2 & 8.3 & 4 & 5.8 \\
Female & 43 & 95.6 & 22 & 91.7 & 65 & 94.2 \\
\hline
\end{tabular}

Position. Table 5 relates to research question one and survey Section 1 . The current academic position held by nurse educators when entering into a full-time position is shown. Academic positions held by novice nurse educators during the 2009-2010 academic year included temporary full-time $(n=4 ; 8.9 \%)$, full-time tenure track $(n=6 ; 13.3 \%)$, and full-time non-tenure $(\mathrm{n}=35 ; 77.8 \%)$. Further data reveals a breakdown of nurse faculty with previous teaching experience which included mostly full-time non-tenure track $(n=14 ; 58.3 \%)$ as well as full-time tenure track $(n=9 ; 37.5 \%)$ positions. One experienced faculty member was hired into a 
temporary full-time $(n=1 ; 4.2 \%)$ position. Overall, most new hires in this study entered into a full-time non-tenure track position.

Table 5

Nurse Faculty Academic Position

\begin{tabular}{lcccccc}
\hline \multirow{2}{*}{ Academic Position } & \multicolumn{2}{c}{ Novice $(n=45)$} & Experienced $(n=24)$ & \multicolumn{2}{c}{ Total (N=69) } \\
\cline { 2 - 7 } & $n$ & $\%$ & $n$ & $\%$ & $\mathrm{~N}$ & $\%$ \\
\hline Temporary Full-time & 4 & 8.9 & 1 & 4.2 & 5 & 7.2 \\
Full-time Tenure Track & 6 & 13.3 & 9 & 37.5 & 15 & 21.7 \\
Full-time Non-tenure & 35 & 77.8 & 14 & 58.3 & 49 & 71.0 \\
\hline
\end{tabular}

Current academic rank. Table 6, as seen on the following page, further relates to research question one and provides information from the survey's Section 1.The current academic rank of nurse educators included instructor, assistant professor, associate professor, and professor. Table 6 also notes the academic rank contrasted between novice nurse educators (0 or 1 year teaching experience) and experienced nurse educators (more than 1-year teaching experience). Most novice hires were classified as instructors $(n=26 ; 57.8 \%)$. Novice educators also indicated they entered into their academic positions as an assistant professor $(n=15 ; 33.3 \%)$. Interestingly, only one of the novice faculty was ranked as an associate professor $(\mathrm{n}=1 ; 2.2 \%)$ and a few as professor $(n=2 ; 4.4 \%)$. The selection of other $(n=1 ; 2.2 \%)$ was also listed in this section. The participant who selected this option did not indicate what type of rank "other" was. Most of the experienced faculty members were assistant professors $(n=15 ; 62.5 \%)$ and instructors $(n=8 ; 33.3 \%)$. One participant selected "other" in this section $(n=1 ; 4.2 \%)$. Again, the participant did not specify what "other" was. It is important to note that this study did not include adjunct or part-time faculty in the criteria. 
Table 6

Nurse Faculty Current Academic Rank

\begin{tabular}{lcccccc}
\hline \multirow{2}{*}{ Academic Rank } & \multicolumn{2}{c}{ Novice $(n=45)$} & \multicolumn{2}{c}{ Experienced $(n=24)$} & \multicolumn{2}{c}{ Total $(\mathrm{N}=69)$} \\
& $n$ & $\%$ & $n$ & $\%$ & $\mathrm{~N}$ & $\%$ \\
\hline Instructor & 26 & 57.8 & 8 & 33.3 & 34 & 49.3 \\
Assistant Professor & 15 & 33.3 & 15 & 62.5 & 30 & 43.5 \\
Associate Professor & 1 & 2.2 & 0 & 0.0 & 1 & 1.4 \\
Professor & 2 & 4.4 & 0 & 0.0 & 2 & 2.9 \\
Other & 1 & 2.2 & 1 & 4.2 & 2 & 2.9 \\
\hline
\end{tabular}

Teaching experience. Table 7 is also related to research question one and Section 1 of the survey. Profiles for the years of teaching experience indicated that over half of the novice educators had no prior teaching experience $(n=24 ; 53.3 \%)$. Novice educators also indicated that they had one year of previous teaching experience $(n=21 ; 46.7 \%)$.

The majority of experienced educators had four to five years of teaching experience $(n=10 ; 41.7 \%)$. Some had two or three years of previous teaching experience $(n=6 ; 25 \%)$. Others indicated that they had 6-9 years of experience in teaching $(n=2 ; 8.3 \%)$. There were also educators who entered into their new positions with 10 or more years of teaching experience $(n=6 ; 25 \%)$.

Table 7

Nurse Faculty Teaching Experience

\begin{tabular}{ccccccc}
\hline \multirow{2}{*}{ Years of Experience } & \multicolumn{2}{c}{ Novice $(n=45)$} & Experienced $(n=24)$ & \multicolumn{2}{c}{ Total $(\mathrm{N}=69)$} \\
\cline { 2 - 6 } & $n$ & $\%$ & $n$ & $\%$ & $\mathrm{~N}$ & $\%$ \\
\hline 0 & 24 & 53.3 & 0 & 0.0 & 24 & 34.8 \\
1 & 21 & 46.7 & 0 & 0.0 & 21 & 30.4 \\
$2-3$ & 0 & 0.0 & 6 & 25.0 & 6 & 8.7 \\
$4-5$ & 0 & 0.0 & 10 & 41.7 & 10 & 14.5 \\
$6-9$ & 0 & 0.0 & 2 & 8.3 & 2 & 2.9 \\
Greater than 10 & 0 & 0.0 & 6 & 25.0 & 6 & 8.7 \\
\hline
\end{tabular}




\section{PERCEIVED COMPETENCIES OF NURSE EDUCATORS}

Teaching responsibilities. Table 8 also answers research question one and Section 1 of the survey. The overall group of participants had teaching responsibilities in the clinical, classroom, or clinical and classroom settings. Very few of the participants had only clinical responsibilities $(n=3 ; 4.3 \%)$. Others had only classroom responsibilities $(n=6 ; 8.6 \%)$. Most educators, regardless of their previous teaching experience, had clinical and classroom responsibilities $(n=60 ; 87 \%)$. The data suggest that new faculty in this sample have classroom and clinical setting responsibilities. Moreover, regardless of the number of years of teaching experience in nursing education, the majority of faculty members had responsibilities in clinical and classroom settings.

Table 8

Nurse Faculty Teaching Responsibilities

\begin{tabular}{lcccccc}
\hline \multirow{2}{*}{ Teaching Responsibilities } & \multicolumn{2}{c}{ Novice $(n=45)$} & Experienced $(n=24)$ & \multicolumn{2}{c}{ Total $(\mathrm{N}=69)$} \\
\cline { 2 - 7 } & $n$ & $\%$ & $n$ & $\%$ & $\mathrm{~N}$ & $\%$ \\
\hline Clinical & 1 & 2.2 & 2 & 8.3 & 3 & 4.3 \\
Classroom & 1 & 2.2 & 5 & 20.8 & 6 & 8.7 \\
Clinical and Classroom & 43 & 95.5 & 17 & 70.8 & 60 & 87.0 \\
\hline
\end{tabular}

Academic setting. Table 9 relates to research question one and describes the type of academic setting in which new faculty members were employed. This data refers to Section 1 of the survey. The academic settings included: hospital, community college, liberal arts college, or research university. The majority of novice educators were newly employed in a community college $(n=20 ; 44.4 \%)$. The next highest academic setting that employed novice educators was the liberal arts university $(n=13 ; 28.9 \%)$. Novice faculty were also hired into research universities $(n=5 ; 11.1 \%)$. Other novice educators were employed by a hospital based nursing program $(\mathrm{n}=7 ; 15.6 \%)$. 


\section{PERCEIVED COMPETENCIES OF NURSE EDUCATORS}

Experienced nurse educators were equally hired into community colleges $(n=7 ; 29.2 \%)$ and research universities $(n=7 ; 29.2 \%)$. Some of the experienced educators were hired into a hospital based nursing school $(n=6 ; 25 \%)$. Only a few of the experienced educators entered into a position at a liberal arts institution $(n=4 ; 16.6 \%)$. These findings indicated that all types of academic settings had new faculty positions available in the 2009-2010 academic year. The results were widely distributed among the employer institutions regardless of the number of years of teaching experience the educator possessed.

Table 9

Nurse Faculty Academic Setting

\begin{tabular}{lcccccc}
\hline \multirow{2}{*}{ Academic Setting } & \multicolumn{2}{c}{ Novice $(n=45)$} & Experienced $(n=24)$ & \multicolumn{2}{c}{ Total $(\mathrm{N}=69)$} \\
\cline { 2 - 7 } & $n$ & $\%$ & $n$ & $\%$ & $\mathrm{~N}$ & $\%$ \\
\hline Hospital/Diploma & 7 & 15.6 & 6 & 25.0 & 13 & 18.8 \\
Community College & 20 & 44.4 & 7 & 29.2 & 27 & 39.1 \\
Liberal Arts College & 13 & 28.9 & 4 & 16.6 & 17 & 24.6 \\
Research University & 5 & 11.1 & 7 & 29.2 & 12 & 17.4 \\
\hline
\end{tabular}

Program type. Table 10, as seen on the following page, presents the type of nursing program in which the hired educators taught. The programs which new faculty members were teaching during the 2009-2010 academic year included: diploma/hospital, associate, and baccalaureate degree. Most novice $(n=18 ; 40 \%)$ and experienced $(n=11 ; 45.8 \%)$ faculty members were teaching in a baccalaureate degree program. Both novice $(n=17 ; 37.8 \%)$ and experienced faculty $(\mathrm{n}=7 ; 29.2 \%)$ members were hired into associate degree nursing programs. The diploma program was the least common type of program in which the novice $(n=10 ; 22.2 \%)$ and experienced $(\mathrm{n}=6 ; 25 \%)$ nurse educator was hired. 
Table 10

Nursing Programs

\begin{tabular}{lcccccc}
\hline \multirow{2}{*}{ Program Type } & \multicolumn{2}{c}{ Novice $(n=45)$} & \multicolumn{2}{c}{ Experienced $(n=24)$} & \multicolumn{2}{c}{ Total (N=69) } \\
\cline { 2 - 7 } & $n$ & $\%$ & $n$ & $\%$ & $\mathrm{~N}$ & $\%$ \\
\hline Diploma & 10 & 22.2 & 6 & 25.0 & 16 & 23.2 \\
Associate Degree & 17 & 37.8 & 7 & 29.2 & 24 & 34.8 \\
Baccalaureate & 18 & 40.0 & 11 & 45.8 & 29 & 42.0 \\
\hline
\end{tabular}

\section{Research Question Two}

The second research question was: What qualifications (education, clinical practice, collaborator and leadership, and scholar) do novice nurse educators possess who teach in prelicensure registered nurse programs?

Academic qualifications. In order to answer Research Question 2, profiles are shown for the level of academic preparation of newly hired nurse educators. Participants were asked to select all applicable educational options (degree types). For example, in Table 11, it may be noted that 20 of the 45 Novice participants indicated "MSN Nursing Education." The data in this table corresponds to Section 2 of the survey.

The most frequent type of degree held by the novice educator was the Master of Science in Nursing degree with a nursing education (MSN Ed.) focus $(n=20 ; 44.4 \%)$. Next was the Master of Science in Nursing (MSN) ( $\mathrm{n}=15,33.3 \%)$ and the Master of Science (non-nursing) with a Bachelor of Science in Nursing $(n=15 ; 33.3 \%)$. Novice faculty also held a Master of Science in Nursing degree with an advanced practice focus $(n=9 ; 20 \%)$. Only one newly hired novice $(\mathrm{n}=1 ; 2.2 \%)$ held a Ph.D. in Nursing without a MS or MSN degree.

The most common type of degree held by experienced educators was the Master of Science in Nursing with a nursing education focus $(n=10 ; 41.7 \%)$. Participants also held a BSN and MS (non-nursing) $(n=8 ; 33.3 \%)$ and a Master of Science in Nursing $(n=7 ; 29.2 \%)$. 


\section{PERCEIVED COMPETENCIES OF NURSE EDUCATORS}

Experienced faculty equally held a Master of Science degree with an advanced practice focus $(\mathrm{n}=4 ; 16.7)$ and a Ph.D. and MSN (n=4; 16.7). A few of the remaining participants held other degrees such as a Ph.D. in a related field and MSN ( $n=1,4.2 \%)$, a Ph.D. in Nursing and a MSN with an advanced practice focus $(n=1 ; 4.2 \%)$, an EdD with MSN $(n=1 ; 4.2 \%)$ and a Doctor of Nursing Practice $(n=1 ; 4.2 \%)$. Overall, the most common type of degree held by novice and experienced educator was the Master of Science in Nursing with a nursing education focus.

Table 11

Nurse Faculty Academic Qualifications

\begin{tabular}{lcccc}
\hline \multirow{2}{*}{ Educational Options } & \multicolumn{2}{c}{ Novice $(n=45)$} & \multicolumn{2}{c}{ Experienced $(n=24)$} \\
\cline { 2 - 5 } & Selected & $\%$ & Selected & $\%$ \\
\hline BSN and MS (non-nursing) & 15 & 33.3 & 8 & 33.3 \\
MSN & 15 & 33.3 & 7 & 29.2 \\
MSN Nursing Education & 20 & 44.4 & 10 & 41.7 \\
MSN Advanced Practice & 9 & 20.0 & 4 & 16.7 \\
DNP & 0 & 0.0 & 1 & 4.2 \\
Ph.D. Nursing and MSN & 0 & 0.0 & 4 & 16.7 \\
Ph.D. Nursing and MSN AP & 0 & 0.0 & 1 & 4.2 \\
Ph.D. Nursing without MS or MSN & 1 & 2.2 & 0 & 0.0 \\
Ph.D. Related Field and MSN & 0 & 0.0 & 1 & 4.2 \\
EdD and MSN & 0 & 0.0 & 1 & 4.2 \\
\hline
\end{tabular}

Note. "Selected" indicates the number of participants who chose the item.

Acute care qualifications. Table 12 illustrates results for Research Question 2, which consisted of the acute care qualifications of newly hired nurse faculty. Most novice educators had greater than five years of acute care clinical experience $(n=36 ; 80 \%)$. The number of years of practice least common to the nurse educator was "one year acute care experience" $(n=1 ; 2.2 \%)$. Similarly, experienced nurse educators possessed greater than five years of acute care practice experience $(n=19 ; 79.2 \%)$. 
Table 12

Nurse Faculty Experience: Acute Care

\begin{tabular}{lrrrrrr}
\hline \multirow{2}{*}{ Years } & \multicolumn{2}{c}{ Novice $(n=45)$} & \multicolumn{2}{c}{ Experienced $(n=24)$} & \multicolumn{2}{c}{ Total $(\mathrm{N}=69)$} \\
\cline { 2 - 7 } 1 Year & $n$ & $\%$ & $n$ & $\%$ & $\mathrm{~N}$ & $\%$ \\
\hline 2 - 3 Years & 1 & 2.2 & 1 & 4.2 & 2 & 2.9 \\
4 - 5 Years & 2 & 4.4 & 1 & 4.2 & 3 & 4.3 \\
$>$ 5 Years & 3 & 6.7 & 1 & 4.2 & 4 & 5.8 \\
None Selected & 36 & 80.0 & 19 & 79.2 & 55 & 79.8 \\
\hline
\end{tabular}

Specialty practice qualifications. Table 13 presents the findings regarding the nurse educators' specialty practice qualifications. Most novice educators $(n=32 ; 71.1 \%)$, had greater than five years of specialty practice experience. Some indicated four or five years of specialty practice experience $(\mathrm{n}=5 ; 11.1 \%)$. Other novice educators possessed two or three years of specialty practice $(n=3 ; 6.7 \%)$. None of the novice educators had just one year of specialty practice experience.

Most of the experienced educators $(n=20 ; 83.3 \%)$ had greater than five years of specialty practice experience. Others indicated four or five years of specialty practice experience $(n=2$; 8.3\%). The remaining participants had either two or three years of specialty practice experience $(n=1 ; 4.2 \%)$ or one year of specialty practice experience $(n=1 ; 4.2 \%)$.

Table 13

Nurse Faculty Experience: Specialty Practice

\begin{tabular}{lrrrrrr}
\hline \multirow{2}{*}{ Years } & \multicolumn{2}{c}{ Novice $(n=45)$} & \multicolumn{2}{c}{ Experienced $(n=24)$} & \multicolumn{2}{c}{ Total $(\mathrm{N}=69)$} \\
\cline { 2 - 7 } & $n$ & $\%$ & $n$ & $\%$ & $\mathrm{~N}$ & $\%$ \\
\hline 1 Year & 0 & 0.0 & 1 & 4.2 & 1 & 1.4 \\
2 - 3 Years & 3 & 6.7 & 1 & 4.2 & 4 & 5.8 \\
4 - 5 Years & 5 & 11.1 & 2 & 8.3 & 7 & 10.1 \\
$>$ 5 Years & 32 & 71.1 & 20 & 83.3 & 52 & 75.4 \\
None Selected & 5 & 11.1 & 0 & 0.0 & 5 & 7.2 \\
\hline
\end{tabular}




\section{PERCEIVED COMPETENCIES OF NURSE EDUCATORS}

Table 14 presents findings for current positions held in the clinical practice setting. These included either a registered nurse or an advanced practice nurse. An option of management or supervisory experience was also included in this section of the survey. Participants were asked to select all applicable practice experiences (clinical, advanced practice, management). Almost half of the novice educators $(n=20 ; 44.4 \%)$ practiced as a registered nurse while teaching in their academic positions. Other novice educators $(n=8 ; 17.8 \%)$ worked as an advanced practice nurse. Most novices ( $\mathrm{n}=29 ; 64.4 \%)$ indicated that they possessed management or supervisory experience.

The experienced educators also indicated management and supervisory experience $(n=16$; $66.7 \%)$. The remaining experienced educators had either practiced as a registered nurse $(\mathrm{n}=5$; $20.8 \%)$ or an advanced practice nurse $(n=3 ; 12.5 \%)$ while teaching in the academic setting.

Table 14

Nurse Faculty Experience: Clinical Practice, Advanced Practice, and Management/Supervisory

\begin{tabular}{lcccc}
\hline \multirow{2}{*}{ Practice Experience } & \multicolumn{2}{c}{ Novice $(n=45)$} & \multicolumn{2}{c}{ Experienced $(n=24)$} \\
\cline { 2 - 5 } & Selected & $\%$ & Selected & $\%$ \\
\hline Current Clinical Practice Experience & 20 & 44.4 & 5 & 20.8 \\
Current Advanced Practice Experience & 8 & 17.8 & 3 & 12.5 \\
Management/Supervisory Experience & 29 & 64.4 & 16 & 66.7 \\
\hline
\end{tabular}

Note. "Selected" indicates the number of participants who chose the item.

Leadership qualifications. Table 15 presents data regarding research question two which identified the current level of leadership experience of newly hired educators. Participants were instructed to select all applicable leadership qualifications. Most novice nurse educators maintained an active membership in at least one professional nursing organization $(n=38$; 84.4\%). Novice participants also indicated they exhibited team collegial working relationships and interpersonal skills $(\mathrm{n}=38 ; 84.4 \%)$. Novice faculty members were also able to actively apply 


\section{PERCEIVED COMPETENCIES OF NURSE EDUCATORS}

knowledge of social, political and economic forces to influence nursing practice and health care $(n=30 ; 66.7 \%)$. The lowest frequency noted among the leadership qualifications for the novice educator was their experience in serving as a role of an expert nurse consultant $(n=6 ; 13.3 \%)$.

The experienced nurse educators had greater frequencies and percentages in all of the leadership qualification items in the survey. Almost all of the experienced educators maintained an active membership in at least one professional nursing organization $(n=22 ; 91.7 \%)$. The experienced educators also indicated that they exhibited team collegial working relationships and effective interpersonal skills $(\mathrm{n}=22 ; 91.7 \%)$. Most experienced educators had served as a member on a multidisciplinary task force $(n=18 ; 75.0 \%)$ and were able to actively apply knowledge of social, economic, and political forces to influence nursing practice and health care $(\mathrm{n}=18$; $75.0 \%)$. Others additionally served in some capacity as a nurse consultant $(\mathrm{n}=11 ; 45.8 \%)$.

Table 15

Nurse Faculty Leadership Qualifications

\begin{tabular}{ccccc}
\hline & \multicolumn{2}{c}{ Novice $(n=45)$} & \multicolumn{2}{c}{ Experienced $(n=24)$} \\
\cline { 2 - 5 } Leadership Qualifications & Selected & $\%$ & Selected & $\%$ \\
\hline $\begin{array}{c}\text { Active member in at least one } \\
\text { professional nursing organization }\end{array}$ & 38 & 84.4 & 22 & 91.7 \\
$\begin{array}{c}\text { Apply team collegial working } \\
\text { relationships and effective } \\
\text { interpersonal skills }\end{array}$ & 38 & 84.4 & 22 & 91.7 \\
$\begin{array}{c}\text { Serve or served on a } \\
\text { multidisciplinary task force }\end{array}$ & 23 & 51.1 & 18 & 75.0 \\
$\begin{array}{c}\text { Apply social, economic, and political } \\
\text { forces to influence nursing } \\
\text { practice and health care }\end{array}$ & 30 & 66.7 & 18 & 75.0 \\
$\begin{array}{c}\text { Serve or served in the role of an } \\
\text { expert nurse consultant }\end{array}$ & 6 & 13.3 & 11 & 45.8 \\
\hline
\end{tabular}

Note. "Selected" indicates the number of participants who chose the item.

Scholar qualifications. Research question 2 asked the participants to identify their scholar qualifications and to select all applicable scholar qualifications. Table 16 presents data relevant to this question. The highest frequency within this section for novice educators was the 
ability to translate applicable health related research into practice $(n=34 ; 75.6 \%)$. Few novice educators indicated they were able to conduct research related to nursing and health care ( $\mathrm{n}=9$; 20.0\%). In addition, few novice educators identified their ability to present scholarship activities on a local and regional level $(n=8 ; 17.8 \%)$. Only a few of the novice educators had published research findings $(n=2 ; 4.4 \%)$ or presented research on a national level $(n=3 ; 6.7 \%)$.

The highest selected scholar qualification among the experienced educators $(n=16$; $66.7 \%$ ) was the same as the novice educators, which was the ability to translate applicable health related research into practice. Experienced educators $(n=8 ; 33.3 \%)$ indicated that they were able to conduct research related to nursing education at a greater frequency than novice educators. Experienced educators were able to present research on a national level ( $n=7 ; 29.2 \%)$. Only a few of the experienced educators had funded area of research $(n=4 ; 16.7 \%)$.

Table 16

Nurse Faculty Scholar Qualifications

\begin{tabular}{|c|c|c|c|c|}
\hline \multirow[b]{2}{*}{ Scholar Qualifications } & \multicolumn{2}{|c|}{ Novice $(n=45)$} & \multicolumn{2}{|c|}{ Experienced $(n=24)$} \\
\hline & Selected & $\%$ & Selected & $\%$ \\
\hline Maintain a funded area of research & 0 & 0.0 & 4 & 16.7 \\
\hline $\begin{array}{l}\text { Publish research findings in peer } \\
\text { reviewed journals }\end{array}$ & 2 & 4.4 & 6 & 25.0 \\
\hline $\begin{array}{l}\text { Present research on a national } \\
\text { level }\end{array}$ & 3 & 6.7 & 7 & 29.2 \\
\hline $\begin{array}{l}\text { Translate applicable health } \\
\text { related research into practice }\end{array}$ & 34 & 75.6 & 16 & 66.7 \\
\hline $\begin{array}{l}\text { Present scholarship activities on } \\
\text { local and regional levels }\end{array}$ & 8 & 17.8 & 5 & 20.8 \\
\hline $\begin{array}{l}\text { Conduct research related to } \\
\text { nursing and health care }\end{array}$ & 9 & 20.0 & 6 & 25.0 \\
\hline $\begin{array}{l}\text { Conduct research related to } \\
\text { nursing education }\end{array}$ & 5 & 11.1 & 8 & 33.3 \\
\hline
\end{tabular}




\section{PERCEIVED COMPETENCIES OF NURSE EDUCATORS}

\section{Research Question Three}

The third research question was, How do newly hired nurse educators rate themselves on their knowledge and skills to fulfill the nurse educator competencies (facilitate learning, facilitate learner development and socialization, use assessment and evaluation strategies, design curriculum and evaluate program outcomes, function within the educational environment, exhibit leader and collaborator role, and demonstrate scholar role competencies)?

\section{Self-perceived competency differences: novice vs. experienced faculty. To answer}

research question three, $t$-Tests were computed to determine if there were statistically significant (at least $p<.05$ ) differences between novice nurse educators (one year or less of previous teaching experience) and experienced nurse educators (greater than one year of previous teaching experience) ratings of their proficiency levels to fulfill the nurse educator competencies. Thus, the independent variable was the years of experience in nursing education. The dependent variables were the nurse educator competencies, which included the nurse educator's ability to: (a) facilitate learning, (b) facilitate learner development and socialization, (c) use assessment and evaluation strategies, (d) design curriculum and evaluate program outcomes, (e) function within the educational environment, (f) exhibit leader and collaborator role competencies, and (g) demonstrate scholar role competency.

The dependent variable for Section 6 of the survey was "nurse practice competency." The possible range of scores for items (6.1 through 6.12) was (0 through 48). The mean score for the novice nurse educator $(\mathrm{n}=45)$ was $41.7(\mathrm{SD}=5.0)$ and the mean score for the experienced nurse educator $(\mathrm{n}=24)$ was $42(\mathrm{SD}=4.7)$. An independent sample $t$-Test was conducted to compare the perceived nurse practice competency scores for novice and experienced nurse educators. An independent $t$-Test revealed that there was no significant difference in scores for novice and 


\section{PERCEIVED COMPETENCIES OF NURSE EDUCATORS}

experienced nurse educators $t(67)=0.25, p=0.79$ (two-tailed), $p>.05$ (not statistically significant). This result is shown in Table 17.

The dependent variable for Section 7A of the survey was "facilitate learning." The possible range of scores for items (7A1 thorough 7A6) was (0 through 24). There were no significant differences in mean scores for novice $\mathrm{M}=16.9(\mathrm{SD}=4.3)$ and experienced nurse educators, $\mathrm{M}=17(\mathrm{SD}=4.5)$. The independent sample $t$-Test revealed $t(67)=0.13, p=0.89$ (twotailed), $p>.05$ (not statistically significant). This result is shown in Table 17 .

The dependent variable for Section 7B of the survey was "facilitate learner development and socialization." The possible range of scores for item 7B1 through 7B6 was (0 through 24). The mean score for novice nurse educators was $17.5(\mathrm{SD}=4.3)$ and the mean score for experienced educators was $17.8(\mathrm{SD}=4.3)$. The perceived ability of newly hired nurse educators to facilitate student learning development and socialization $t$-Test yielded $t(67)=0.20, p=0.84$, $p>.05$ (not statistically significant). See Table 17 .

The dependent variable for Section 7C of the survey was "use assessment and evaluation strategies." The possible range of scores for item 7C1 through 7C5 was (0 thorough 20). The mean score for novice nurse educators was $12.6(\mathrm{SD}=3.9)$ and the mean score for experienced nurse educators was 12.6 ( $\mathrm{SD}=4.7)$. The perceived ability of newly hired nurse educators to use assessment and evaluation strategies $t$-Test yielded $t(67)=0.03, p=0.97, \mathrm{p}>.05$ (not statistically significant). This result is shown in Table 17.

The dependent variable for Section 7D of the survey was "design curriculum and evaluate program outcomes." The possible range of scores for item 7D1 through 7D5 was (0 through 20). The mean score for novice nurse educators was $10.4(\mathrm{SD}=5.4)$ and the mean score for experienced nurse educators was $11.0(\mathrm{SD}=4.7)$. The perceived ability of newly hired nurse 


\section{PERCEIVED COMPETENCIES OF NURSE EDUCATORS}

educators to design curriculum and evaluate program outcomes $t$-Test yielded $t(67)=0.48, p=$ $0.64, p>.05$ (not statistically significant). This result is shown in Table 17.

The dependent variable for Section 7E of the survey was "function within the educational environment." The possible range of scores for items 7E1 through 7E4 was (0 through 16). The mean score for novice nurse educators was $11.2(\mathrm{SD}=3.3)$ and the mean for experienced nurse educators was $11.7(\mathrm{SD}=3.6)$. The perceived ability of nurse educators to function within the educational environment independent samples $t$-Test yielded $t(67)=0.59, \mathrm{p}=0.55, p>.05$ (not statistically significant). This result is shown in Table 17.

The dependent variable for Section 7F of the survey was "leader and collaborator role competency." The possible range of scores for items 7F1 through 7F4 was (0 through 12). The mean for novice educators was $9.4(\mathrm{SD}=2.1)$ and the mean for experienced educators was 9.0 $(\mathrm{SD}=2.3)$. The perceived ability of nurse educators to demonstrate leader and collaborator abilities independent samples $t$-Test yielded $t(67)=0.72, p=0.48, p>.05$ (not statistically significant). This result is shown in Table 17.

The dependent variable for Section 7G of the survey was "scholar role competency." The possible range of scores for items $7 \mathrm{G} 1$ through $7 \mathrm{G} 7$ was ( 0 through 28$)$. The mean score for novice educators was $14(\mathrm{SD}=7.6)$ and the mean score for experienced educators was 12.6 $(\mathrm{SD}=6.9)$. The perceived ability of nurse educators to demonstrate scholar role abilities between novice and experienced nurse educators $t$-Test yielded $t(67)=0.80, p=0.42, p>.05$ (not statistically significant). This result is shown in Table 17. 


\section{PERCEIVED COMPETENCIES OF NURSE EDUCATORS}

Table 17

Differences in Perceived Competencies: Novice Versus Experienced Nurse Educators

\begin{tabular}{|c|c|c|c|c|}
\hline Competency Category & $\begin{array}{c}\text { Novice } \\
n=45 \\
\mathrm{M}(\mathrm{SD})\end{array}$ & $\begin{array}{c}\text { Experienced } \\
n=24 \\
\mathrm{M}(\mathrm{SD})\end{array}$ & $t(\mathrm{df})=$ value & $p$ \\
\hline Nurse practice Competencies & $41.7(5.0)$ & $42.0(4.7)$ & $(67)=0.26$ & $0.79 p>.05 \mathrm{NS}$ \\
\hline Facilitate Learning & $16.9(4.3)$ & $17.0(4.5)$ & $(67)=0.13$ & $0.89 p>.05 \mathrm{NS}$ \\
\hline $\begin{array}{l}\text { Facilitate Learning Development and } \\
\text { Socialization }\end{array}$ & $17.5(4.3)$ & $17.8(4.3)$ & $(67)=0.20$ & $0.84 p>.05 \mathrm{NS}$ \\
\hline Use Assessment and Evaluation & $12.6(3.9)$ & $12.6(4.7)$ & $(67)=0.03$ & $0.97 p>.05 \mathrm{NS}$ \\
\hline Design Curriculum & $10.4(5.4)$ & $11.0(4.7)$ & $(67)=0.48$ & $0.64 p>.05 \mathrm{NS}$ \\
\hline $\begin{array}{l}\text { Function within the Educational } \\
\text { Environment }\end{array}$ & $11.2(3.3)$ & $11.7(3.6)$ & $(67)=0.59$ & $0.55 p>.05 \mathrm{NS}$ \\
\hline Leader and Collaborator & $9.4(2.1)$ & $9.0(2.3)$ & $(67)=0.72$ & $0.48 p>.05 \mathrm{NS}$ \\
\hline Scholar Role Competency & $14.0(7.6)$ & $12.6(6.9)$ & $(67)=0.80$ & $0.42 p>.05 \mathrm{NS}$ \\
\hline
\end{tabular}

Note. NS = Not Significant

Newly hired nurse educators were additionally asked to rate their own level of proficiency for each competency in Section 6, "Nurse Practice Competencies," and Section 7, "Teaching and Advising Role Competencies" of the survey. The difference in perceived frequencies and percentages for new and experienced faculty are provided in Table 18.

The framework of Benner (1984), "From Novice to Expert," was used to indicate the rating of nurse educators' own level of proficiency in each competency area. The ratings included (0) no experience, (1) advanced beginner, (2) competent, (3) proficient and (4) expert. Moreover, the participants were provided a brief description of each level of proficiency as they rated themselves in each section and subsection of the survey. Thus, the description of the rating of (0) No Experience indicated that faculty had no experience in the identified competency area or its subsections. The description provided for the rating of (1) Advanced Beginner indicated that faculty had some previous knowledge and practical experience with the stated competency. This rating indicated that frequent guidance in this area was needed. The description provided for 


\section{PERCEIVED COMPETENCIES OF NURSE EDUCATORS}

(2) Competent indicated faculty had sufficient knowledge, required little guidance, and were able to perform the competency confidently. The description given for (3) Proficient indicated that the educators demonstrated a holistic understanding of the competency and were able to integrate past experiences to guide decision-making in the competency area. The description given for (4) Expert indicated faculty members were highly skilled and possessed a deep understanding of the competency.

The independent variable for research question three was "years of experience." The dependent variable was the identified competency. These included: facilitate learning, facilitate learner development and socialization, use assessment and evaluation strategies, design curriculum and evaluate program outcomes, function within the educational environment, exhibit leader and collaborator role competencies, and demonstrate scholar role competencies.

Perceived proficiency levels: Facilitate learning. The "Facilitate Learning" competency contained six sections (Table 18). In the "utilize teaching strategies based on educational theory subsection," novice educators rated themselves predominately as "competent" $(\mathrm{n}=20 ; 44 \%)$; a lower proficiency level rating than experienced educators. Experienced educators rated themselves predominately as "proficient" $(\mathrm{n}=11 ; 46 \%)$. In the subsection, "integrate and apply information technologies into teaching practice," novice educators rated themselves as "competent" ( $\mathrm{n}=18 ; 40 \%)$ and "proficient" $(\mathrm{n}=15 ; 33 \%)$. Similarly, the experienced educators rated themselves as "competent" $(n=7 ; 29 \%)$ and "proficient" $(n=9,38 \%)$.

In the subsection of "engage students in scholarly activities," the novice educators rated themselves predominately as "competent" $(n=12 ; 27 \%)$ and "proficient" $(n=18 ; 40 \%)$. The experienced educators rated themselves as "proficient" $(n=10 ; 42 \%)$. In the "facilitate student 


\section{PERCEIVED COMPETENCIES OF NURSE EDUCATORS}

skill development in information literacy," the novice educators rated themselves as "proficient" $(\mathrm{n}=16 ; 36 \%)$. The experienced educators rated themselves as "proficient" $(\mathrm{n}=9 ; 38 \%)$.

In the ability to "demonstrate respect, enthusiasm, and interest in students, the novice educators rated themselves as "proficient" $(\mathrm{n}=20 ; 44 \%)$ and "expert" $(\mathrm{n}=22 ; 49 \%)$, while the experienced educators rated themselves as "expert" $(\mathrm{n}=15 ; 63 \%)$. In the subsection of the ability to "modify teaching strategies to accommodate diverse learning styles," novice educators rated themselves as "proficient" $(\mathrm{n}=20 ; 44 \%)$. The experienced educators rated themselves as "proficient" (n=10; 42\%).

Table 18

Proficiency Ratings to Facilitate Learning

\begin{tabular}{llc} 
Povice $(n=45)$ & \multicolumn{2}{c}{ Experienced $(n=24)$} \\
Proficiency Level & $n^{\text {Non }}$ & $n$ \\
\cline { 2 - 4 }
\end{tabular}

7A1: Use teaching strategies based on educational theory

\begin{tabular}{|c|c|c|c|c|}
\hline No Experience & 0 & 0.0 & 0 & 0.0 \\
\hline Advanced Beginner & 4 & 9.0 & 5 & 21.0 \\
\hline Competent & 20 & 44.0 & 4 & 17.0 \\
\hline Proficient & 13 & 29.0 & 11 & 46.0 \\
\hline Expert & 8 & 18.0 & 4 & 17.0 \\
\hline \multicolumn{5}{|c|}{ 7A2: Integrate and apply information technologies into teaching } \\
\hline No Experience & 0 & 0.0 & 0 & 0.0 \\
\hline Advanced Beginner & 2 & 4.0 & 2 & 8.0 \\
\hline Competent & 18 & 40.0 & 7 & 29.0 \\
\hline Proficient & 15 & 33.0 & 9 & 38.0 \\
\hline Expert & 10 & 22.0 & 6 & 25.0 \\
\hline \multicolumn{5}{|c|}{ 7A3: Engage students in scholarly activities related to nursing } \\
\hline No Experience & 0 & 0.0 & 1 & 4.0 \\
\hline Advanced Beginner & 7 & 16.0 & 1 & 4.0 \\
\hline Competent & 12 & 27.0 & 9 & 38.0 \\
\hline Proficient & 18 & 40.0 & 10 & 42.0 \\
\hline Expert & 8 & 18.0 & 3 & 13.0 \\
\hline \multicolumn{5}{|c|}{ 7A4: Facilitate skill development in information literacy } \\
\hline No Experience & 0 & 0.0 & 0 & 0.0 \\
\hline Advanced Beginner & 5 & 11.0 & 3 & 13.0 \\
\hline
\end{tabular}


Table 18

Proficiency Ratings to Facilitate Learning (continued)

\begin{tabular}{|c|c|c|c|c|}
\hline \multirow[b]{2}{*}{ Proficiency Level } & \multicolumn{2}{|c|}{ Novice $(n=45)$} & \multicolumn{2}{|c|}{ Experienced $(n=24)$} \\
\hline & $n$ & $\%$ & $n$ & $\%$ \\
\hline Competent & 15 & 33.0 & 7 & 29.0 \\
\hline Proficient & 16 & 36.0 & 9 & 38.0 \\
\hline Expert & 9 & 20.0 & 5 & 21.0 \\
\hline \multicolumn{5}{|c|}{ 7A5: Demonstrate respect, enthusiasm, and interest in students } \\
\hline No Experience & 0 & 0.0 & 0 & 0.0 \\
\hline Advanced Beginner & 1 & 2.0 & 0 & 0.0 \\
\hline Competent & 2 & 4.0 & 1 & 4.0 \\
\hline Proficient & 20 & 44.0 & 8 & 33.0 \\
\hline Expert & 22 & 49.0 & 15 & 63.0 \\
\hline \multicolumn{5}{|c|}{ 7A6: Modify teaching based on diverse learning styles } \\
\hline No Experience & 0 & 0.0 & 0 & 0.0 \\
\hline Advanced Beginner & 1 & 2.0 & 1 & 4.0 \\
\hline Competent & 12 & 27.0 & 7 & 29.0 \\
\hline Proficient & 20 & 44.0 & 10 & 42.0 \\
\hline Expert & 12 & 27.0 & 6 & 25.0 \\
\hline
\end{tabular}

Perceived proficiency levels: Facilitate learner development and socialization. A

second competency in the survey's Section 7 was "Facilitate Learner Development and

Socialization." Again, nurse educators were asked to rate themselves according to their

proficiency level in this competency which contained six subsections (7B1 to 7B6). Table 19

outlines findings for new and experienced nurse educators. In the ability to "foster cognitive,

psychomotor and affective development in learners," the novice nurse educators rated

themselves "competent" $(\mathrm{n}=16 ; 36 \%)$ and "proficient" $(\mathrm{n}=19 ; 42 \%)$. Similarly, the experienced educators rated themselves as "competent" $(n=9 ; 38 \%)$ and "proficient" $(n=8 ; 33 \%)$.

In the subsection "facilitate student socialization into the nursing profession," novice educators rated themselves predominately as "proficient" $(n=18 ; 40 \%)$. Experienced educators rated themselves as "competent" $(\mathrm{n}=9 ; 38 \%)$. In the ability to "implement strategies to bridge theory and clinical practice, novice educators rated themselves as "proficient' $(n=17 ; 38 \%)$. 


\section{PERCEIVED COMPETENCIES OF NURSE EDUCATORS}

Some novices considered themselves "expert" in this area $(n=10 ; 22 \%)$, similar to the experienced educators $(n=5 ; 21 \%)$. Experienced educators also rated themselves "proficient" $(n=9 ; 38 \%)$.

The novice educators predominately rated themselves as "proficient" $(\mathrm{n}=19 ; 42 \%)$ in the subsection of "exhibit a variety of personal teaching styles and interactions to positively influence learners. The experienced educators also rated themselves predominately as "proficient" ( $\mathrm{n}=11 ; 46 \%)$. In the subsection of "display expertise in clinical practice while serving as a role model, preceptor, mentor, and guide to students," novice educators $(\mathrm{n}=21 ; 47 \%)$ and experienced educators $(\mathrm{n}=14 ; 58 \%)$ rated themselves as "expert."

The subsection of "ability to provide adequate and expert clinical supervision of students," was rated by the novice as "proficient" (n=19; 42\%) and the experienced faculty $(\mathrm{n}=12 ; 50 \%)$ predominately as "expert."

Table19

Proficiency Ratings to Facilitate Learner Development and Socialization

\begin{tabular}{|c|c|c|c|c|}
\hline \multirow[b]{2}{*}{ Proficiency Level } & \multicolumn{2}{|c|}{ Novice $(n=45)$} & \multicolumn{2}{|c|}{ Experienced $(n=24)$} \\
\hline & $n$ & $\%$ & $n$ & $\%$ \\
\hline \multicolumn{5}{|c|}{ 7B1: Foster cognitive, psychomotor, and affective development in learners } \\
\hline No Experience & 0 & 0.0 & 0 & 0.0 \\
\hline Advanced Beginner & 3 & 7.0 & 2 & 8.0 \\
\hline Competent & 16 & 36.0 & 9 & 38.0 \\
\hline Proficient & 19 & 42.0 & 8 & 33.0 \\
\hline Expert & 7 & 16.0 & 5 & 21.0 \\
\hline \multicolumn{5}{|c|}{ 7B2: Facilitate student socialization into the nursing profession } \\
\hline No Experience & 0 & 0.0 & 0 & 0.0 \\
\hline Advanced Beginner & 3 & 7.0 & 1 & 4.0 \\
\hline Competent & 12 & 27.0 & 9 & 38.0 \\
\hline Proficient & 18 & 40.0 & 7 & 29.0 \\
\hline Expert & 12 & 27.0 & 7 & 29.0 \\
\hline \multicolumn{5}{|c|}{ 7B3: Implement strategies to bridge theory and practice } \\
\hline No Experience & 0 & 0.0 & 0 & 0.0 \\
\hline
\end{tabular}




\section{PERCEIVED COMPETENCIES OF NURSE EDUCATORS}

Table19

Proficiency Ratings to Facilitate Learner Development and Socialization (continued)

\begin{tabular}{|c|c|c|c|c|}
\hline \multirow[b]{2}{*}{ Proficiency Level } & \multicolumn{2}{|c|}{ Novice $(n=45)$} & \multicolumn{2}{|c|}{ Experienced $(n=24)$} \\
\hline & $n$ & $\%$ & $n$ & $\%$ \\
\hline Advanced Beginner & 4 & 9.0 & 2 & 8.0 \\
\hline Competent & 14 & 31.0 & 8 & 33.0 \\
\hline Proficient & 17 & 38.0 & 9 & 38.0 \\
\hline Expert & 10 & 22.0 & 5 & 21.0 \\
\hline \multicolumn{5}{|c|}{ 7B4: Exhibit a variety of teaching styles to positively influence learner outcomes } \\
\hline No Experience & 0 & 0.0 & 0 & 0.0 \\
\hline Advanced Beginner & 3 & 7.0 & 2 & 8.0 \\
\hline Competent & 13 & 29.0 & 6 & 25.0 \\
\hline Proficient & 19 & 42.0 & 11 & 46.0 \\
\hline Expert & 10 & 22.0 & 5 & 21.0 \\
\hline \multicolumn{5}{|c|}{ 7B5: Display expertise in clinical practice while serving as a role model and mentor } \\
\hline No Experience & 0 & 0.0 & 0 & 0.0 \\
\hline Advanced Beginner & 1 & 2.0 & 0 & 0.0 \\
\hline Competent & 6 & 13.0 & 5 & 21.0 \\
\hline Proficient & 17 & 38.0 & 5 & 21.0 \\
\hline Expert & 21 & 47.0 & 14 & 58.0 \\
\hline \multicolumn{5}{|c|}{ 7B6: Demonstrate ability to demonstrate adequate and expert clinical supervision of students } \\
\hline No Experience & 0 & 0.0 & 0 & 0.0 \\
\hline Advanced Beginner & 2 & 4.0 & 0 & 0.0 \\
\hline Competent & 6 & 13.0 & 3 & 13.0 \\
\hline Proficient & 19 & 42.0 & 9 & 38.0 \\
\hline Expert & 18 & 40.0 & 12 & 50.0 \\
\hline
\end{tabular}

Perceived proficiency levels: Use assessment and evaluation strategies. Section 7C

asked nurse educators to rate their level of proficiency regarding the competency of "Use Assessment and Evaluation Strategies." There were five subsections for this competency. The results regarding this competency for novice and experienced nurse educators can be found in Table 20. Within the ability to "describe appropriate evaluation strategies to assess student learning," novice educators rated themselves predominately as "competent" $(\mathrm{n}=17 ; 38 \%)$. 


\section{PERCEIVED COMPETENCIES OF NURSE EDUCATORS}

Novice faculty members were also "proficient" $(n=13 ; 29 \%)$ in this area. Most of the experienced faculty rated themselves as "competent" $(\mathrm{n}=8 ; 33 \%)$ as well as "expert" $(\mathrm{n}=8 ; 33 \%)$.

The subsection of "apply evidence based assessment and evaluation practices within the academic arena," was rated by novice educators as predominately as "competent" (n=16; 36\%). Experienced educators rated themselves predominately as "proficient" ( $n=9 ; 38 \%)$.

In the subsection of "develop test blueprints that reflect course objectives" showed novice educators rated themselves as "competent" $(n=16 ; 36 \%)$ and experienced educators $(n=10 ; 42 \%)$ rated themselves as "advanced beginners" which indicated they needed guidance in this area. The results for this section also revealed a wide range of answers in all proficiency areas. This section had notably higher frequencies in the "advanced beginner" proficiency level for novice and experienced educators.

Novice educators rated themselves predominately as "competent" $(\mathrm{n}=21 ; 47 \%)$ and experienced educators rated themselves as "advanced beginner" $(n=8 ; 33 \%)$ in the subsection of "provide evidence of the ability to interpret test analysis."

Subsection, "demonstrate organizational skills and ability to maintain appropriate and accurate academic records," indicated novice educators rated themselves as "proficient" (n=19; 42\%). Similarly, experienced educators rated themselves as "proficient" $(n=11 ; 46 \%)$.

Table 20

Proficiency Ratings to Use Assessment and Evaluation Strategies

\begin{tabular}{|c|c|c|c|c|}
\hline \multirow{2}{*}{ Proficiency Level } & \multicolumn{2}{|c|}{ Novice $(n=45)$} & \multicolumn{2}{|c|}{ Experienced $(n=2$} \\
\hline & $n$ & $\%$ & $n$ & $\%$ \\
\hline \multicolumn{5}{|c|}{ 7C1: Describe appropriate evaluation strategies to assess student learning } \\
\hline perience & 0 & 0.0 & 0 & 0.0 \\
\hline ceed Beginner & 5 & 11.0 & 2 & 8.0 \\
\hline etent & 17 & 38.0 & 8 & 33.0 \\
\hline ient & 13 & 29.0 & 6 & 25.0 \\
\hline
\end{tabular}


Table 20

Proficiency Ratings to Use Assessment and Evaluation Strategies (continued)

\begin{tabular}{|c|c|c|c|c|}
\hline \multirow{2}{*}{ Proficiency Level } & \multicolumn{2}{|c|}{ Novice $(n=45)$} & \multicolumn{2}{|c|}{ Experienced $(n=24)$} \\
\hline & $n$ & $\%$ & $n$ & $\%$ \\
\hline Expert & 10 & 22.0 & 8 & 33.0 \\
\hline \multicolumn{5}{|c|}{ 7C2: Apply evidence based assessment and evaluation practices within the academic arena } \\
\hline No Experience & 1 & 2.0 & 0 & 0.0 \\
\hline Advanced Beginner & 7 & 16.0 & 4 & 17.0 \\
\hline Competent & 16 & 36.0 & 4 & 17.0 \\
\hline Proficient & 13 & 29.0 & 9 & 38.0 \\
\hline Expert & 8 & 18.0 & 7 & 29.0 \\
\hline \multicolumn{5}{|c|}{ 7C3: Develop test blueprints that reflect course objectives } \\
\hline No Experience & 0 & 0.0 & 0 & 0.0 \\
\hline Advanced Beginner & 9 & 20.0 & 10 & 42.0 \\
\hline Competent & 16 & 36.0 & 3 & 13.0 \\
\hline Proficient & 15 & 33.0 & 7 & 29.0 \\
\hline Expert & 5 & 11.0 & 4 & 17.0 \\
\hline \multicolumn{5}{|c|}{ 7C4: Provide evidence of the ability to interpret test analysis } \\
\hline No Experience & 0 & 0.0 & 1 & 4.0 \\
\hline Advanced Beginner & 7 & 16.0 & 8 & 33.0 \\
\hline Competent & 21 & 47.0 & 7 & 29.0 \\
\hline Proficient & 14 & 31.0 & 5 & 21.0 \\
\hline Expert & 13 & 7.0 & 3 & 13.0 \\
\hline \multicolumn{5}{|c|}{ 7C5: Demonstrate organizational skills and ability to maintain accurate academic records } \\
\hline No Experience & 0 & 0.0 & 0 & 0.0 \\
\hline Advanced Beginner & 2 & 4.0 & 4 & 17.0 \\
\hline Competent & 12 & 27.0 & 4 & 17.0 \\
\hline Proficient & 19 & 42.0 & 11 & 46.0 \\
\hline Expert & 12 & 27.0 & 5 & 21.0 \\
\hline
\end{tabular}

\section{Perceived proficiency levels: Design curriculum and evaluate program outcomes.}

Section 7D was "Design Curriculum and Evaluate Program Outcomes." There were five subsections in this competency and Table 21 presents these data. Although there was a wide range of ratings in all areas of proficiencies, this competency was rated higher in the "no experience" level than most other competencies. Novice educators indicated they had "no experience" at a higher frequency and percentage in most subsections for this competency. 


\section{PERCEIVED COMPETENCIES OF NURSE EDUCATORS}

In the subsection of "develop nursing curricula that reflects the institutional philosophy and mission statement," novice educators rated themselves predominately as "advanced beginner" $(\mathrm{n}=12 ; 27 \%)$ and "competent" $(\mathrm{n}=12 ; 27 \%)$. Experienced educators rated themselves as "competent" $(\mathrm{n}=8 ; 33 \%)$. The "no experience" proficiency level indicated novice $(\mathrm{n}=7 ; 16 \%)$ and experienced $(\mathrm{n}=3 ; 13 \%)$ educators lacked knowledge and practice in this competency area.

The subsection of "develop nursing curricula in relation to the institutions conceptual framework," showed novice educators predominately rated themselves as "competent" (n=14; $31 \%)$. Likewise, experienced educators $(n=9 ; 38 \%)$ rated themselves as "competent." A small percentage of novice $(n=8 ; 18 \%)$ and experienced educators $(n=3 ; 13 \%)$ indicated "no experience" in this area. Novice educators rated themselves predominately as "competent" $(n=14 ; 31 \%)$ in the subsection of "demonstrate ability to write student competency statements and learning objectives." Experienced educators rated themselves as "competent" (n=10;42\%).

The subsection, "demonstrate ability to select appropriate clinical experiences in accordance with course outcomes and learner needs," showed novice educators rated themselves as "proficient" ( $\mathrm{n}=16 ; 36 \%)$. Experienced educators rated themselves predominately as "proficient" (n=10; 42\%).

The subsection, “develop course learning activities and lesson content consistent with learner needs," revealed novice educators rated themselves mostly as "proficient" (n=19; 42\%). Experienced educators rated themselves as "proficient" in this subsection $(n=9 ; 38 \%)$.

Table 21

Proficiency Ratings to Design Curriculum and Evaluate Program Outcomes

\begin{tabular}{cccccc}
\hline \multirow{2}{*}{ Proficiency Level } & \multicolumn{2}{c}{ Novice $(n=45)$} & \multicolumn{2}{c}{ Experienced $(n=24)$} \\
& & $n$ & $\%$ & $\mathrm{~N}$ & $\%$ \\
\cline { 2 - 5 } No experience & $7 D 1:$ Design curricula that reflects & institutional philosophy and mission \\
\hline & & 7 & 16.0 & 3 & 13.0 \\
\hline
\end{tabular}


Table 21

Proficiency Ratings to Design Curriculum and Evaluate Program Outcomes (continued)

\begin{tabular}{|c|c|c|c|c|}
\hline \multirow[b]{2}{*}{ Proficiency Level } & \multicolumn{2}{|c|}{ Novice $(n=45)$} & \multicolumn{2}{|c|}{ Experienced $(n=24)$} \\
\hline & $n$ & $\%$ & $n$ & $\%$ \\
\hline Advanced Beginner & 12 & 27.0 & 6 & 25.0 \\
\hline Competent & 12 & 27.0 & 8 & 33.0 \\
\hline Proficient & 11 & 24.0 & 5 & 21.0 \\
\hline Expert & 3 & 7.0 & 2 & 8.0 \\
\hline \multicolumn{5}{|c|}{ 7D2: Develop curricula in relation to the institution's conceptual framework } \\
\hline No Experience & 8 & 18.0 & 3 & 13.0 \\
\hline Advanced Beginner & 11 & 24.0 & 6 & 25.0 \\
\hline Competent & 14 & 31.0 & 9 & 38.0 \\
\hline Proficient & 9 & 20.0 & 4 & 17.0 \\
\hline Expert & 3 & 7.0 & 2 & 8.0 \\
\hline \multicolumn{5}{|c|}{ 7D3: Demonstrate ability to write student competency statements } \\
\hline No Experience & 4 & 9.0 & 2 & 8.0 \\
\hline Advanced Beginner & 9 & 20.0 & 3 & 13.0 \\
\hline Competent & 14 & 31.0 & 10 & 42.0 \\
\hline Proficient & 13 & 29.0 & 7 & 29.0 \\
\hline Expert & 5 & 11.0 & 2 & 8.0 \\
\hline \multicolumn{5}{|c|}{ 7D4: Demonstrate ability to select appropriate clinical experiences } \\
\hline No Experience & 3 & 7.0 & 0 & 0.0 \\
\hline Advanced Beginner & 6 & 13.0 & 3 & 13.0 \\
\hline Competent & 12 & 27.0 & 7 & 29.0 \\
\hline Proficient & 16 & 36.0 & 10 & 42.0 \\
\hline Expert & 8 & 18.0 & 4 & 17.0 \\
\hline \multicolumn{5}{|c|}{ 7D5: Develop course learning activities and lesson content consistent with learner needs } \\
\hline No Experience & 3 & 7.0 & 0 & 0.0 \\
\hline Advanced Beginner & 8 & 18.0 & 4 & 17.0 \\
\hline Competent & 10 & 22.0 & 7 & 29.0 \\
\hline Proficient & 19 & 42.0 & 9 & 38.0 \\
\hline Expert & 5 & 11.0 & 4 & 17.0 \\
\hline
\end{tabular}

Perceived proficiency levels: Function within the educational environment. Section $7 \mathrm{E}$ was

"Function within the Educational Environment." See the competency subsections in Table 22.

Novice educators $(n=20 ; 44 \%)$ rated themselves as "proficient" and experienced educators $(\mathrm{n}=13 ; 54 \%)$ rated themselves predominately as "expert," in the subsection of "demonstrate an understanding and respect for the values and beliefs of students and colleagues." 


\section{PERCEIVED COMPETENCIES OF NURSE EDUCATORS}

The subsection of "articulate professional goals consistent with the nursing program and parent institution's mission and philosophy statements," novice educators rated themselves predominately as "proficient" $(\mathrm{n}=23 ; 51 \%)$. Experienced nurse educators rated themselves as "proficient" (n=9; 38\%).

Within the subsection of "articulate an understanding of the educator role expectations in accordance with the academic setting," novice educators rated themselves predominately as "proficient" $(\mathrm{n}=23 ; 51 \%)$. Experienced educators also rated themselves as "proficient" $(\mathrm{n}=9$ $38 \%$ ). The subsection of "demonstrate knowledge of legal and ethical issues in relation to higher education," novice nurse educators predominately rated themselves as "proficient" (n=19; 42\%). Experienced educators rated themselves as "expert" $(\mathrm{n}=7 ; 29 \%)$.

Table 22

Proficiency Ratings to Function within the Educational Environment

$$
\text { Novice }(n=45) \quad \text { Experienced }(n=24)
$$

Proficiency Level

n $\%$

n $\%$

7E1: Demonstrate understanding and respect for the values and beliefs of students

$\begin{array}{lrrrr}\text { No Experience } & 1 & 2.0 & 0 & 0.0 \\ \text { Advanced Beginner } & 0 & 0.0 & 0 & 0.0 \\ \text { Competent } & 8 & 18.0 & 4 & 17.0 \\ \text { Proficient } & 20 & 44.0 & 7 & 29.0 \\ \text { Expert } & 16 & 36.0 & 13 & 54.0\end{array}$

7E2: Articulate professional goals consistent with the nursing program

\begin{tabular}{lcccc} 
No Experience & 1 & 2.0 & 0 & 0.0 \\
Advanced Beginner & 4 & 9.0 & 2 & 8.0 \\
Competent & 8 & 18.0 & 5 & 21.0 \\
Proficient & 23 & 51.0 & 9 & 38.0 \\
Expert & 9 & 20.0 & 8 & 33.0 \\
& 7E3: Articulate understanding of educator role expectations & \\
No Experience & 2 & 4.0 & 0 & 0.0 \\
Advanced Beginner & 3 & 7.0 & 4 & 17.0 \\
Competent & 9 & 20.0 & 4 & 17.0 \\
Proficient & 23 & 51.0 & 9 & 38.0 \\
\hline
\end{tabular}


Table 22

Proficiency Ratings to Function within the Educational Environment (continued)

\begin{tabular}{lcccc}
\hline \multicolumn{1}{c}{ Proficiency Level } & \multicolumn{2}{c}{ Novice $(n=45)$} & \multicolumn{2}{c}{ Experienced $(n=24)$} \\
Expert & $n$ & $\%$ & $n$ & $\%$ \\
\cline { 2 - 5 } & 7E4: Demonstrate & knowledge & of legal and ethical issues & \\
No Experience & 1 & 2.0 & 1 & 4.0 \\
Advanced Beginner & 5 & 11.0 & 4 & 17.0 \\
Competent & 13 & 29.0 & 6 & 25.0 \\
Proficient & 19 & 42.0 & 6 & 25.0 \\
Expert & 7 & 16.0 & 7 & 29.0 \\
\hline
\end{tabular}

Perceived proficiency levels: Leader and collaborator role. Section 7F asked the nurse educator to rate their proficiency level regarding their ability to exhibit "Leader and Collaborator Role Competencies." Table 23 presents the results regarding the frequencies and percentages of novice and experienced nurse educators for this competency. This section of the survey contained three subsections labeled 7F1-7F3.

Novice educators rated themselves predominantly as "proficient" ( $\mathrm{n}=23 ; 51 \%)$ within the subsection of “exhibit ability to convey ideas respectfully.” Experienced educators rated themselves mostly as "expert" ( $\mathrm{n}=10 ; 42 \%)$.

Within the subsection of "demonstrate overall clinical and professional leadership abilities," novice educators predominately rated themselves as "expert" $(n=20 ; 44 \%)$. Experienced educators rated themselves as "proficient" $(n=8 ; 33 \%)$ and "expert" $(n=12 ; 50 \%)$. The subsection of "demonstrate excellence in public speaking," novice nurse educators rated themselves predominately as "proficient" $(\mathrm{n}=21 ; 47 \%)$ and experienced educators rated themselves predominately as "proficient" $(\mathrm{n}=9 ; 38 \%)$. 
PERCEIVED COMPETENCIES OF NURSE EDUCATORS

Table 23

Proficiency Ratings to Demonstrate Leader and Collaborator Role Competencies

\begin{tabular}{|c|c|c|c|c|}
\hline \multirow{2}{*}{ Proficiency Level } & \multicolumn{2}{|c|}{ Novice $(n=45)$} & \multicolumn{2}{|c|}{ Experienced $(n=24)$} \\
\hline & $n$ & $\%$ & $n$ & $\%$ \\
\hline \multicolumn{5}{|c|}{ 7F1: $\overline{\text { Exhibit ability to convey ideas respectfully }}$} \\
\hline No experience & 0 & 0.0 & 0 & 0.0 \\
\hline Advanced Beginner & 1 & 2.0 & 2 & 8.0 \\
\hline Competent & 4 & 9.0 & 4 & 17.0 \\
\hline Proficient & 23 & 51.0 & 8 & 33.0 \\
\hline Expert & 17 & 38.0 & 10 & 42.0 \\
\hline \multicolumn{5}{|c|}{ 7F2: Demonstrate overall clinical and leadership abilities } \\
\hline No Experience & 0 & 0.0 & 0 & 0.0 \\
\hline Advanced Beginner & 1 & 2.0 & 0 & 0.0 \\
\hline Competent & 5 & 11.0 & 4 & 17.0 \\
\hline Proficient & 19 & 42.0 & 8 & 33.0 \\
\hline Expert & 20 & 44.0 & 12 & 50.0 \\
\hline \multicolumn{5}{|c|}{ 7F3: Demonstrate excellence in public speaking } \\
\hline No Experience & 2 & 4.0 & 0 & 0.0 \\
\hline Advanced Beginner & 2 & 4.0 & 3 & 13.0 \\
\hline Competent & 8 & 18.0 & 8 & 33.0 \\
\hline Proficient & 21 & 21.0 & 9 & 38.0 \\
\hline Expert & 12 & 12.0 & 4 & 17.0 \\
\hline
\end{tabular}

Perceived proficiency levels: Scholar role. Section $7 \mathrm{G}$ asked nurse educators to rate their level of proficiency in their ability to demonstrate "Scholar Role Competencies." Table 24 presents the perceived ratings of novice and experienced nurse educators for this competency which contained seven subsections labeled 7G1-7G7.

In the subsection, "describe knowledge of evidence based practice and clinical implementation strategies," novice educators rated themselves as "proficient" $(n=22 ; 49 \%)$. Experienced educators rated themselves predominately as "proficient" $(n=9 ; 38 \%)$. The subsection of "engage in scholarly activities within area of expertise," was rated predominately by novice educators as "proficient" $(\mathrm{n}=13 ; 29 \%)$. Experienced educators rated themselves as 


\section{PERCEIVED COMPETENCIES OF NURSE EDUCATORS}

“competent" ( $\mathrm{n}=8 ; 33 \%)$. The proficiency level of "no experience" was also selected by novice $(\mathrm{n}=5 ; 11 \%)$, and experienced $(\mathrm{n}=1 ; 4 \%)$ educators.

In the subsection of "exemplify skills as a researcher in nursing and health care," novice educators rated themselves predominantly as "advanced beginner" $(\mathrm{n}=13 ; 29 \%)$. This was also the highest level of proficiency for experienced educators $(n=10 ; 42 \%)$. This subsection accounted for a rating of "no experience" by novice faculty $(\mathrm{n}=7 ; 16 \%)$.

Within the subsection of "assist others to interpret and apply research into clinical practice," novice educators rated themselves predominately as "competent" $(n=15 ; 33 \%)$. Experienced educators rated themselves as "competent" $(\mathrm{n}=10 ; 42 \%)$. Novice educators rated themselves predominately as "competent" $(\mathrm{n}=14 ; 31 \%)$ within the subsection of "identify areas of need and opportunities to conduct nursing research." Experienced educators rated themselves predominately as "advanced beginner" $(n=8 ; 33 \%)$.

Novice educators rated themselves as "advanced beginner" ( $\mathrm{n}=14 ; 31 \%)$ within the subsection of "engage in scholarly writing activities." Novice educators indicated that they had "no experience" in this area $(n=9 ; 20 \%)$. Experienced educators rated themselves predominately as "advanced beginner" $(\mathrm{n}=9 ; 38 \%)$. Within the subsection of "proposal writing and program development," novice and experienced educators rated themselves with greater frequency as having "no experience."

Table 24

Proficiency Ratings to Demonstrate Scholar Role Competencies

\begin{tabular}{ccccc} 
& \multicolumn{2}{c}{ Novice $(n=45)$} & \multicolumn{2}{c}{ Experienced $(n=24)$} \\
Proficiency Level & $n$ & $\%$ & $n$ & $\%$ \\
\cline { 2 - 5 } 7G1: Describe knowledge of evidence based & practice & and & clinical implementation \\
nerience & 0 & 0.0 & 0 & 0.0 \\
need Beginner & 4 & 9.0 & 3 & 13.0 \\
\hline
\end{tabular}


Table 24

Proficiency Ratings to Demonstrate Scholar Role Competencies (continued)

\begin{tabular}{|c|c|c|c|c|}
\hline \multirow[t]{2}{*}{ Proficiency Level } & \multicolumn{2}{|c|}{ Novice $(n=45)$} & \multicolumn{2}{|c|}{ Experienced $(n=24)$} \\
\hline & $n$ & $\%$ & $n$ & $\%$ \\
\hline Competent & 9 & 20.0 & 8 & 33.0 \\
\hline Proficient & 22 & 49.0 & 9 & 38.0 \\
\hline Expert & 10 & 22.0 & 4 & 17.0 \\
\hline \multicolumn{5}{|c|}{ 7G2: Engage in scholarly activities within area of expertise } \\
\hline No Experience & 5 & 11.0 & 1 & 4.0 \\
\hline Advanced Beginner & 8 & 18.0 & 6 & 25.0 \\
\hline Competent & 10 & 22.0 & 8 & 33.0 \\
\hline Proficient & 13 & 29.0 & 5 & 21.0 \\
\hline Expert & 9 & 20.0 & 4 & 17.0 \\
\hline \multicolumn{5}{|c|}{ 7G3: Exemplify skills as a researcher in nursing and health care } \\
\hline No Experience & 7 & 16.0 & 3 & 13.0 \\
\hline Advanced Beginner & 13 & 29.0 & 10 & 42.0 \\
\hline Competent & 9 & 20.0 & 8 & 33.0 \\
\hline Proficient & 10 & 22.0 & 1 & 4.0 \\
\hline Expert & 6 & 13.0 & 2 & 8.0 \\
\hline \multicolumn{5}{|c|}{ 7G4: Assist others to interpret and apply research into clinical practice } \\
\hline No Experience & 4 & 9.0 & 3 & 13.0 \\
\hline Advanced Beginner & 10 & 22.0 & 5 & 21.0 \\
\hline Competent & 15 & 33.0 & 10 & 42.0 \\
\hline Proficient & 9 & 20.0 & 4 & 17.0 \\
\hline Expert & 7 & 16.0 & 2 & 8.0 \\
\hline \multicolumn{5}{|c|}{ 7G5: Identify areas of need and opportunities to conduct research } \\
\hline No Experience & 6 & 13.0 & 3 & 13.0 \\
\hline Advanced Beginner & 12 & 27.0 & 8 & 33.0 \\
\hline Competent & 14 & 31.0 & 7 & 29.0 \\
\hline Proficient & 7 & 16.0 & 3 & 13.0 \\
\hline Expert & 6 & 13.0 & 3 & 13.0 \\
\hline \multicolumn{5}{|c|}{ 7G6: Engage in scholarly writing activities } \\
\hline No Experience & 9 & 20.0 & 4 & 17.0 \\
\hline Advanced Beginner & 14 & 31.0 & 9 & 38.0 \\
\hline Competent & 8 & 18.0 & 8 & 33.0 \\
\hline Proficient & 11 & 24.0 & 1 & 4.0 \\
\hline Expert & 3 & 7.0 & 2 & 8.0 \\
\hline \multicolumn{5}{|c|}{ 7G7: Skilled in proposal writing and program development } \\
\hline No Experience & 14 & 31.0 & 9 & 38.0 \\
\hline Advanced Beginner & 13 & 29.0 & 7 & 29.0 \\
\hline Competent & 8 & 18.0 & 6 & 25.0 \\
\hline Proficient & 8 & 18.0 & 1 & 4.0 \\
\hline Expert & 2 & 4.0 & 1 & 4.0 \\
\hline
\end{tabular}




\section{PERCEIVED COMPETENCIES OF NURSE EDUCATORS}

\section{Research Question Four}

Research question four was: Do nurse educators with a graduate degree focus in advanced practice differ from nurse educators with a nursing education degree focus in their perceived competencies to (a) facilitate learning, (b) facilitate learner development and socialization, (c) use assessment and evaluation strategies, (d) design curriculum and evaluate program outcomes, (e) function within the educational environment, (f) exhibit leader and collaborator role competencies, and (g) demonstrate scholar role competencies?

Competency differences: Degree types. To answer this research question, $t$-Tests were computed to determine if there were statistically significant (at least $p<.05$ ) differences in perceived competencies between nurse educators that held a Master of Science degree with a nursing education focus and nurse educators with a Master of Science degree and an advanced practice focus. Thus, the independent variable was the type of degree focus (nursing education versus advanced practice). The dependent variables were the nurse educator competencies which included nursing practice, facilitate learning, facilitate learner development and socialization, use assessment and evaluation strategies, design curriculum and evaluate program outcomes, function within the educational environment, exhibit leader and collaborator competencies, and demonstrate scholar role competencies.

The dependent variable for Section 6 of the survey was "nurse practice competency." The possible range of scores for items (6.1 through 6.12) is (0 through 48). The mean score for the Master of Science degree with a nursing education focus (MSN Ed.), was 42.3 (SD=4.6), and the mean score for the Master of Science Degree with an advanced practice focus (MSN AP), was $42.0(\mathrm{SD}=3.5)$. The nurse practice competency independent sample $t$-Test yielded a $t(41)=$ $0.17, p=0.86, p>.05$ (not statistically significant). Table 25 illustrates these data. 


\section{PERCEIVED COMPETENCIES OF NURSE EDUCATORS}

The dependent variable for Section 7A of the survey was the competency of "facilitate learning." The possible range of scores for items (7A1 thorough 7A6) was (0 through 24). The mean score for the MSN Ed. was 16.9 ( $\mathrm{SD}=4.6)$, and the mean for the MSN AP group was 16.2 (SD=3.9). The facilitate student learning $t$-Test yielded $t(41)=0.48, p=0.63, p>.05$ (not statistically significant). See Table 25 for these data.

The dependent variable for Section 7B of the survey was "facilitate learner development and socialization." The range of scores for items (7B1 through 7B6) was (0 through 24). The mean score for the MSN Ed. was $17.3(\mathrm{SD}=4.5)$ and the mean score for the MSN AP was 16.7 $(\mathrm{SD}=3.5)$. This was very similar once again, thus both groups have similar competency levels in their ability to facilitate student learning and socialization of students. The facilitate student learning development and socialization independent sample $t$-Test yielded $t(41)=0.50, p=0.61$, $\mathrm{p}>.05$ (not statistically significant), as shown in Table 25 .

The dependent variable for Section 7C of the survey was "use assessment and evaluation strategies." The range of scores for items (7C1 through 7C5) was (0 thorough 20$)$. The mean score for the MSN Ed. was $12.3(\mathrm{SD}=4.0)$ and the mean for the MSN AP was $13.0(\mathrm{SD}=3.8)$. The ability of the nurse educator to use assessment and evaluation strategies $t$-Test yielded $t(41)$ $=0.57, p=0.57, p>.05$ (not statistically significant). See Table 25 .

The dependent variable for Section 7D of the survey was "design curriculum and evaluate program outcomes." The range of scores for item (7D1 through 7D5) was (0 through 20). The mean score for the MSN Ed. was $10.1(\mathrm{SD}=5.5)$ and the mean score for the MSN AP was $10.4(\mathrm{SD}=3.0)$. The ability for the nurse educator to design curriculum and evaluate program outcomes independent samples $t$-Test yielded $t(41)=0.27, p=0.78, p>.05$ (not significant). 


\section{PERCEIVED COMPETENCIES OF NURSE EDUCATORS}

Section 7E's dependent variable was "function within the educational environment." The range of scores for items (7E1 through 7E4) was (0 through 16). The mean score for the MSN Ed. was $11.0(\mathrm{SD} 3.5)$ and the mean for the MSN AP was $11.8(\mathrm{SD}=2.8)$. The ability for the nurse educator to function within the educational environment $t$-Test yielded $t(41)=0.75, p=$ 0.45, $p>.05$ (two-tailed) (not statistically significant). See Table 26.

In Section 7F the dependent variable was "leader and collaborator competency." The range of scores for items (7E1 through 7E3) was (0 through 12). The mean for the MSN Ed. was $9.1(\mathrm{SD}=2.1)$ and the mean for the MSN AP was $9.3(\mathrm{SD}=2.1)$. The independent samples $t$-Test yielded $t(41)=0.40, p=0.68, p>.05$ (not statistically significant). Table 25 illustrates this.

The dependent variable for Section 7G of the survey was "scholar role competency." The range of scores for items (7G1 through 7G7) was (0 through 28). The mean for the MSN Ed. group was $13.8(\mathrm{SD}=7.8)$ and the MSN AP group was $13.8(\mathrm{SD}=6.5)$. The ability of the nurse educator to demonstrate scholar role abilities $t$-Test yielded $t(41)=0.00, p=0.99, p>.05$ (not statistically significant). See Table 25.

Table 25

Differences in Nurse Educator Competencies by Degree Type

\begin{tabular}{|c|c|c|c|c|}
\hline Competency Category & $\begin{array}{c}\frac{\mathrm{MSN} E d}{n=30} \\
\mathrm{M}(\mathrm{SD})\end{array}$ & $\begin{array}{c}\text { MSN AP } \\
n=13 \\
\text { M(SD) }\end{array}$ & $t(\mathrm{df})$ & $p$ \\
\hline Nurse Practice Competencies & $42.3(4.63)$ & $42.07(3.52)$ & $(41)=0.17$ & $0.86>.05 \mathrm{NS}$ \\
\hline Facilitate Learning & $16.9(4.55)$ & $16.2(3.94)$ & $(41)=0.48$ & $0.63>.05 \mathrm{NS}$ \\
\hline $\begin{array}{l}\text { Facilitate Learner Development and } \\
\text { Socialization }\end{array}$ & $17.3(4.5)$ & 16.7(3.49) & $(41)=0.50$ & $0.61>.05 \mathrm{NS}$ \\
\hline Use Assessment and Evaluation & $12.3(4.02)$ & $13.0(3.83)$ & $(41)=0.57$ & $0.57>.05 \mathrm{NS}$ \\
\hline $\begin{array}{l}\text { Design Curriculum and Evaluate Program } \\
\text { Outcomes }\end{array}$ & $10.1(5.52)$ & $10.4(3.04)$ & $(41)=0.27$ & $0.78>.05 \mathrm{NS}$ \\
\hline Function within Educational Environment & $11.0(3.53)$ & $11.8(2.83)$ & $(41)=0.75$ & $0.45>.05 \mathrm{NS}$ \\
\hline Leader and Collaborator Competency & $9.1(2.15)$ & $9.3(2.10)$ & $(41)=0.40$ & $0.68>.05 \mathrm{NS}$ \\
\hline Scholar Role Competency & $13.8(7.82)$ & $13.8(6.45)$ & $(41)=0.00$ & $0.99>.05 \mathrm{NS}$ \\
\hline
\end{tabular}




\section{PERCEIVED COMPETENCIES OF NURSE EDUCATORS}

Mentoring. The study's survey also asked newly hired faculty if there was a mentoring program in place for new faculty within their nursing department. Table 26 illustrates these data. Although this information did not specifically apply to a research question, the information was important to consider when entering into a new faculty position. Research has shown that transition into academia is difficult for new nurse faculty members who have recently completed their master's education and possess limited teaching experience. Mentoring has proved to make this transition easier (Anderson, 2008; McDonald, 2004; Sienty, 1988; Young, 1999).

Overall, approximately half of all participants indicated they had a mentoring program in their department $(n=39 ; 56.5 \%)$. Specifically, novice educators reported that there was a mentoring program in their nursing department $(n=29 ; 64.4 \%)$. Novice educators also revealed there was not a mentoring program within their respective nursing departments $(n=16 ; 35.5 \%)$.

Several experienced faculty revealed there was not a mentoring program in their nursing department $(n=14 ; 58.3 \%)$. Less than half of experienced faculty indicated they participated in a mentoring program $(\mathrm{n}=10 ; 41.7 \%)$.

Table 26

Mentoring Program Participation

\begin{tabular}{lcccccc}
\hline \multirow{2}{*}{ Participation } & \multicolumn{2}{c}{ Novice $(n=45)$} & \multicolumn{2}{c}{ Experienced $(n=24)$} & \multicolumn{2}{c}{ Total $(\mathrm{N}=39)$} \\
\cline { 2 - 7 } & $n$ & $\%$ & $n$ & $\%$ & $\mathrm{~N}$ & $\%$ \\
\hline Yes & 29 & 64.4 & 10 & 41.7 & 39 & 56.5 \\
No & 16 & 35.5 & 14 & 58.3 & 30 & 43.5 \\
\hline
\end{tabular}

Faculty members that were involved in mentoring programs also identified the type of program within their respective departments. Table 27 presents the results which pertain only to those educators who indicated that they were participating in a mentoring program. Most of the novice faculty $(\mathrm{n}=11 ; 38 \%)$ had formal mentoring. Other novice faculty had informal mentoring 


\section{PERCEIVED COMPETENCIES OF NURSE EDUCATORS}

$(n=18 ; 62 \%)$.The experienced faculty indicated most of their mentoring took place on an informal basis $(n=6 ; 60 \%)$. Other experienced educators indicated they participated in a formal $\operatorname{program}(n=4 ; 40 \%)$.

Table 27

Mentoring Program Type

\begin{tabular}{lcccccc}
\hline \multirow{2}{*}{ Mentoring Program Type } & \multicolumn{2}{c}{ Novice $(n=29)$} & \multicolumn{2}{c}{ Experienced $(n=10)$} & \multicolumn{2}{c}{ Total $(\mathrm{N}=39)$} \\
\cline { 2 - 6 } & $n$ & $\%$ & $n$ & $\%$ & $\mathrm{~N}$ & $\%$ \\
\hline Formal & 11 & 38.0 & 4 & 40.0 & 15 & 38.5 \\
Informal & 18 & 62.0 & 6 & 60.0 & 24 & 61.5 \\
\hline
\end{tabular}

Participants were also asked to identify the format of their mentoring program. Table 29 presents these results of only those that responded that they participated in a mentoring program. Novice participants indicated that mentoring was conducted face to face $(n=22,76 \%)$, as well as a combination of online and face-to-face $(n=7 ; 24 \%)$. Experienced faculty had mentoring conducted face to face $(\mathrm{n}=8 ; 80 \%)$. Mentoring programs were not administered entirely online.

Table 28

Mentoring Program Delivery

\begin{tabular}{lrrrrrr}
\hline \multirow{2}{*}{ Delivery Format } & \multicolumn{2}{c}{ Novice $(n=29)$} & \multicolumn{2}{c}{ Experienced $(n=10)$} & \multicolumn{2}{c}{ Total $(\mathrm{N}=39)$} \\
\cline { 2 - 7 } & \multicolumn{1}{c}{$\%$} & $\%$ & $n$ & $\%$ & $\mathrm{~N}$ & $\%$ \\
\hline Online & 0 & 0.0 & 0 & 0.0 & 0 & 0.0 \\
Face-to-Face & 22 & 75.9 & 8 & 80.0 & 30 & 76.9 \\
Combination & 7 & & 2 & 20.0 & 9 & 23.1 \\
\hline
\end{tabular}

Faculty members who participated in a mentoring program were also asked if they had a mentor assigned to them throughout the academic year. Table 29 presents information only of those participants that were involved in mentoring programs. Novice faculty indicated a mentor was assigned to them $(n=26 ; 90 \%)$. Few faculty reported not having a mentor $(n=3 ; 10 \%)$. More 


\section{PERCEIVED COMPETENCIES OF NURSE EDUCATORS}

than half of the experienced faculty reported that they had a mentor assigned $(n=7 ; 70 \%)$. There were a few experienced faculty members who did not have an assigned mentor $(n=3 ; 30 \%)$.

Table 29

Nursing Faculty Mentors

\begin{tabular}{lcccccc}
\hline \multirow{2}{*}{ Assigned Mentor } & \multicolumn{2}{c}{ Novice $(n=29)$} & \multicolumn{2}{c}{ Experienced $(n=10)$} & \multicolumn{2}{c}{ Total $(\mathrm{N}=39)$} \\
\cline { 2 - 7 } & $n$ & $\%$ & $n$ & $\%$ & $\mathrm{~N}$ & $\%$ \\
\hline Yes & 26 & 90.0 & 7 & 70.0 & 33 & 84.6 \\
No & 3 & 10.0 & 3 & 30.0 & 6 & 15.4 \\
\hline
\end{tabular}

The final question regarding mentoring asked new faculty if the competencies for nurse educators had been addressed within their mentoring experience. The results are provided in Table 30. Most novice faculty indicated that the competencies were not addressed in their mentoring $(n=10 ; 34 \%)$. Novice faculty also reported that the competencies were only "somewhat" addressed $(\mathrm{n}=7 ; 24 \%)$. Some faculty did indicate the competencies were covered within their mentoring experience $(\mathrm{n}=5 ; 17 \%)$.

Several of experienced faculty reported that the competencies were only "somewhat" covered within their mentoring experience $(n=7 ; 70 \%)$. The smallest percentage reported that competencies were addressed $(n=1 ; 10 \%)$ as well as were not addressed $(n=1 ; 10 \%)$.

Table 30

Core Competencies Addressed through Mentoring Programs

\begin{tabular}{|c|c|c|c|c|c|c|}
\hline \multirow{2}{*}{ Response } & \multicolumn{2}{|c|}{ Novice $(n=29)$} & \multicolumn{2}{|c|}{ Experienced $(n=10)$} & \multicolumn{2}{|c|}{ Total $(\mathrm{N}=39)$} \\
\hline & $n$ & $\%$ & $n$ & $\%$ & $\mathrm{~N}$ & $\%$ \\
\hline Yes & 5 & 17.3 & 1 & 10.0 & 6 & 15.4 \\
\hline No & 10 & 34.5 & 1 & 10.0 & 11 & 28.2 \\
\hline Somewhat & 7 & 24.1 & 7 & 70.0 & 14 & 35.9 \\
\hline No Reply & 7 & 24.1 & 1 & 10.0 & 8 & 20.5 \\
\hline
\end{tabular}




\section{PERCEIVED COMPETENCIES OF NURSE EDUCATORS}

Additional comments. The participants were asked to provide any additional comments regarding their mentoring experience. Not all participants $(n=16)$ provided comments as this question was optional. The results were widely varied. For example, a novice participant stated that the mentoring experience was a "poor" and another stated it was "fabulous," Participants also commented on specific aspects of their mentoring experience which reflected the requirements of their position and institution. Others indicated areas of mentoring that were lacking such as "scholarship" or were not addressed.

Comments: novice educator. The following bulleted items summarize comments that were submitted by novice educators:

- Excellent.

- There is a program; however, the access to information and support are lacking. In order to receive answers, I have often had to search out my own answers. Also, I am not usually told about responsibilities or tasks needed to be done until a couple of days before they have to be done or after they are due. I don't feel much support.

- Once a month all new faculty for this year at the university meet with our tenured faculty members.

- I have been assigned a mentor who is fabulous. She is always available for questions, provides thoughtful feedback but does not micromanage every detail. She allows me to learn on my own with guidance. I feel I could ask her or any staff member questions and assistance would be volunteered with kindness. I feel very fortunate.

- New Faculty Learning community 1-year long program that meets 2 hours every other week.

- I have felt the program worked well. 
- My mentor is also the faculty that I share the course with.

- I really like it; having a mentor helps transition you into the culture of academia.

- I have been assigned a mentor. She informs me of things she thinks I may not know and I can ask questions that come up.

- The mentoring program has been very beneficial to me during this past academic year. I have one specific faculty member who is my mentor, along with others who have assisted me as needed. I would have felt very lost otherwise.

Comments: Experienced educator. The following comments were submitted by experienced educators that participated in the study.

- Dean assigned; no structure. Self and mentor initiated.

- It has been extremely valuable.

- I was able to choose my mentor rather than have one assigned to me.

- I have enjoyed mentoring from the entire staff. Everyone has been open with me and freely has given me direction, answered questions and provided support.

- The faculty member assigned to me is a senior faculty with over 15 years of experience. She has been a great resource.

\section{Summary}

New faculty members in this sample were mostly hired into full-time non-tenure track positions. Their academic rank was instructor or assistant professor. The majority of faculty had clinical and classroom responsibilities. Participants taught in various types of settings and programs.

The two most common types of education for new educators were the Master of Science in Nursing with a teaching focus and a Master's of Science in Nursing with an advanced practice 


\section{PERCEIVED COMPETENCIES OF NURSE EDUCATORS}

focus. Most educators had greater than 5 years of acute care practice experience as well as specialty practice experience.

There was no statistically significant difference in perceived competency levels between novice and experienced educators. Likewise, there was no statistically significant difference in perceived competency levels between the educators that held a Master's degree with a nursing education and those with a Master's degree and an advanced practice focus.

The self-ratings for each of the competency areas for novice and experienced educators revealed that most faculty members (novice and experienced) were "competent" or higher in most areas. The competencies in which novice and experienced faculty did rate a level of proficiency of "no experience" or "advanced beginner" were minimal. These most common competencies reported by faculty as having little knowledge and experience included: facilitate student learning, use assessment and evaluation strategies, design curriculum and evaluate program outcomes and demonstrate scholar role competencies.

Almost all of the participants were assigned a mentor. Mentoring experiences were positive for most new faculty and were conducted face to face. However, the core competencies for nurse educators were not consistently addressed with new faculty.

Chapter five will provide further discussion regarding the results of the study. An examination of faculty deficiencies in the competency areas will be highlighted. Limitations of the study and recommendations for practice and further research in the nursing education profession will be offered. 


\section{Chapter Five}

\section{Summary, Conclusions, and Recommendations}

The intent of this chapter is to summarize this study, provide conclusions from the study, and to make recommendations for practice and further research. This summary will be presented according to the study's four research questions. In addition, an in-depth examination of novice and experienced faculty self-rated deficiencies within the competency areas will be provided. As a result of this analysis, recommendations for nursing education practice will be highlighted. Suggestions of content to include in nurse faculty mentoring programs will be emphasized based on the results of the study, perspectives from the researcher's experience in nursing education, and citing from the literature. Finally, the limitations of the study and the recommendations for future research will be offered.

\section{Summary of the Study}

The purpose of the study was to identify the perceived competencies and qualifications of newly hired nurse faculty who teach in pre-licensure registered nurse programs. The population included newly hired nurse faculty $(\mathrm{N}=69)$ located in six states in the northeastern part of the United States. These states included Pennsylvania, Ohio, West Virginia, Maryland, Virginia, and Kentucky. Demographic data, qualifications, and competencies identified in this study were comprised of those nurse educators with and without previous teaching experience. An on-line survey questionnaire was used to determine the perceived qualifications and competencies of newly hired nurse educators. 


\section{PERCEIVED COMPETENCIES OF NURSE EDUCATORS}

The research questions were:

1. What is the demographic profile (gender, academic position, rank, teaching experience, teaching responsibilities, type of academic setting) of newly hired nurse educators who teach in pre-licensure registered nurse programs?

2. What qualifications (education, clinical practice, collaborator and leadership, and scholar) do newly hired nurse educators possess who teach in pre-licensure registered nurse programs?

3. How do newly hired nurse educators rate themselves on their knowledge and skills to fulfill nurse educator competencies (facilitate learning, facilitate learner development and socialization, use assessment and evaluation strategies, design curriculum and evaluate program outcomes, function within the educational environment, exhibit leader and collaborator role competencies and demonstrate scholar role competencies)?

4. Do nurse educators with a graduate degree focus in advanced practice differ from nurse educators with a nursing education degree focus in their perceived competencies to (a) facilitate learning, (b) facilitate learner development and socialization, (c) use assessment and evaluation strategies, (d) design curriculum and evaluate program outcomes, (e) function within the educational environment, (f) exhibit leader and collaborator role competencies, and (g) demonstrate scholar role competencies?

The analysis indicated there were no statistically significant differences in the perceived competency levels of novice and experienced nurse educators. Although novice and experienced educators commonly reported a proficiency level of "competent" in most competencies areas, such was not the case in all areas. Although minimal deficiencies were noted, (ratings of "no experience" and "advanced beginner"), the areas most deficient for nurse faculty were within the 


\section{PERCEIVED COMPETENCIES OF NURSE EDUCATORS}

scholar role competency, the use of assessment and evaluation strategies, and in the ability to design curriculum and evaluate program outcomes. Following this, faculty members reported deficiencies in their ability to facilitate learning, facilitate learner development and socialization, and to demonstrate leader and collaborator competencies.

Other findings suggested that the most common type of academic background held by the novice educator $(n=20 ; 44.4 \%)$ and experienced educator $(n=10 ; 41.7 \%)$ in this sample was the Master of Science in Nursing degree with a nursing education focus. Additional degrees held common to nurse educators were the Master of Science in Nursing, Master of Science (nonnursing), and Master of Science in Nursing with an advanced practice focus. Further analysis did not indicate any differences in perceived competencies between nurse educators holding a Master of Science in Nursing (advanced practice focus) and a Master's of Science in Nursing (education focus) in this sample.

\section{Research Question One}

Demographics. The nurse educator respondents in this study was dominated by the female gender $(n=65 ; 94.2 \%)$ as opposed to males $(n=4 ; 5.8 \%)$. The gender makeup of this study was consistent with the NLN (2009) and Suplee and Gardner (2009) studies which showed a concern for the predominance of females in the nurse educator population. The National League for Nursing (2009) recognizes that homogeneity exists among nursing faculty, which may pose challenges that limit the profession's ability to provide diverse heath care education.

Current academic rank. The majority of novice and experienced nurse educators in this study entered into a full-time non-tenure track position $(n=49 ; 71 \%)$. Because this study included nurse faculty members that were newly hired into several types of academic institutions, it is possible that tenure track positions were not offered in some or all of these nursing programs. 


\section{PERCEIVED COMPETENCIES OF NURSE EDUCATORS}

The combined percentage of tenure track positions held by nurse faculty members $(n=15)$ was $21.7 \%$. The aim of this study was not to indentify whether or not the type of academic position would influence increased recruitment into nursing education; however, it is reasonable to assume that tenure track positions may likely attract more qualified applicants that are needed during a time of faculty shortage.

The most common current academic rank held by nurse faculty was instructor $(n=34$; $49.3 \%)$ and assistant professor $(n=30 ; 43.5 \%)$. Some of the faculty members with previous teaching experience entered into higher-ranking positions. However, because the study's focus was on newly hired faculty, the predominance of appointments as "instructor" and "assistant professor" would be expected.

Teaching experience. This study intended to examine the qualifications and competencies of newly hired nurse faculty. Findings also revealed that some newly appointed faculty members hired for the 2009-2010 academic year had previous teaching experience. The number of years of prior teaching experience ranged from two to greater than ten years. The study's findings contributed to nursing research and practice by allowing an examination of the perceived competences of both novice and experienced faculty.

Teaching responsibilities. Most of the educators were assigned clinical as well as classroom responsibilities $(n=60 ; 87 \%)$. This fact supports much of the literature in that new faculty members are initially given complex workloads which are often difficult for them to successfully balance ( Blauvelt \& Spath, 2008; Hessler \& Ritchie, 2006; Sienty, 1988). Novice and experienced educators equally had assignments in both areas, indicating that novice faculty did not have a workload assignment in just one area simply because they were new to teaching and had no prior teaching experience. These results were consistent with reports in the literature 
which indicated that new faculty members often become overwhelmed with multiple tasks with which they must become accustomed to during their first year of teaching (Blauvelt \& Spath, 2008; Hessler \& Ritchie, 2006; McDonald, 2004; NLN, 2006; Siler \& Kleiner, 2001).

Academic setting. The type of academic setting in which nurse faculty members were hired was distributed among all four types of settings. These were the hospital $(n=13 ; 18.8 \%)$, community college $(n=27 ; 39.1 \%)$, liberal arts $(n=17 ; 4.6 \%)$, and research universities $(n=12$; $17.4 \%$ ). Because of the variety of settings, not all faculty members may have been required to possess knowledge in some of the competency areas, particularly research and scholarly activities. This is consistent with Poindexter's (2008) finding that the competencies desired by deans and administrators were different according to the type of academic setting. However, this should not have influenced the self-perceptions of the participant's competency levels.

\section{Research Question Two}

Academic preparation. The type of academic degree most commonly held by novice and experienced nurse educators in this sample was the Master of Science in Nursing with an education focus $(n=30 ; 43.5 \%)$. This indicated that nursing faculty who were interested in a career in teaching pursued an educational focus in their graduate studies. This finding is inconsistent with past trends regarding the academic degree chosen by nurse educators. Many nurse educators have chosen to obtain a Master's degree with an advanced practice focus for greater career flexibility in teaching and practice, as well as for opportunities for increased income (Anderson, 2008, Chaska, 2001). Others have chosen this pathway because they were encouraged by professors in graduate education to pursue an advanced practice focus to meet the current evolving needs of a changing health care delivery system (Chaska, 2001; Neese, 2003). Moreover, there had been a decline in the number of graduate schools that emphasized an 


\section{PERCEIVED COMPETENCIES OF NURSE EDUCATORS}

education track (NLN, 2002). The NLN (2002) acknowledged this trend and actively encouraged graduate schools to redirect the focus of their programs toward preparing individuals for a specialized role of teaching nursing students in academic settings.

The fact that a Master's degree with an education focus was the most commonly held degree may also be the result of the NLN's (2002) call to promote talented registered nurses toward a career in nursing education. It also reflects the NLN's Position statement (2002) regarding the type of preparation best suited for meeting the challenges associated with implementing the role successfully (Neese; 2003; NLN, 2002; Sienty; 1988).

The findings of this study were consistent with Poindexter's (2008) findings in that sixtyfive percent of deans and administrators from community colleges preferred a Master of Science with a nursing education focus for tenure earning positions and sixty-nine percent for non-tenure positions. Liberal arts college deans preferred a Master of Science in Nursing with a nursing education focus forty-five percent of the time. Deans from research institutions preferred a doctoral degree. Overall, the results of this study produced encouraging information for the nursing education profession as it revealed that many new nursing faculty in this sample participated in graduate programs designed to prepare individuals for the teaching role.

The other common degree types held by educators in this study were the Master of Science in Nursing $(n=22 ; 31.9 \%)$ and the Master of Science in Nursing with an advanced practice focus $(\mathrm{n}=13 ; 18.8 \%)$. The Master's degree with an advanced practice focus has sometimes been recognized as insufficient preparation for the educator role (NLN, 2002; Zungolo, 2004). However, educators with an advanced practice specialization have been recognized for their value to nursing education programs particularly because of their broad scope of knowledge in the clinical setting (NLN, 2002; Young, 1999). The results of this study 


\section{PERCEIVED COMPETENCIES OF NURSE EDUCATORS}

found that the knowledge of educators with this degree focus may well be greater than is acknowledged. This is explained by the lack of difference in perceived competency levels between educators with a teaching specialization and those with an advanced practice specialization. Notwithstanding this fact, the debate will likely continue regarding the most suitable academic path appropriate for the preparation of the nurse educator. This study offered additional insight into this debate.

Acute care and specialty practice qualifications. Most of the participants had at least five years of clinical, acute care, or specialty practice experience $(n=52 ; 88 \%)$. Many of the participants were still working as registered $(n=25 ; 36.2 \%)$ or advanced practice nurses $(n=11$; $16 \%$ ) while maintaining a nurse educator position. In addition, over half of the participants had a background as a nursing supervisor or manager $(n=45 ; 65.2 \%)$. According to Poindexter (2008), having clinical experience was an important factor to consider when recruiting new faculty. In Poindexter's study, deans and administrators from liberal arts institutions required more experience (two to five years) in acute and specialty care from potential new faculty. Community colleges' deans and administrators had high expectations regarding previous clinical experience as well. Moreover, Poindexter (2008) found that regardless of the type of institution, the majority of deans and administrators did not require management or supervisory experience for a teaching position.

The clinical practice experience of the participants in this study may have contributed positively to the participants' ability to function within the educational environment. Participants mostly indicated that they were "competent" in this area. This finding, however, was inconsistent with Anderson's (2008) study which found that clinical experience did not help the educator adjust to the teaching role. The participants in that study felt that teaching in an academic setting 


\section{PERCEIVED COMPETENCIES OF NURSE EDUCATORS}

was completely different than practicing as a nurse. Likewise, Sienty (1988) found that newly hired educators experienced role strain despite having clinical practice experience. This was attributed to their overall adjustment into a faculty role. Siler and Kleiner (2001) also found the same in their study. Clinically experienced nurse educators reported that the academic environment was completely different than what was anticipated, and one participant stated that the notion that "anyone can teach," (p.399) was far from the truth.

In contrast, Young (1999) found that many of the participants in her study relied on their clinical practice experience to manage and solve problems in the academic environment. Young compared their experiences to the framework of Benner (1987) in that to solve problems participants pooled together their experiences as nurses to help them deal appropriately with student issues.

The findings in this study align with Young's (1999) research. In that study, the majority of faculty members reported high levels of proficiency in most competency areas. It could be speculated that their wide array of clinical experience helped them to better understand the educator's role.

Leader and collaborator qualifications. Experienced nurse educators indicated with greater frequency than did novice educators that they were accomplished in aspects of nursing leadership, public speaking, as well as their ability to convey ideas for the benefit of the profession. The majority of nurse educators $(n=60 ; 87 \%)$ maintained an active membership in a professional organization. Over half of the novice and experienced educators $(n=48 ; 69 \%)$ perceived that they were able to actively apply knowledge of social, economic and political forces to influence nursing practice and health care. Poindexter (2008) also found that these 


\section{PERCEIVED COMPETENCIES OF NURSE EDUCATORS}

qualifications were preferred by deans and administers in order to be considered for a nursing faculty position.

Scholar qualifications. The aspect of scholarly qualifications that was noted most frequently by novice and experienced educators as deficiencies in this study was their ability to translate research into practice $(n=40 ; 58 \%)$. Few faculty indicated that they were able to conduct research related to nursing and health care $(n=15 ; 22 \%)$. Very few faculty members indicated that they had maintained a funded area of research or had published or presented research $(n=4$; $6 \%$ ). This could be explained by the fact that most novice faculty members were hired into community colleges that typically do not emphasize or reward scholarly activities. Poindexter's (2008) research supports this rationale.

\section{Research Question Three}

Novice versus experienced educators self-rating of competencies. There were no statistically significant differences in mean scores for nurse educators with and without teaching experience regarding self-rating of each of the competency areas ( $p=.42-.97$, two-tailed). One possible explanation for this result could be related to the new generation of faculty. Although age was not a demographic variable in this study, the fact remains that upcoming faculty may likely be more technologically savvy, independent, and driven to succeed (Hessler \& Ritchie, 2006). Therefore, they may perceive themselves to be quite knowledgeable in each of the competency areas

Another possible factor contributing to the high self-ratings in the competency areas for novice educators was their preparation for the role. Forty-two percent of the educators were prepared with a Master's Degree and a nursing education focus. This finding is consistent with Neese (2003), who indicated that possessing this type of degree enhanced the knowledge 
required to fulfill the educator role. Similarly, the findings of this study were aligned with those viewpoints established by the NLN (2002). This organization recognized the Master of Science degree with a nursing education focus as the most valuable degree to successfully execute the role of the educator.

Lastly, because the survey was completed during the eighth month of the academic year, it is possible that newly hired faculty members became more confident as they gained experience in their role. This time frame could have provided for additional growth and development in the role, and may have contributed to higher self-ratings of proficiency in the competency areas. Siler and Kleiner (2001) indicated that new faculty members developed an increased understanding of their responsibilities as the academic year progressed.

Although the self-ratings were generally high in level of proficiencies, there were areas in which the novice and experienced educator predominately indicated a proficiency level of "no experience" or "advanced beginner." These areas were the competencies of demonstrating scholarly role activities, designing curriculum and evaluating program outcomes, and using assessment and evaluation strategies.

Deficiencies reported by novice and experienced educators. For the novice educator, deficiencies were reported in various subsections of almost all of the competency areas. It is important to note, however, that within the majority of the competency areas and their respective subsections, the novice educator predominately rated themselves at a proficiency level of "competent" or higher. Halstead (2007) noted that it is possible that novice nurse educators can be competent in many areas. However, it is essential for nurse educators to continue their development with the objective of eventually becoming an expert in the field. 


\section{PERCEIVED COMPETENCIES OF NURSE EDUCATORS}

Even experienced educators indicated deficiencies within certain competency areas and their respective subsections. As compared to the novice educators, the competency areas rated as "no experience" or "advanced beginner" were very similar to novice educators; e.g., scholarly role, design curriculum and evaluate program outcomes, and use of assessment and evaluation strategies. Most often, however, there were fewer deficiencies reported by the experienced educator as compared to the novice educator.

Overall, only a small percentage range (0-25\%) of novice and experienced faculty indicated that they either had "no experience" or were "advanced beginners" in the competencies and their subsections. The rank ordering of reported deficiencies for both groups included: demonstrate scholar role competencies, design curriculum and evaluate program outcomes, use assessment and evaluation strategies, facilitate learning, function within the education environment, facilitate learner development and socialization, and exhibit leader and collaborator role competencies. The results of this study were consistent with Poindexter's (2008) study for the rank ordering of preferred competencies by deans and administrators. The rank ordering of preferred competencies by dean and administrators when hiring new faculty for all institution types was: exhibit leader and collaborator role competencies, facilitate learner development and socialization, facilitate learning, and function within the education environment, use assessment and evaluation strategies, design curriculum and evaluate program outcomes, and demonstrate scholar role competency. This shows that faculty members did perceive that they possessed the qualities preferred by deans and administrators as revealed through Poindexter's (2008) research.

Although there were no overall statistical differences between the two groups in their perceived levels of proficiencies, there were some "non-significant" differences worth noting. The following figures are presented to provide a visual representation of how experienced and 
novice educators rated themselves for the "no experience" and "advanced beginner" competency areas and their subcategories.

Facilitate learning. As displayed in Figure 2, an in-depth picture of the deficiency areas for the competency of "Facilitate Learning" is provided. In addition, the six subsections are listed below Figure 2.

Figure 2: Faculty Deficiency Comparison: Facilitate Learning Competency

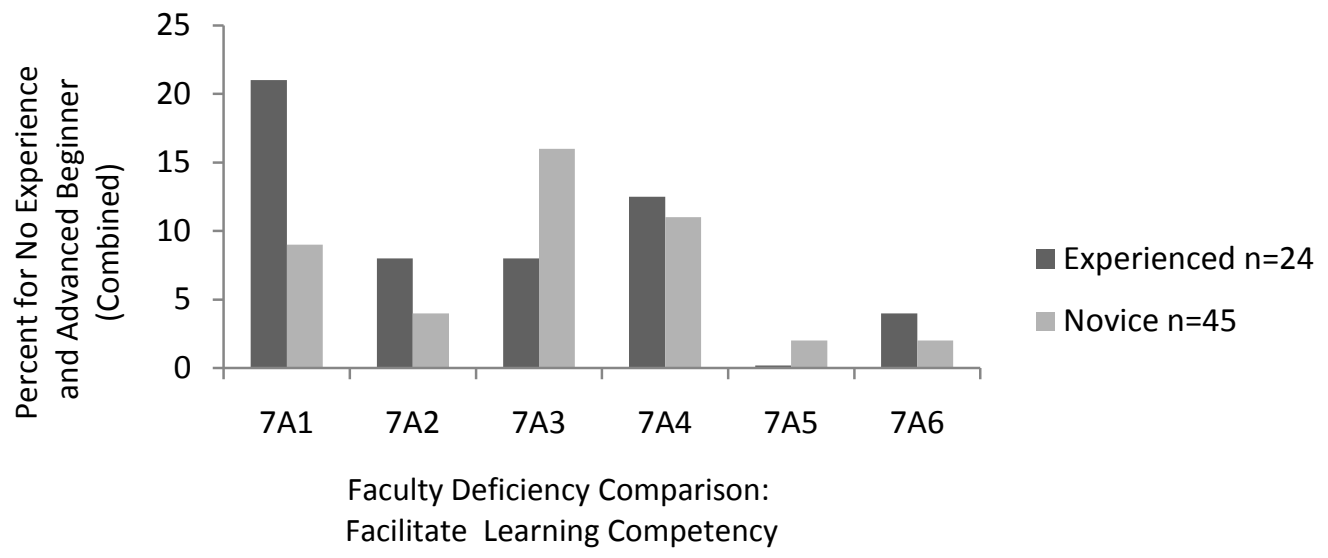

Facilitate Learning Competency: Sub-categories

(7A1) Utilize teaching strategies based on educational theory and evidence based teaching/learning methodologies

(7A2) Integrate and apply information technologies into teaching practice

(7A3) Engage students in scholarly activities related to nursing

(7A4) Facilitate student skill development in information literacy

(7A5) Demonstrate respect and interest in students

(7A6) Modify teaching strategies to accommodate diverse learning styles

The deficiencies for this competency are noted for both novice and experienced faculty in

Figure 2. The experienced faculty reported a higher percentage of perceived deficiencies in the 7A1, 7A2, 7A4, and 7A6 subsections. Although it was not the purpose of the study, one might speculate that with more teaching experience, these educators had a greater scope of understanding of what is required to implement this competency successfully. As a result, they 
rated themselves more deficient. In addition, the experienced educator's perceived teaching skill deficiency might reveal a lack of confidence and skill development relative to current-day curriculum and instructional delivery. Moreover, a fewer number of experienced faculty held a Master of Science in Nursing with a nursing education focus and therefore may not possess the knowledge of the teaching practices required to suit today's diverse student population.

Because almost all of the educators in this study had classroom and clinical responsibilities, deficiencies in this area may be of concern for faculty who must effectively deliver content with the pedagogical skills required for nursing education. Faculty members with deficits in the competency of facilitating student learning may rely heavily on long-established teaching practices and neglect to appropriately engage students in the teaching-learning process required in nursing education today.

Siler and Kleiner (2001) reported that faculty members were uncertain of how to practice in a classroom environment and lacked an understanding of methods to effectively deliver classroom content. Because senior faculty did not have the opportunity to observe the teaching practices of new faculty, the overall teaching effectiveness of new faculty was determined by student feedback. The findings in this study were consistent with Young's (1999) research in that novice faculty reported having difficulty implementing classroom responsibilities.

As mentioned, although the combined percentage of deficiencies is not alarming, refining these skills would only further develop their abilities and increase confidence levels in this area. The NLN's (2005c) Position Statement, “Transforming Nursing Education,” asserted that the profession has and must continue to revisit the need for change in the way in which subject matter is delivered to students. 
Facilitate learner development and socialization. Figure 3 on the following page

shows a detailed comparison of the combined perceived proficiency levels for this competency and subsections. Competency subcategories are listed below the graph.

Figure 3: Faculty Defining Comparison: Facilitate Learner Development and Socialization

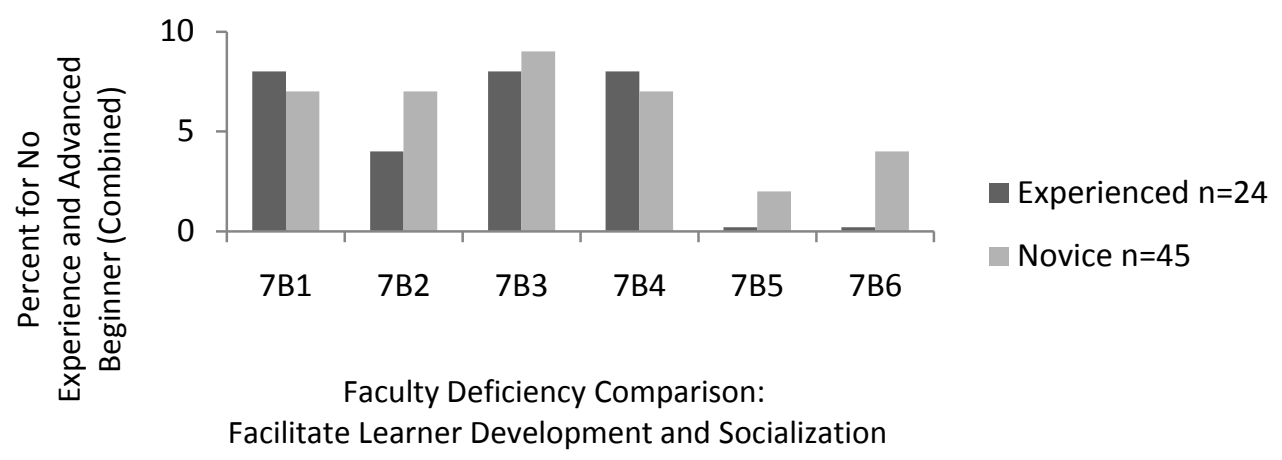

Facilitate Learner Development and Socialization: Sub-categories

(7B1) Foster cognitive, psychomotor, and affective development in learners

(7B2) Facilitate student socialization into the nursing profession

(7B3) Implement strategies to bridge theory and practice

(7B4) Exhibit a variety of personal teaching styles and interactions to positively influence students

(7B5) Display expertise in clinical practice while serving as a role model, preceptor, mentor, and guide to students

(7B6) Demonstrate the ability to provide adequate and expert clinical supervision

The experienced faculty reported higher deficiencies in the 7B1 and 7B4 subsections.

One possible explanation for this could be that the experienced educators could objectively reflect on only the teaching style with which they have become accustomed. Upon doing so the experienced educators may have realized that they did not exhibit a wide array of styles to accommodate today's student demographics. It could also be speculated that the naiveté of the novice educators may have contributed to an inaccurate perception of their ability to practice a variety of teaching styles. 
Espeland and Shanta (2001) indicated that it is typically difficult for nurse faculty to facilitate the development of students because of the change in student demographics as well as the continued pressures of meeting student demands. These authors supported the importance of empowering students to take an active part in their learning so that knowledge is shared and accountability is demonstrated by students. Contrary to what these authors found, this was not problematic for the participants in this study.

Use assessment and evaluation strategies. Both novice and experienced faculty reported a greater percentage of deficiencies for this competency section. Figure 4 illustrates the combined deficiencies among the competencies and lists the various sub-categories.

Figure 4: Faculty Deficiency Comparison: Use Assessment and Evaluation Strategies

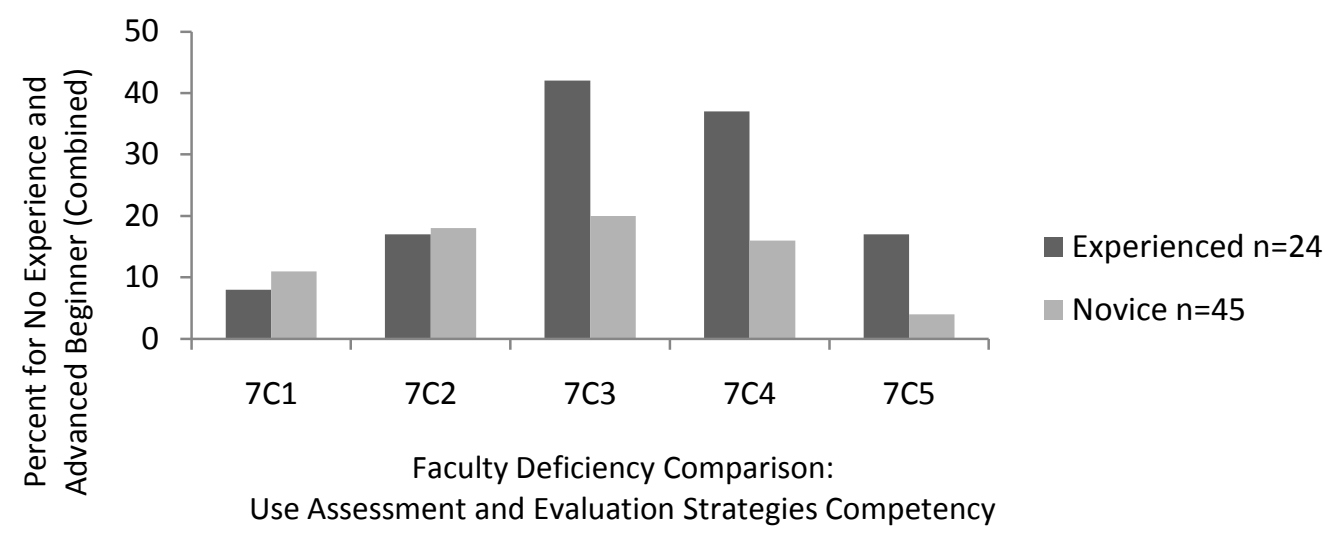

Use Assessment and Evaluation Strategies Competency: Sub-categories

(7C1) Describe appropriate evaluation strategies to assess student learning in the cognitive, affective, psychomotor domains

(7C2) Apply evidenced-based assessment and evaluation practices within an academic arena

(7C3) Develop test blueprints that reflect course objectives

(7C4) Provide evidence of the ability to interpret test analysis data to improve teaching/learning process

(7C5) Demonstrate organizational skills and maintain appropriate and accurate academic records 


\section{PERCEIVED COMPETENCIES OF NURSE EDUCATORS}

The experienced educator reported higher deficiencies in the 7C3, 7C4, and 7C5

subsections. It could be speculated that experienced educators lacked assessment skills required of today's academic institutions and their respective nursing programs. It is an expectation of nurse faculty to have to ability to design course objectives, measure their attainment, and revise courses as necessary. In comparison, since this is a relatively recent focus in education, it is possible that novice faculty may have been exposed to this competency more so than were earlier educated experienced faculty. New and experienced faculty members must possess an understanding of assessment and evaluation in the clinical and classroom settings and have frequently reported to be challenged in this area (Halstead, 2007). The study's findings revealed that nursing faculty members have limited knowledge and experience in this area.

The use of blueprinting and test analysis has recently increased in nursing education and experienced educators may be unfamiliar with the process. It is possible that given workload complexities, experienced educators may not have had time to perform this practice in their previous positions. Novice educators may have had some experience in their graduate programs.

McDonald (2004) indicated novice educators struggled with evaluation measures and were unsure and concerned if they were evaluating students accurately. New faculty members were unclear of the level of knowledge and depth students should posses while completing a task. McDonald also conveyed that participants in her study were uncertain about evaluating students too easy or too rigidly. This may be a possible explanation of higher deficiencies of novice educators' self-ratings in this competency subsection.

Kirchoff (2008) found that developing and blueprinting tests were problematic for new faculty. Participants in Kirchoff's (2008) study indicated they had no experience in test item writing or test analysis. There was also very little guidance offered to them in this area. Siler and 
Kleiner (2001) likewise found that faculty did not have an understanding of test interpretation. If students performed poorly on exams, participants were not sure if it was a result of their teaching or attributable to the composition of their exam questions.

Hessler and Ritchie (2006) strongly suggested that a thorough review of evaluation measures such as mock testing be provided for new faculty in order to better assist new faculty in this area. Overall, this study confirmed that there are generally more weaknesses in this competency area for both novice and experienced faculty.

Design curriculum and evaluate program outcomes. The competency, "Curriculum Design and Evaluation of Program Outcomes," had several subsections that novice and experienced faculty indicated a need for further development. Figure 5 shows the comparison.

Figure 5: Faculty Deficiency Comparison: Design Curriculum and Evaluate Program Outcomes

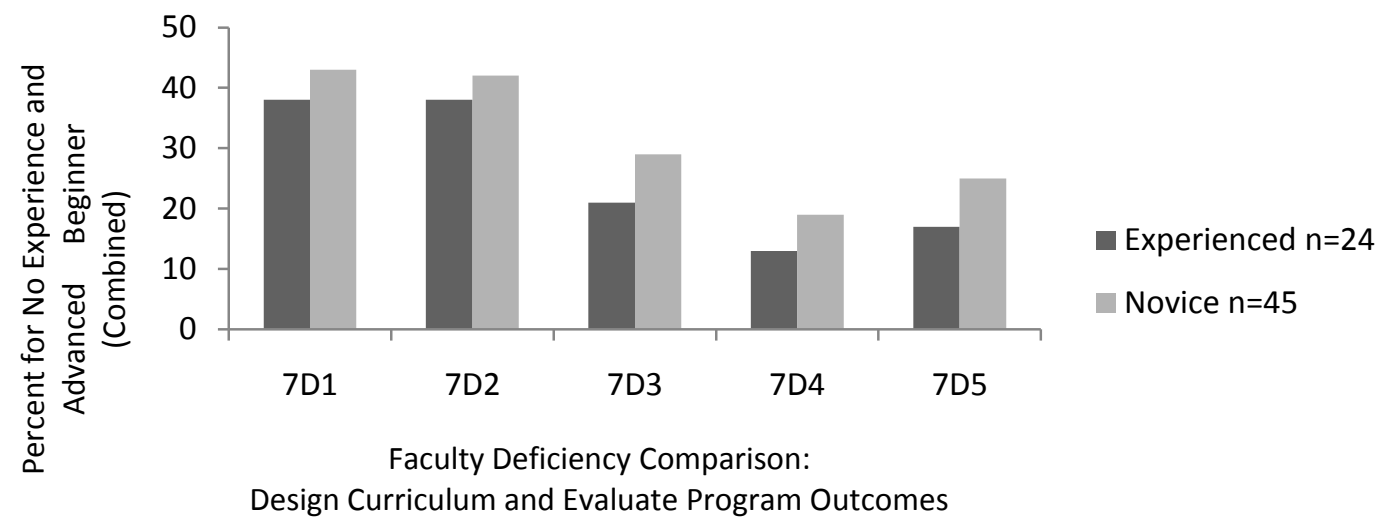

Design Curriculum and Evaluate Program Outcomes Competency: Sub-categories

(7D1) Design nursing curricula that reflects the institutional philosophy and mission statement

(7D2) Develop nursing curricula in relation to the institution's conceptual framework

(7D3) Demonstrate ability to write student competency statements and learning objectives

(7D4) Demonstrate ability to select appropriate clinical experiences in accordance with course outcomes

(7D5) Develop course learning activities and lesson content consistent with learner needs and course outcomes 
As illustrated, faculty had difficulty understanding the components involved in designing curricula. This competency area was the only area that novice faculty consistently reported higher deficiencies than did the experienced faculty. One would expect this to be the case given the previous work background of experienced faculty. With previous exposure to nursing education, experienced faculty members could better relate to and understand these items.

Curricula is an evolving process that faculty frequently encounter in their role.

Regardless of the program type, faculty will need to understand the components of curriculum and evaluate program outcomes. Zungolo (2004) indicated that in her experience as program administrator that faculty members frequently did not possess adequate knowledge in curriculum design and program outcome evaluation, especially if they held an advanced practice focus degree. Hessler and Ritchie (2006) noted that an overview of curriculum was necessary to provide to new faculty. Poindexter (2008) found that deans and administrators anticipated a lower level of knowledge in this area.

Function within the educational environment. The competency, "Function Within the Educational Environment," had limited reports of "no experience" or "advanced beginner" proficiency levels. Figure 6 illustrates the competency subsections most deficient. Figure 6: Faculty Deficiency Comparison: Function Within the Educational Environment

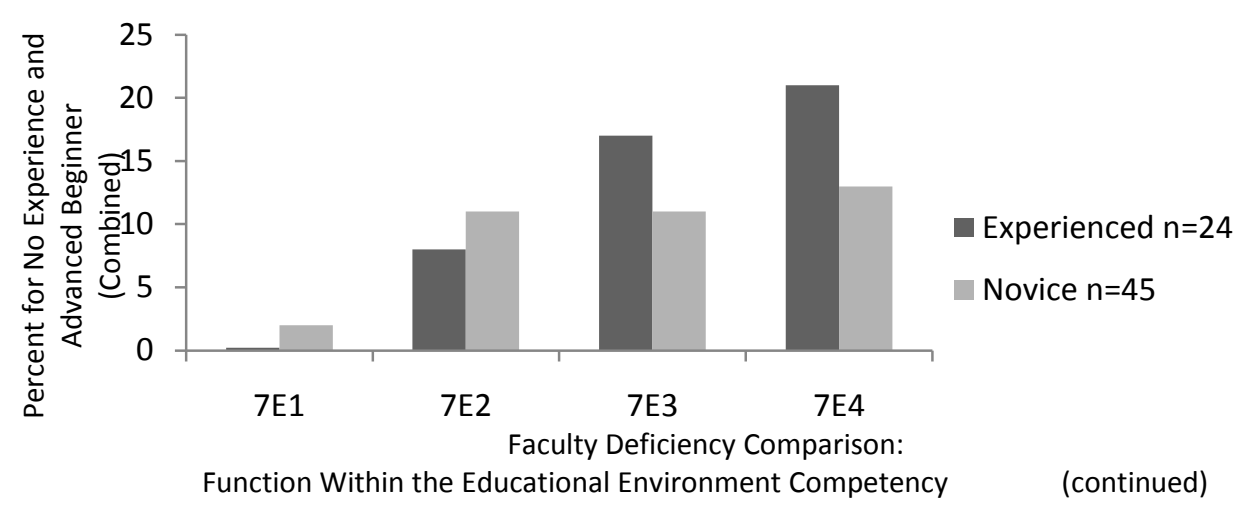


Figure 6: Deficiency Comparison: Function Within the Educational Environment (continued)

Function within the Educational Environment Competency: Sub-categories

(7E1) Demonstrate understanding and respect for the values and beliefs of students

(7E2) Articulate professional goals consistent with the nursing program

(7E3) Articulate an understanding of educator role expectations in accordance with the academic setting

(7E4) Demonstrate knowledge of legal and ethical issues in relation to higher education

The subsections of 7E3 and 7E4 were rated as a higher level of deficiency by the experienced educators. One could speculate that experienced faculty members possessed a greater understanding of what it was that they did not know. Another explanation could be related to their graduate education. The Master's degree most often focuses on the sciences in comparison to the course work emphasized in a program focusing on education. The concepts of leadership, budget, academic promotion, securing tenure, governance, are generally not part of a Master of Science curriculum and program of study. Likewise, nurse faculty members are generally not educated in university protocol or the governing structure of the university. Nevertheless, nursing faculty members need to be knowledgeable in the legal and ethical aspects in higher education given today's issues within the academic environment. They need to better understand how political dynamics influence nursing education and how it relates to the wellbeing of the governing organization (Halstead, 2007).

This result (less than $25 \%$ combined deficiency) is contrary to reports in the literature, which indicated that many nurse educators are unaware of their role expectations as they entered into academia (McDonald, 2004). A possible explanation of this could be the timing of the administration of this study's survey (eight to nine months into their positions). The educators may have come to better understand what was expected of them in their role. Poindexter's (2008) research regarding the ability of the nurse educator to perform this 
competency was rated by deans and administrators at a proficiency level of "competent." This was consistent with the results of this study as performance in this competency area was not as problematic for novice faculty as it was for experienced faculty.

Leader and collaborator role competency. This competency area was one of the least reported deficiencies by all educators. Figure 7 provides further analysis of this competency and the respective sub-categories.

Figure 7: Faculty Deficiency Comparison: Leader and Collaborator Role Competency

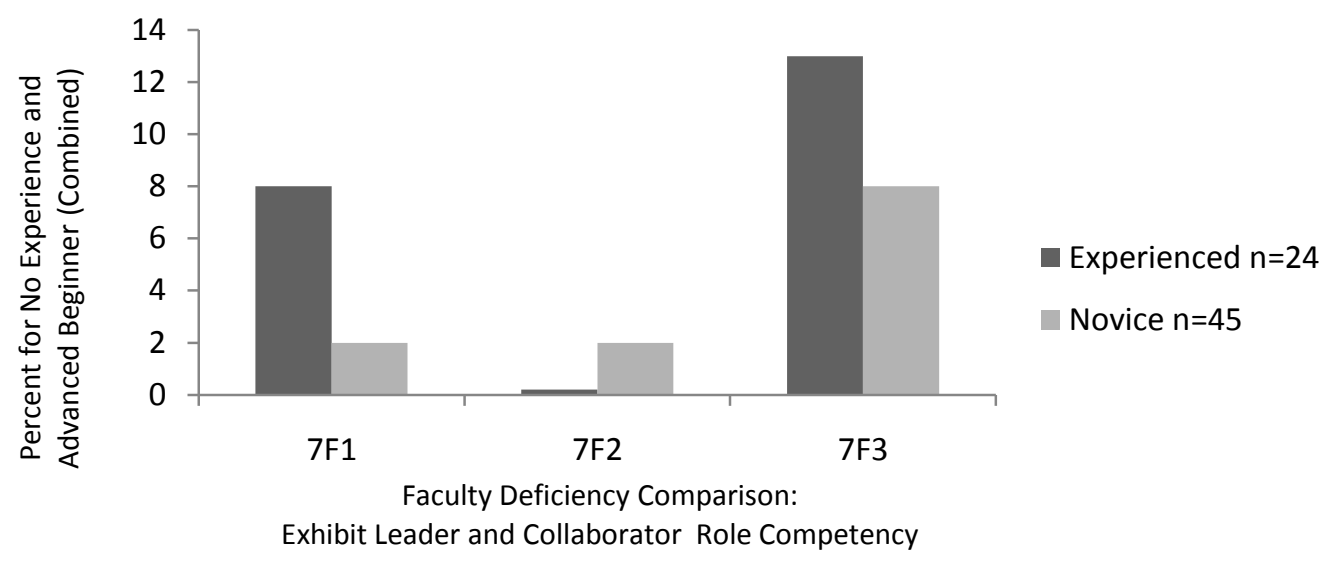

Exhibit Leader and Collaborator Role Competency: Sub-categories

(7F1) Exhibit ability to convey ideas respectfully

(7F2) Demonstrate overall clinical and professional leadership abilities

(7F3) Demonstrate excellence in public speaking

The experienced faculty members rated themselves as more deficient in 7F1 and 7F3 subsections. One possible explanation for this could be that it may be more difficult to speak to the increased number of students in today's classroom. Similarly, the classroom environment has significantly changed over the years, and the experienced faculty member may not feel as comfortable in this setting. Moreover, the comfort of communicating to patients is much different than communicating in public or in the classroom. Faculty members' tolerance to convey ideas respectfully could be limited due to today's changes in classroom dynamics. 
Although it appears that there are deficiencies in this competency, the combined percentages for proficiency levels of "no experience" and "advanced beginner" are less than $14 \%$. The subsection reported as most deficient was the ability to demonstrate excellence in public speaking. Poindexter (2008) found that deans and administrators preferred skills within this competency when hiring new faculty, which is supported by the findings in this study.

Scholar role competency. In the "Scholar Role Competency", the majority of subsections identified by educators were: (a) no experience or (b) advanced beginner. Figure 8 illustrates perceived deficiencies and the relevant sub-categories.

Figure 8: Faculty Deficiency Comparison: Scholar Role Competency

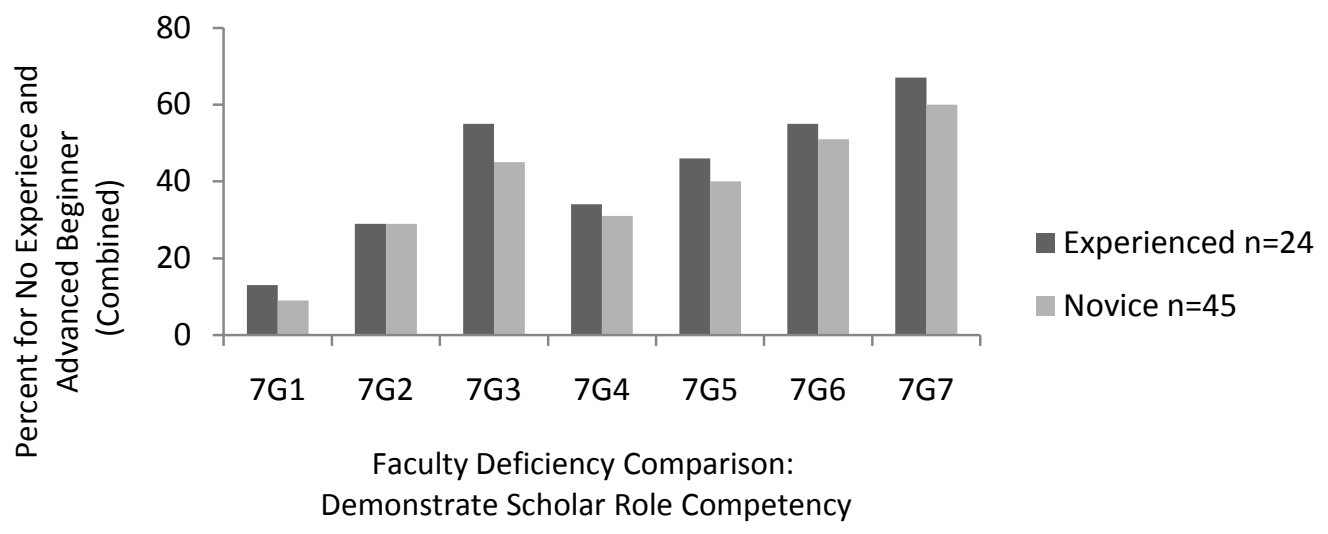

Demonstrate Scholar Role Competencies Sub-categories

(7G1) Describe knowledge of evidence based practice and clinical implementation strategies

(7G2) Engage in scholarly activities within area of expertise

(7G3) Exemplify skills as a researcher in nursing and health care

(7G4) Assist others to interpret and apply research into clinical practice

(7G5) Identify areas of need and opportunities to conduct nursing research

(7G6) Engage in scholarly writing activities

(7G7) Skilled in proposal writing and program development

Figure 8 also illustrates that experienced faculty members rated themselves as more deficient in all of the subsections of this competency area. One could speculate that the 
experienced educator may have been previously employed in institutions with a teaching rather than research emphasis. The deficiencies also may be attributed to the type of institution in which the faculty members were currently hired. The experienced participants were mostly hired into community colleges and research universities. Poindexter (2008) indicated that deans and administrators did not expect knowledge in research from new faculty in community colleges. By comparison, deans and administrators in the research university did prefer the new faculty member to be competent in this area. Emphasis on this area, rather than teaching could cause undue stress on both novice and experienced faculty desiring to improve their teaching skills. Another possible explanation for experienced faculty deficiencies could be related to the requirements of their graduate programs. It is possible that the extent of scholarly work was focused on course projects and assignments based on limited empirical study.

The high percentage of deficiency for both the novice and experienced faculty could also be attributed to the fact that the participants were not educationally prepared at the doctoral level. Suplee and Gardner (2009) found that new and experienced faculty members have difficulty meeting the needs of the changing student population while adjusting to additional obligations in research. Furthermore, these authors acknowledged that all faculty members should be involved in aspects of research, lifelong learning, and continued professional development. However, if faculty members lack the skills to interpret and apply research, accurately translating evidence based practice of health care issues to students may be problematic.

\section{Research Question Four}

Advanced practice verses nursing education focus. Much of the literature reported that educators with an advanced practice background lack the skills associated with the educator role (Zungolo, 2004; NLN, 2002). Zungolo (2004) indicated that advanced practice educators often 


\section{PERCEIVED COMPETENCIES OF NURSE EDUCATORS}

lack the skills to effectively teach in an academic setting. Advanced practice educators also enter into their new positions with deficiencies in pedagogy and curriculum development and oftentimes lack strategies to facilitate student learning. These educators have been reported to rely upon teaching methods based on past experiences, rather than through formal preparation for a teaching role.

Anderson (2008) found that the work-role transition from clinician to educator was rather difficult for new faculty. It was reported that new faculty felt overwhelmed regarding the complexity of their teaching positions. The experience of being a new faculty member in nursing education was completely different from what faculty had expected. The professional adjustment was difficult for the new nurse educator (Anderson, 2008; Sienty, 2004; Young, 1999). The results of this study indicated that there was no difference in perceived competency levels between nurse educators with a specialization in advanced practice and those with a specialization in nursing education.

Faculty mentoring. Faculty mentoring occurred most of the time according to the participants. This was conducted formally, informally, and a combination of both. Not all participants were assigned a mentor. Mentoring has clearly shown to produce positive results for new faculty including increased productivity, job satisfaction, and retention (Blauvelt and Spath, 2008; Young, 1999; Horat, 2008). McDonald (2004) also found that "formal orientation, mentors, team meetings, and informal meetings with colleagues were sources of assistance for the novice teachers" (p.101). Research conducted in nursing education programs that have implemented faculty mentoring have reported increased individual assistance, increased socialization, and increased support regarding faculty insecurities and concerns. 
Most of the new and experienced faculty in this study reported that the core competencies were either not addressed in their mentoring program or only somewhat addressed. This is a concern for the profession because the competencies have been developed to facilitate a comprehensive understanding of the challenging aspects of the role of the educator. Moreover, the competencies serve as a blueprint for the role and emphasize the body of knowledge required to accomplish success in teaching. Successful implementation of the required knowledge begins with an understanding of the competencies, which would allow for further development and advancement toward becoming an expert in the field.

\section{Recommendations for Practice}

Based on evidence found in this study, there are several recommendations that may offer further advancement in the practices associated with the nursing education profession.

Recruit diverse faculty. Increased recruitment for a diverse faculty, including males, is needed. The nursing education profession should continue to support and encourage the recruitment of faculty of diversity, especially males, to effectively meet the needs of our diverse student population (Suplee \& Gardner, 2009; NLN, 2010). Ultimately, this would reduce some

of the issues with which faculty often struggle, including the changing demographics of students and cultural competence (Suplee \& Gardner, 2009; NLN, 2009).

Reduce workload complexity. Careful consideration should be given to the workload complexity of new faculty. Workload complexity continues to be problem in the profession and will continue to be so unless adjustments are made in teaching complexity. Because of the documented examples of faculty role strain and stress that have resulted in faculty departing from their positions, both novice and experienced faculty should have reduced workload complexity until they adjust to their new professional environments. 
Individualize faculty needs. Assessing, examining, and individualizing the needs of all new faculty members is very important. Nursing programs should examine the individual differences of new faculty and not predetermine their qualifications and competencies solely on their years of experience or educational credentials. An individualized inventory of faculty strengths and weaknesses based on the core competencies for nurse educators should be initiated. Efforts can then be undertaken to reduce the stress and anxiety of new faculty by acknowledging their strengths and supporting their weaknesses to fulfill the nurse educator role.

Develop formal mentoring programs. The development of formal mentoring programs is warranted and should be implemented by all nursing programs to guide new and experienced educators in improving their overall role performance. Attention to professional development is essential for both new and experienced faculty members who especially report the need for further assistance in the competency areas. The prioritization of topics for a well-developed mentoring program should occur in the following sequence based on the results of this study:

1. Development of Scholar Role Competencies (depending on type of academic setting)

2. Proficient development in Designing Curriculum and Evaluating Program Outcomes

3. Effective use Assessment and Evaluation Strategies

4. Strategies to Facilitate Learning

5. Learning how to Function within the Educational environment

6. Developing means to Facilitate Learner Development and Socialization

7. Learning Leader and Collaborator Role Competencies 


\section{PERCEIVED COMPETENCIES OF NURSE EDUCATORS}

Provide competency overview. Providing an overview of the each of the competency areas is necessary for all faculty members to effectively approach the complexities of their role, as well as allow an opportunity for advancement in the field. Many new educators have endured a difficult transition in academia because of the lack of understanding of their responsibilities (Young, 1999; McDonald, 2004; Hessler and Ritchie, 2006; Sienty, 1988; Horat, 2008). This could be alleviated if new faculty members are given the time and opportunity to embrace the challenges associated with their positions. One participant from this study stated: "This survey provided me with areas in which I can strive to improve on and also new areas to explore. It showed how little mentoring I am receiving at my institution.” It is apparent that this participant became familiar with the expectations of the role after reviewing the core competencies listed in the survey. By gaining an understanding of these competencies, the participant was given the framework from which to build and expand upon in the profession.

Encourage scholarly research and writing. Engaging in scholarly writing and conducting research are essential for the educator to remain or achieve tenure standards in their institution. However, tenure attainment is only one aspect of a successful career in nursing education. Faculty members should strive to attain advancement in research in order to be fully equipped to appropriately guide and prepare students. All faculty members should contribute to evidence-base practice not only for the betterment of the profession but also to provide students with the latest standards of patient care. This could be accomplished through the development of research partnerships with new and seasoned faculty. New faculty would also possess an increased sense of belonging and contribution not only to the institution but also to the profession as well. Publication syndicates could also be developed as reported by McVeigh et al., (2002) to help newly hired educators to better develop and hone their research and writing skills. 
Ultimately, this would foster the socialization of new faculty, and more importantly, aid in the retention of quality faculty.

Additional recommendations for mentoring in this area would be to encourage and support new faculty to attend research conferences and workshops to further develop their research skills. Often senior faculty members are given preference to attend workshops and conferences, but new faculty members should be equally supported and provided with comparable faculty development opportunities.

Faculty members should also be introduced to campus resources and work in concert with appropriate departments to facilitate their research efforts. Personal and electronic networking should be encouraged with faculty in other programs who share common interests to develop innovative projects.

Engage in program and curriculum development. A thorough review of curriculum should be offered to new faculty members. Faculty should be taught how the conceptual framework of the program is threaded throughout the curriculum. A review of program accreditation procedures should be offered. New faculty should assist in the process of self-study writing to enhance their understanding of the program in its entirety. The importance of understanding program outcomes and evaluating these outcomes should be continually reviewed.

Review assessment and evaluation procedures. The use of assessment and evaluation techniques should also be a priority for mentoring. Experienced faculty should assist new faculty with test preparation and interpretation. Faculty members should be taught how to approach and handle low exam scores and how to evaluate the indicators of good and poor test questions. Perhaps reviewing prior exams and examining the results would help alleviate the anxiety associated with this process. 
Faculty participation in test blueprinting should be encouraged. Mock-grading activities would assist new faculty with grading and evaluating students. Grading should not be stressful to new faculty if specific examples of appropriate scoring and rubrics are reviewed in advance with faculty. Workshops regarding assessments should also be offered to new faculty.

Implement professional development for teaching strategies. The most current teaching practices should be integrated into the classroom and clinical settings. Facilitating student learning strategies should be reviewed with faculty during the first year of teaching. The classroom setting poses the greatest challenge for new faculty; therefore, adequate support is both necessary and critical. Therefore, the issue should remain an area to be emphasized in mentoring new faculty. This could begin by having new faculty members attend the seasonedfaculty lectures to observe teaching strategies and techniques. In turn, seasoned faculty should attend new faculty lectures not only to decrease their sense of isolation in an educational environment, but also to reduce the fear and anxiety that has been associated with this responsibility. Seasoned-faculty support should be present to address lecture content inconsistencies, assist with answering questions, and promote a positive productive classroom environment.

New faculty should be taught how to approach their lecture content based on course objectives and how to effectively engage students to attain these objectives. Assessment skills must also be learned to make improvements in teaching activities. Debriefing should occur after each class so that new faculty members can examine the strengths and weakness of their lectures in a timely manner.

Educate about departmental and university responsibilities. Functioning within the education environment can be better accomplished with new faculty through a review of job 
descriptions and expectations of the position. Faculty should understand where they fit within the department and larger college/university environment. Policies for the department and the institution should be reviewed and periodically updated. New faculty should not merely be given a handbook and told to review it. There must be specific points and items of importance that are examined through interactive discussions. Senior faculty should encourage new faculty to attend university committee meetings, especially faculty senate meetings to enhance the understanding of the political culture of the university.

Faculty should be oriented to the university expectations regarding merit, tenure, and promotion guidelines. The areas of teaching, scholarship, and service should be reviewed. Methods in which to achieve these requirements should be offered. Senior faculty could help new faculty immediately develop a teaching portfolio rather than wait until the time the requirements are due.

Define clinical faculty role. New faculty members need to be socialized into the clinical setting. One effective approach for socialization would be to accompany new faculty in the clinical environment until they feel comfortable. Senior faculty ought to assist the new faculty in conducting pre and post conferences and offer strategies that have been historically successful in meeting the learning needs of students.

Promote professional involvement opportunities. Leader and collaborator competencies could be further developed if new faculty members work in conjunction with other faculty in advising student organizations and accompanying students to educational workshops. New faculty members should be guided toward involvement in local and state organizations. New faculty should also be invited to present at conferences or offered advice on submitting 
abstracts to local or national conferences. Faculty should be taught the importance of a reciprocal teacher/student relationship where information is shared and faculty serves as a role model.

Encourage lifelong learning. The profession of nursing education should continue to accent the importance of mentoring faculty throughout their careers. Reports in this study revealed that even experienced faculty members indicate a need for additional development in certain core competency areas. Lifelong learning is essential for nurse educators to discover the latest trends associated with health care and nursing education.

\section{Summary}

In summary, it is not possible to accomplish these suggestions in one semester or even in one academic year. Mentoring new faculty is an ongoing process that could last for years. Interest and enthusiasm in new faculty member's contribution to the department should occur both professionally and personally. An effective nursing care plan is a well developed, deliberately thought out plan that individually meets specific patient needs and outcomes. Senior faculty should embrace and commit to the same process by nurturing new faculty with a similar process. Reassurance and guidance for new faculty should be ongoing, especially during times of faculty stress and frustration. Practicing nurses receive assistance and orientation when beginning new positions regardless of their experience. Nurse educators deserve the same attention; therefore, nursing programs should adopt orientation practices that align with the practices featured in today's health care organizations.

\section{Recommendations for Future Research}

The results of this study can enhance the future of nursing education. Given this, continued research and evidence-based practice is needed in nursing education. The following are recommendations for future research. 
- Replicate this study with a pre/post examination of new faculty at the beginning and at the end of their first year of hire. This would determine any improvements in the core competencies as well as evaluate the effectiveness of the mentoring process.

- The current study could be replicated using adjunct faculty members.

- A comparative study of the newly hired faculty member and their mentors could be conducted using the perceptions of new faculty themselves and how the mentors perceive the competencies of new faculty.

- A comparative study of nursing deans and administrators could be conducted, to determine the differences between new faculty self-perceptions and the dean and administrator perceptions.

- Future investigations regarding nurse-faculty mentoring could be conducted to determine effective mentoring methods for new faculty and which are best suited for nursing education.

- Further studies could be conducted regarding the amount of time invested in mentoring new faculty. The challenges and obstacles associated with mentoring and workloads of faculty in nursing education could also be examined.

- Qualitative studies could further explore the rationale of the perceived deficiency levels for novice and experienced educators.

- Subsequent studies could examine the competencies from a longitudinal perspective through all career phases of nurse faculty including early, mid, and late careers.

\section{Conclusion}

Given the shortage of nurse educators, many interventions are needed at several levels to retain nurse educators and continue the advancement of nursing education as a distinguished 


\section{PERCEIVED COMPETENCIES OF NURSE EDUCATORS}

profession. Because of the challenges associated with today's diverse student population and the changing health care system, it is important for novice and experienced faculty members to conduct a self-assessment of nursing educator competencies to become familiar with what is expected of them. Self-assessment should occur not only in the first year of teaching of faculty, but throughout their entire professional career. Self-assessment would enhance their development and advancement in the role and provide senior faculty with a baseline of knowledge to accurately guide new faculty members in becoming accustomed to their roles and responsibilities.

The fact that self-assessment is necessary also supports that faculty with varying academic backgrounds need to be assessed to determine the skills and abilities of new faculty. Nursing education has recognized the advantages of possessing a graduate degree with focus on advanced practice and nursing education. However, the underlying knowledge of new educators with these backgrounds is still necessary to determine their potential to be successful in the faculty role.

This contribution to nursing research has recognized that newly hired novice nurse faculty members have entered into the nurse educator role perceiving themselves as "competent" educators. Still, there are areas in which additional learning is needed. Newly hired experienced faculty also primarily feel "competent" in their role performance, but have deficiencies as well. The deficiencies of nurse educators, whether novice or experienced in the role, should not be overlooked.

Finally, and most importantly, providing a thorough comprehensive mentoring experience for newly hired novice and experienced faculty would contribute significantly toward the retention of nurse educators. Retaining newly hired faculty, who possess the knowledge and 
dedication required to generate qualified graduate nurses to deliver safe nursing care to our communities, constitutes one of the highest concerns facing the nursing education profession.

\section{Limitations}

The following items were limitations of the study:

- Perceived accuracy from which the educators rated themselves may have contributed to the study's limitation.

- The study's timing, which was near the end of the academic year, may have contributed to a rapid, less than accurate completion of the survey because of heightened faculty demands at this time.

- The newly hired educator had gained eight months of experience in the competency areas, which could have increased their self-rated proficiency levels in the competency areas.

- The power of the statistical analyses could be analyzed to interpret a possible reason for some of the non-significant results.

- Unequal distribution of schools by state/type. 


\section{PERCEIVED COMPETENCIES OF NURSE EDUCATORS}

\section{References}

Alteen, A., Didham, P., \& Stratton, C. (2009). Reflecting, refueling, and reframing: A 10 year retrospective model for faculty development and its implications for nursing scholarship. The Journal of Continuing Education in Nursing, 40(6), 267-72.

American Nurses Association (ANA). (1996). Scope and Standards of Advanced Practice Registered Nursing. American Nurses Publishing. Washington, DC.

American Association of Colleges of Nursing (AACN). (2008a). Nursing Shortage Fact Sheet. Available at: http://www.aacn.nche.edu/media/FactSheets/NursingShortage.htm American Association of Colleges of Nursing (AACN). (2008b). Nursing Faculty Shortage Fact Sheet. Retrieved June 30, 2009 from the AACN Web site: http://www.aacn.nche.edu/media/FactSheets/FacultyShortage.htm http://www.aacn.nche.edu/media/FactSheets/Faculty Shortage.htm

American Association of Colleges of Nursing (AACN). (2009). Press Release. Student Enrollment Expands at U.S. Nursing Colleges and Universities for the $9^{\text {th }}$ year despite Financial Challenges and Capacity Restraints. Available at: http://www.aacn.nche.edu/Media/NewsReleases/2009/StudentEnrollment.html

Anderson, J. (2008). An academic fairy tale: A metaphor of the work-role transition form clinician to academician. Nurse Educator, 33(2), 79-82.

Baker, S. (2007). Faculty matters. Nursing Education Perspectives, 28(5), 238-40.

Bartels, J. E. (2007). Preparing nursing faculty for baccalaureate-level and graduate-level nursing programs: Role preparation for the academy. Journal of Nursing Education, 46(4), 154-8. 
Benner, P. (1984). From Novice to expert. Excellence and power in clinical nursing practice. California: Addison-Wesley.

Billings, D. M. (2003). What does it take to be a nurse educator? Journal of Nursing Education. 42(3), 99-100.

Billings, D., \& Halstead, J. (2009). Teaching in nursing. A guide for faculty. St. Louis, Missouri: Saunders.

Blauvelt, M., \& Spath, M. (2008). Passing the torch: A faculty mentoring program at one school of nursing. Nursing Education Perspectives, 29(1), 29-33.

Boyer, E. (1990). Scholarship reconsidered. Priorities of the professoriate. San Francisco, CA: Jossey-Bass Inc.

Brady, M. (2007). Recruitment and retention of associate degree nursing faculty. Journal of Nursing Education, 46(4), 190-2. Retrieved 12/10/2009 from http://vnweb.hwwilsonweb.com/hww/results/results_single_ftPES.jhtml

Chaska, N. L. (2001). The nursing profession tomorrow and beyond. Thousand Oaks, California: Sage Publications.

Davis, D., Stullenbarger, E., Dearman, C., \& Kelly, J. (2005). Proposed nurse educator competencies: Development and validation of a model. Nursing Outlook, 53(4), 206-211.

Dempsey, L. (2007). The experiences of Irish nurse lectures role transition from clinician to educator. International Journal of Nursing Education Scholarship, 4(1), 1-10. Available at: http://www.bepress.com/ijnes/vol4/iss1/art13

Didham, P. (2003). From the tower to the trenches: A nurse educators reflections on the knowledge of experience. Journal of Nursing Education, 42 (11), 485-87. 


\section{PERCEIVED COMPETENCIES OF NURSE EDUCATORS}

Dillman, D., Smyth, J., \& Christian, L. (2009). Internet, mail, and mixed-mode surveys. The tailored design method. Hoboken, New Jersey: John Wiley \& Sons Inc.

Dracup, K. (2005). Master's nursing programs. American Association of Colleges of Nursing. Available at: http://www.aacn.nche.edu/Education/nurse_ed/MSNArticle.htm

Dozier, T. (2007). Turning good teachers into great leaders. Educational Leadership, 65, 54-58.

Ellis, J., \& Hartley, C. (2008). Nursing in Today's World. Trends, Issues, and Management. Ninth Ed. Wolters Kluwer Health, Lippincott Williams \& Wilkins

Espeland, K., \& Shanta, L. (2001). Empowering versus enabling in academia. Journal of Nursing Education, 40(8), 342-46.

Foxall, M., Megel, M., Grigsby, K., Billings, J. (2009). Faculty retirement: Stemming the tide. Journal of Nursing Education, 48(3), 172-5.

Falk, N. (2007). Strategies to enhance retention and effective utilization of aging nurse faculty. Journal of Nursing Education, 46(4), 165-169.

Goldenberg, D., Andrusyszyn, M. A., \& Iwasiw, C. (2004). The effect of classroom simulation on nursing students' self-efficacy related to health teaching. Journal of Nursing Education, 44(7), 310-314.

Goodwin, L., \& Stevens, E. (1998). An exploratory study of the role of mentoring in the retention of faculty. Journal of Staff, Program and Organizational Development, 16(1), 39-47. (ERIC Document Reproduction Service No. EJ 586 468).

Halstead, J. (2007). Nurse Educator Competencies: Creating an evidenced-based practice for nurse educators. National League for Nursing: New York.

Hawranik, P., \& Thorpe, K. (2008). Helping faculty enhance scholarship. The Journal of Continuing Education in Nursing, 39(4), 155-65. 


\section{PERCEIVED COMPETENCIES OF NURSE EDUCATORS}

Hessler, K., \& Ritchie, H. (2006). Recruitment and retention of novice faculty. Journal of Nursing Education, 45(5), 150-4. Retrieved 12/10/2009 from http://vnweb.hwwilsonweb.com/hww/results/results_single_ftPES.jhtml

Horat, C. (2008). Phenomenological study of new nursing faculty in Georgia Universities: Experiences affecting retention and attrition decisions. Dissertation. UMI3338356

Ironside, P. (2004). "Covering content" and teaching thinking: Deconstructing the additive curriculum. Journal of Nursing Education, 43(1), 5-12.

Johnson, K., Aasgaard, H., Wahl, A., \& Salminen, L. (2002). Nurse educator competence: A study of Norwegian nurse educators' opinions of the importance and application of different nurse educator competence domains. Journal of Nursing Education, 41(7), 295301.

Kalb, K. (2008). Core competencies of nurse educators; Inspiring excellence in the nurse educator practice. Nursing Education Perspectives, 29(4), 217-19.

Kalischuk, R., \& Thorpe, K. (2002). Thinking creatively: From nursing education to practice. The Journal of Continuing Education in Nursing, 33(4), 155-63.

Kirchoff, D. (2008). The Mentoring Experience of Nursing Faculty; A Qualitative Examination in an Associate Degree Nursing Program. Unpublished manuscript.

Lewallen, L., Crane, P., Letvak, S., Jones, E., \& Hu, J. (2003). An innovative strategy to enhance new faculty success. Nursing Education Perspectives, 24(5), 257-60.

McDonald, J. (2004). From practice to teaching; The experiences of new teachers. Dissertation. ISBN: 0-612-94293-7. 


\section{PERCEIVED COMPETENCIES OF NURSE EDUCATORS}

McVeigh, C., Moyle, K., Forrester, K., Chaboyer, W., Patterson, E., \& St. John, W. (2002).

Publication syndicates: in support of nursing scholarship. The Journal of Continuing Education in Nursing, 33(2), 63-66.

National League for Nursing (NLN). (2002). Position statement: The preparation of nurse educators. New York: National League for Nursing. Available at: http://www.nln.org/aboutnln/PositionStatements/prepofnursed02.htm

National League for Nursing (NLN). (2005a). Nurse Faculty Shortage Fact Sheet. Available at: http://www.nln.org/governmentaffairs/pdf/NurseFacultyShortage.pdf

National League for Nursing (NLN). (2005b). The Scope of Practice for Academic Nurse Educators. New York, NY: National League for Nursing.

National League for Nursing (NLN). (2005c). Position statement: Transforming nursing education. New York, NY: National League for Nursing.

National League for Nursing (NLN). (2006). Position statement: Mentoring of nurse faculty. New York: National League for Nursing. Available at http://www.nln.org/aboutnln/Position Statements/mentoring_3_21_06.pdf

National League for Nursing (NLN). (2009). Report to the Committee on Finance United States Senate. Hearing on Workforce Issues in Health Care Reform: Assessing the Present and Preparing for the Future.

National League for Nursing (NLN). (2010). Nurse Educator Shortage Fact Sheet. Available at: http://www.nln.org/governmentaffairs/pdf/nursefacultyshortage.pdf

Neese, R. (2003). A transformational journey from clinician to educator. The Journal of Continuing Education in Nursing, 34(6), 258-62. 


\section{PERCEIVED COMPETENCIES OF NURSE EDUCATORS}

Piercy, F., Giddings, V., Allen, K., Dixon, B., Meszaros, P., \& Joest, K. (2005). Improving campus climate to support faculty diversity and retention: a pilot program for new faculty. Innovative Higher Education, 30(1), 53- 66.

Poindexter, K. (2008). Essential Novice Nurse Educator Role competencies and qualifications to teach in a pre-licensure registered nurse program. A Dissertation UMI 3316931.

Poindexter, K. (2009). Nurse Educator Competency and Qualification Inventory. Unpublished Survey.

Records K., and Emerson R. J. (2003). Mentoring for research skill development. Journal of Nursing Education. 42(12), 553-7.

Seila, D., Twibell, R., Keller, V. (2008). The shortage of nurse and nursing faculty: What critical care nurses can do. AACN Advanced Critical Care, 19(1), 66-77.

Sienty, M. (1988). Role strain in the nurse educators first teaching position. UMI Dissertations

Siler, B., \& Kleiner, C. (2001). Novice faculty: Encountering expectations in academia. Journal of Nursing Education, 40(9), 397-403.

Smith, D., \& Garteig, L. (2003). Using a linked learning activity to foster nursing students’ professional growth. Journal of Nursing Education, 42(5), 27-30.

SPSS User Manual. (1999-2010). Customer Guide to account navigation, survey creation, distribution \& analysis. Available at: http://s3.amazonaws.com/SurveyMonkeyFiles/UserManual.pdf

Suplee, P.D., \& Gardner, M. (2009). Fostering a smooth transition to the faculty role. The Journal of Continuing Education in Nursing 40 (11), 514-520.

Tanner, C. A. (2002). Education's response to the nursing shortage: Leadership, innovation, and publication. Journal of Nursing Education, 41(11), 467-68. 
Thorpe, K., \& Kalischuk, R. (2003). A collegial mentoring model for nurse educators. Nursing Forum, 38(1), 5-15.

Thrall, T. (2005). Teachers wanted. Hospitals \& Health Networks, 79(4), 20-22.

Valiga, T. M. (2003). The nursing faculty shortage: National League for Nursing Perspectives Presented to the National Advisory Council on Nurse Education and Practice.

Villanova University. (2009). Master's Nursing Education Overview. Web site available at: http:/www.villanova.edu/nursing/programs/graduate/masters/concentrations/education/ Young, P. (1999). Joining the academic community; The lived experiences of new teachers in nursing education. Dissertation Abstracts International. (UMI No. 800-521-060)

Zungolo, E. (2004). Faculty preparation: Is clinical specialization a benefit or a deterrent to quality nursing education? Journal of Continuing Education in Nursing, 35(1), 19-23. 


\section{Appendix A}

Poindexter Survey (2009)

\section{Nurse Educator Competency and Qualification Inventory}

Nurse educator role competencies and qualifications listed below have been identified from the literature and validated as entry level requirements by nursing educational program administrators across the United States. Nurse educator role expectations vary according to the type of academic instruction, position, and type of nursing program in which they are employed. This inventory may be used to evaluate educator qualifications, competencies, individualize development programs and track competence proficiency progression.

Please review each of the qualifications and competencies noted below. Identify the professional qualifications that reflect your current status. Then identify your perceived level of proficiency for each of the competencies listed in each of the sections.

\section{Section 1. Academic Experience}

\section{Circle those that reflect your current academic experience}

\begin{tabular}{|c|c|}
\hline Gender & Female \\
\hline 1.1. Position & FT Non-Tenure \\
\hline 1.2. Current Academic Rank (circle one) & $\begin{array}{l}\text { Instructor } \\
\text { Associate Professor }\end{array}$ \\
\hline 1.3. Years of full time teaching experience & 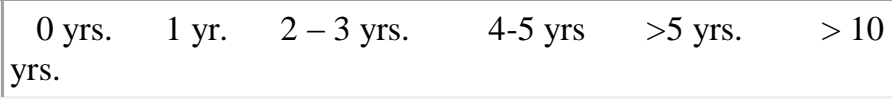 \\
\hline 1.4. Primary teaching responsibilities (circle one) & Clinical \& Classroom \\
\hline 1.5. Type of academic setting (circle one) & $\begin{array}{lll}\text { Community College } & \text { Liberal Arts } \\
\text { Diploma/Hospital } & \text { N/A }\end{array}$ \\
\hline 1.6. Location of Nursing Program & $\mathrm{MD} \quad \mathrm{OH}$ \\
\hline
\end{tabular}

\begin{tabular}{|c|c|}
\hline \multirow{2}{*}{$\begin{array}{l}\text { Section 2. Education Qualifications } \\
\text { Check level of Academic Preparation }\end{array}$} & \multirow{2}{*}{$\begin{array}{l}\text { Section 3. Clinical Practice Qualifications } \\
\text { Check ALL applicable practice qualifications }\end{array}$} \\
\hline & \\
\hline 2.1. BSN and MS (non-nursing) & 3.1. 1 year Acute care clinical practice experience \\
\hline 2.2. MSN & 3.2. 2 - 3 years Acute care clinical practice experience \\
\hline 2.3. MSN Nursing Education & 3.3. 4 -5 years Acute care clinical practice experience \\
\hline $\begin{array}{l}\text { 2.4. MSN AP } \\
\text { (NP, CNS, CNM, or CRNA) }\end{array}$ & $\begin{array}{l}\text { 3.4. Greater than } 5 \text { years Acute care clinical practice } \\
\text { experience }\end{array}$ \\
\hline 2.5. DNP & 3.5. 1 year of Specialty practice experience \\
\hline 2.6. $\mathrm{PhD}$ in Nursing and MSN & 3.6. $2-3$ years Specialty practice experience \\
\hline 2.7. $\mathrm{PhD}$ in Nursing and MSN AP & 3.7. $4-5$ years Specialty practice experience \\
\hline $\begin{array}{l}\text { 2.8. } \mathrm{PhD} \text { in Nursing } \\
\text { (without MS or MSN) }\end{array}$ & $\begin{array}{l}\text { 3.8. Greater than } 5 \text { years of Specialty practice } \\
\text { experience }\end{array}$ \\
\hline 2.9. $\mathrm{PhD}$ in Related Field and MSN & 3.9. Management or supervisory experience \\
\hline 2.10 EdD and MSN & 3.10. Current clinical practice role \\
\hline
\end{tabular}




\begin{tabular}{|c|c|}
\hline $\begin{array}{c}\text { Section 2. Education Qualifications } \\
\text { Check level of Academic Preparation }\end{array}$ & \multicolumn{2}{c|}{ Section 3. Clinical Practice Qualifications } \\
\cline { 2 - 3 } 2.11 Other degree (please specify) & Check ALL applicable practice qualifications \\
\hline
\end{tabular}

\section{Section 4. Collaborator and Leadership Qualifications}

Identify the following qualifications that reflect your level of leadership experience. Mark all that apply.

4.1. Maintain active membership in at least one professional nursing organization

4.2. Hold or have held a leadership position in a professional nursing organization

4.3. Exhibit team collegial working relationships and effective interpersonal skills

4.4. Serve or have served as a member on a multidisciplinary task force

4.5. Actively apply knowledge of social, economic, and political forces to influence nursing practice and health care

4.6. Serve or have served in the role of an expert nurse consultant

\section{Section 5. Scholar Qualifications}

Identify the following qualifications that reflect your level of scholarly activities. Mark all that apply.

5.1. Maintain a funded area of research

5.2. Publish research findings in peer reviewed journals

5.3. Present research on a national level

5.4. Translate applicable health related research into practice

5.5. Present scholarship activities on a local and regional level

5.6. Conduct research related to nursing and health care

5.7. Conduct research related to nursing education

Please review each of the following nurse educator role competencies associated with clinical practice and indicate your current level of proficiency according to the following scale.

No experience: No previous knowledge or practical experience with state competency. Requires continuous guidance.

Advanced Beginner: Some previous knowledge or practical experience with stated competency. Requires frequent guidance.

Competent: Sufficient knowledge able to perform confidently. Requires little guidance.

Proficient: Holistic understanding of competency; integrates past experiences to guide decision making.

Expert: Highly skilled; deep understanding of competency; provides guidance to others. 


\section{PERCEIVED COMPETENCIES OF NURSE EDUCATORS}

\begin{tabular}{|c|c|c|c|c|c|}
\hline Section 6. Nurse Practice Competencies & $\mathbf{0}$ & 1 & 2 & 3 & 4 \\
\hline \multicolumn{6}{|c|}{ 0: No Experience 1: Advanced Beginner 2: Competent $\quad$ 3: Proficient $\quad$ 4: Expert } \\
\hline \multicolumn{6}{|c|}{$\begin{array}{l}\text { 6.1. Implement and evaluate evidence based practice to improve patient } \\
\text { outcomes }\end{array}$} \\
\hline \multicolumn{6}{|l|}{ 6.2. Practice expertise in a specialized area of clinical practice } \\
\hline \multicolumn{6}{|l|}{ 6.3. Clinical practice expertise as a nurse generalist } \\
\hline \multicolumn{6}{|l|}{ 6.4. Provide guidance and coaching to patients and families } \\
\hline \multicolumn{6}{|l|}{ 6.5. Ability to multi-task, problem solve, and prioritize patient care needs } \\
\hline \multicolumn{6}{|l|}{$\begin{array}{l}\text { 6.6. Utilize diverse health and illness management techniques while caring } \\
\text { for patients }\end{array}$} \\
\hline \multicolumn{6}{|l|}{ 6.7. Administer direct patient care } \\
\hline \multicolumn{6}{|l|}{$\begin{array}{l}\text { 6.8. Collaborate with members of the health care team to improve health } \\
\text { outcomes }\end{array}$} \\
\hline \multicolumn{6}{|l|}{ 6.9. Function as a nurse within the acute care environment } \\
\hline \multicolumn{6}{|l|}{ 6.10. Incorporate ethical decision-making in clinical practice } \\
\hline \multicolumn{6}{|l|}{ 6.11. Serve as a professional nursing role model } \\
\hline 6.12. Exhibit cultural competence in the provision of nursing care & & & & & \\
\hline
\end{tabular}

The following 5 subcategories indicate competencies associated with the nurse educator role. Review each of the following educator role competencies associated with teaching \& advising, leadership, and scholarship requirements then indicate your current level of proficiency for each of the categories. Mark a 0 if the competency is not a requirement of your current position.

\section{Section 7: Teaching and Advising Role Competencies} 0: No Experience 1: Advanced Beginner 2: Competent 3: Proficient 4: Expert

\section{A : Facilitate Student Learning}

7A1. Utilize teaching strategies based on educational theory and evidenced based teaching/learning methodologies

7A2. Integrate and apply information technologies into teaching practice

7A3. Engage students in scholarly activities related to nursing

7A4. Facilitate student skill development in information literacy

7A5. Demonstrate respect, enthusiasm, and interest in students

7A6. Modify teaching strategies to accommodate diverse learning styles

$$
\text { 0: No Experience 1: Advanced Beginner 2: Competent 3: Proficient 4: Expert }
$$

\section{B : Facilitate Learning Development and Socialization}

7B1. Foster cognitive, psychomotor and affective development in learners

7B2. Facilitate student socialization into the nursing profession

7B3. Implement strategies to bridge theory and clinical practice

7B4. Exhibit a variety of personal teaching styles and interactions to positively 


\begin{tabular}{|c|c|c|c|c|c|}
\hline \multicolumn{6}{|c|}{ Section 7: Teaching and Advising Role Competencies } \\
\hline \multicolumn{2}{|l|}{ 0: No Experience 1: Advanced Beginner 2: Competent } & \multicolumn{4}{|c|}{ 4: Expert } \\
\hline \multicolumn{6}{|l|}{ influence learner outcomes } \\
\hline \multicolumn{6}{|l|}{$\begin{array}{l}\text { 7B5. Display expertise in clinical practice while serving as a role model, preceptor, } \\
\text { mentor, and guide to students }\end{array}$} \\
\hline \multicolumn{6}{|l|}{$\begin{array}{l}\text { 7B6. Demonstrate the ability to provide adequate and expert clinical supervision of } \\
\text { students }\end{array}$} \\
\hline \multicolumn{6}{|c|}{ 0: No Experience 1: Advanced Beginner $\quad$ 2: Competent $\quad$ 3: Proficient $\quad$ 4: Expert } \\
\hline 7C : Assessment and Evaluation Strategies & $\mathbf{0}$ & 1 & 2 & 3 & 4 \\
\hline \multicolumn{6}{|l|}{$\begin{array}{l}\text { 7C1. Describe appropriate evaluation strategies to assess student learning in the } \\
\text { affective, psychomotor, and cognitive domains }\end{array}$} \\
\hline \multicolumn{6}{|l|}{$\begin{array}{l}\text { 7C2. Apply evidenced based assessment and evaluation practices within an } \\
\text { academic arena }\end{array}$} \\
\hline \multicolumn{6}{|l|}{ 7C3. Develop test blueprints that reflect course objectives } \\
\hline \multicolumn{6}{|l|}{$\begin{array}{l}\text { 7C4. Provide evidence of the ability to interpret test analysis data to improve } \\
\text { teaching/learning process }\end{array}$} \\
\hline \multicolumn{6}{|l|}{$\begin{array}{l}\text { 7C5. Demonstrate organizational skills and ability to maintain appropriate and } \\
\text { accurate academic records }\end{array}$} \\
\hline 7D: Curriculum Design and Evaluation of Program Outcomes & $\mathbf{0}$ & 1 & 2 & 3 & 4 \\
\hline \multicolumn{6}{|l|}{$\begin{array}{l}\text { 7D1. Design nursing curricula that reflects the institutional philosophy and mission } \\
\text { statement }\end{array}$} \\
\hline \multicolumn{6}{|l|}{$\begin{array}{l}\text { 7D2. Develop nursing curricula in relation to the institution's conceptual } \\
\text { framework }\end{array}$} \\
\hline \multicolumn{6}{|l|}{$\begin{array}{l}\text { 7D3. Demonstrate ability to write student competency statements and learning } \\
\text { objectives }\end{array}$} \\
\hline \multicolumn{6}{|l|}{$\begin{array}{l}\text { 7D4. Demonstrate ability to select appropriate clinical experiences in accordance } \\
\text { with course outcomes and learner needs }\end{array}$} \\
\hline \multicolumn{6}{|l|}{$\begin{array}{l}\text { 7C5. Develop course learning activities and lesson content consistent with learner } \\
\text { needs and course outcomes }\end{array}$} \\
\hline \multicolumn{6}{|c|}{ 0: No Experience 1: Advanced Beginner 2: Competent 3: Proficient 4: Expert } \\
\hline 7E: Function within the Educational Environment & $|\mathbf{0}|$ & 1 & 2 & 3 & 4 \\
\hline \multicolumn{6}{|l|}{$\begin{array}{l}\text { 7E1. Demonstrate understanding and respect for the values and beliefs of students } \\
\text { and colleagues }\end{array}$} \\
\hline \multicolumn{6}{|l|}{$\begin{array}{l}\text { 7E2. Articulate professional goals consistent with the nursing program and parent } \\
\text { institution's mission and philosophy statements }\end{array}$} \\
\hline \multicolumn{6}{|l|}{$\begin{array}{l}\text { 7E3. Articulate understanding of educator role expectations in accordance with the } \\
\text { academic setting }\end{array}$} \\
\hline \multicolumn{6}{|l|}{$\begin{array}{l}\text { 7E4. Demonstrate knowledge of legal and ethical issues in relation to higher } \\
\text { education }\end{array}$} \\
\hline 0: No Experience 1: Advanced Beginner 2: Competent & 3: Proficient & & & & \\
\hline 7F : Leader and Collaborator Role Competencies & $\mathbf{0}$ & 1 & 2 & 3 & 4 \\
\hline
\end{tabular}




\begin{tabular}{|c|c|c|c|c|c|}
\hline \multicolumn{6}{|c|}{ Section 7: Teaching and Advising Role Competencies } \\
\hline \multicolumn{2}{|c|}{ 0: No Experience 1: Advanced Beginner 2: Competent 3: Proficient } & \multicolumn{4}{|c|}{ 4: Expert } \\
\hline \multicolumn{6}{|c|}{\begin{tabular}{|l|l|} 
7F1. Exhibit ability to convey ideas respectfully (written, electronic, and oral) &
\end{tabular}} \\
\hline \multicolumn{6}{|l|}{ 7F2. Demonstrate overall clinical and professional leadership abilities } \\
\hline \multicolumn{6}{|l|}{ 7F3. Demonstrate excellence in public speaking } \\
\hline \multicolumn{6}{|c|}{ 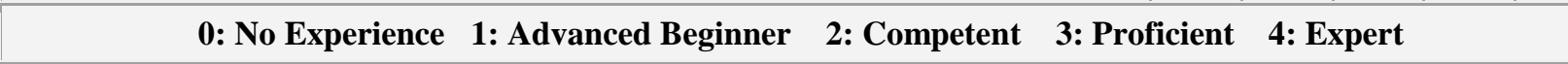 } \\
\hline 7G: Scholar Role Competencies & \begin{tabular}{l|l|} 
& $\mathbf{0}$
\end{tabular} & 1 & 2 & 3 & 4 \\
\hline \multicolumn{6}{|l|}{$\begin{array}{l}\text { 7G1. Describe knowledge of evidence based practice and clinical implementation } \\
\text { strategies }\end{array}$} \\
\hline \multicolumn{6}{|l|}{ 7G2. Engage in scholarly activities within area of expertise } \\
\hline \multicolumn{6}{|l|}{ 7G3. Exemplify skills as a researcher in nursing and health care* } \\
\hline \multicolumn{6}{|l|}{ 7G4. Assist others to interpret and apply research into clinical practice } \\
\hline \multicolumn{6}{|l|}{ 7G5. Identify areas of need and opportunities to conduct nursing research* } \\
\hline \multicolumn{6}{|l|}{ 7G6. Engage in scholarly writing activities* } \\
\hline 7G7. Skilled in proposal writing and program development & & & & & \\
\hline
\end{tabular}

* Not a requirement for Community College Nurse Educators

8.1Are you presently participating in a mentoring program? Yes, No

8.2 What type of mentoring program are you part of? Formal, Informal, or both Formal or Informal

8.3 How is you mentoring program administered? Face to Face, On-line, or Combination of both

8.4 Have you been assigned a mentor?

8.5 Have the competencies for nurse educators been addressed in your mentoring experience? Yes, No, Somewhat

Other (Please Describe): 


\section{Appendix B}

Initial Letter to Deans and Administrators

\section{Denice Kirchoff, MSN, ACNS, BC, CNE \\ Doctorial Candidate - Educational Leadership Studies \\ West Virginia University \\ Dr. Ernest Goeres, Committee Chair}

December 4, 2009

Dear Professor NAME:

I am currently a doctoral student at West Virginia University, and within the next year I hope to complete my dissertation. The study examines entry-level competencies of new full-time nurse faculty and determines how to best assist the novice nurse educator's transition toward role proficiency.

In preparation of gathering the appropriate data, I have been asked to identify nursing programs that have hired new, full-time faculty since August 2009 or will be hiring within the Spring 2010 semester. I have been granted permission from my method's advisor and chair of my doctoral committee to obtain this preliminarily information to determine the potential number of participants for my study.

At this time, would you please provide the number of new, full-time faculty that were hired during the identified timeline by replying to this e-mail. Please include the following information:

1. Number of full-time hires

2. Program's Name

Thank you for your time in assisting me with preparing for my dissertation research. If you have any questions, please contact me at 304-367-4391.

Denice Kirchoff, MSN, ACNS, BC, CNE

Doctoral Candidate at West Virginia University 
Appendix C

Nurse Educator Competency and Qualification Inventory

Kathleen Poindexter, PhD, RN, CNE

Denise Kirchoff has my permission to use the Nurse Educator Competency and Qualification Inventory as part of her dissertation study with appropriate references related to modifications for the purposes of the dissertation.

Kathleen Poindexter, PhD, MSN, RN, CNE

MSN CNS Education Concentration Coordinator

LS A109

College of Nursing

Michigan State University

East Lansing, MI

517/884-1263 (o)

231/250-5310 (c)

kathleen.poindexter@hc.msu.edu 
Appendix D

Letter to Deans and Administrators

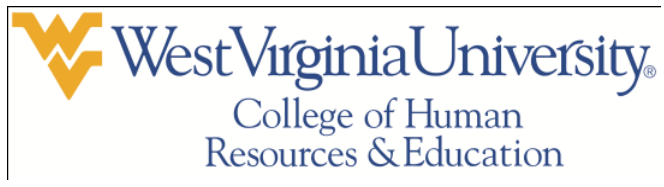

Subject Line: Dissertation Study: A Novice Nurse Educator Survey

Dear Nursing Program Administrator:

A few months ago, you received an email indicating that an upcoming research study would be conducted involving the competencies and qualifications of novice nurse educators. Thank you for responding to the email as it provided me with the preliminary data regarding the number of new hires within your program.

Currently, I am asking that you forward this email with the survey link to your new full-time faculty members that were hired for the 2009-2010 academic year.

If you have any questions, please feel free to contact me at (304) 291-2625 or at dkirchof@mix.wvu.edu. You may also contact my dissertation chair, Dr. Ernest Goeres at (304) 293-2088 or at ernest.goeres @ mail.wvu.edu.

Thank you,

Denice Kirchoff

Phone: 304-293-3707

Fax: 304-293-2279

\author{
Educational Leadership Studies \\ 608 Allen Hall \\ PO BX 6122 \\ Morgantown, WV 26506
}


Appendix E

To: Goeres, Ernest

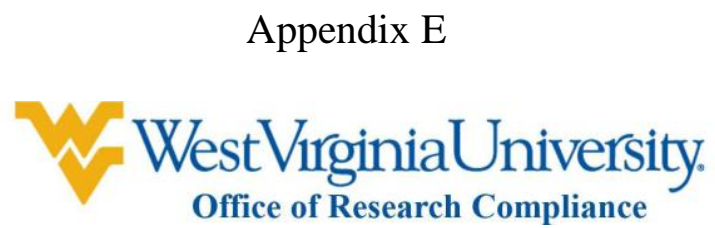

\section{Expedited-IRB Protocol-Exemption}

From: WVU Office of Research Compliance

Date: Friday, March 12, 2010

Subject: Exemption Acknowledgement

Tracking \#: H-22335

Title: The Perceived Role Competencies and Qualifications of Novice Nurse Educators in Prelicensure Registered Nurse Programs

The above-referenced study was reviewed by the West Virginia University Institutional Review Board (IRB) and was granted exemption in accordance with 45 CFR 46.101(2).

This protocol was reviewed using the following:

The following documents have been acknowledged for use in this study and are available in the BRAAN system:

Exemption Checklist (210r)

This research study was granted an exemption in accordance with Research that involves educational tests, survey procedures, interview procedures or observation of public behavior [45 CFR 46.101(2)].

Surveys, Questionnaires, Interviews

Attachments

Nurse Educator Competency and Qualification Inventory.doc

Miscellaneous Attachments

Attachments

Email to deans letter.rtf This letter is the letter that the deans and

administrators will receive with the survey link.

letter to novice faculty.rtf This is the revised letter with Dr. Goeres' contact information.

Thank you.

Board Designee: White, Barbara

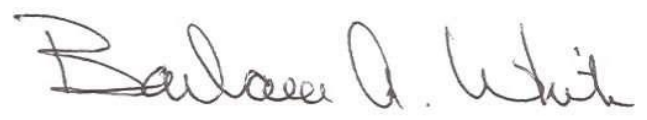

Letter Sent By: White, Barbara, 3/12/2010 11:25 AM

Once you begin your human subject research, the following regulations apply:

1. Any modifications to the study protocol must be reviewed and acknowledged by the IRB prior to implementation.

2. You may not use a modified form until it has been acknowledged by the IRB 
Appendix F

Letter to Participants

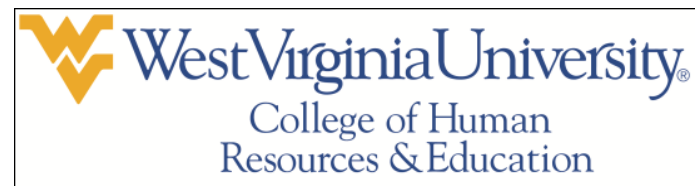

\section{Dear Participant,}

This letter is a request for you to take part in a research project to assess your level of qualifications and competencies during your first year as a nurse educator. This project is being conducted by Denice Hamula Kirchoff, MSN, APRN, BC, CNE in the College of Human Resources and Education at WVU with supervision of Dr. Ernest Goeres, Ph.D, a professor in the College of Human Resources and Education, for a Doctoral Degree in Educational Leadership Studies. Your participation in this project is greatly appreciated and will take approximately 10 minutes to fill out the attached questionnaire.

Your involvement in this project will be kept as confidential as legally possible. All data will be reported in the aggregate. You must be 18 years of age or older to participate. I will not ask any information that should lead back to your identity as a participant. Your participation is completely voluntary. You may skip any question that you do not wish to answer and you may discontinue at any time. Your current position will not be affected if you decide either not to participate or to withdraw. West Virginia University's Institutional Review Board acknowledgement of this project is on file.

I hope that you will participate in this research project, as it could be beneficial in understanding the strengths and shortcomings of new nurse educators as they enter into a challenging new role. The results of the study will help nursing programs to be better able to assist the learning needs of the new educator. Thank you very much for your time. Much success is wished for you in your new position. Should you have any questions about this letter or the research project, please feel free to contact Denice Kirchoff (304) 367-4391 or by e-mail at dkirchof@mix.wvu.edu

Thank you for your time and help with this project.

Sincerely,

Denice Kirchoff

Phone: 304-293-3707

Fax: 304-293-2279

Educational Leadership Studies

608 Allen Hall

PO BX 6122

Morgantown, WV 26506 
Appendix G

Curriculum Vitae

\author{
DENICE HAMULA KIRCHOFF EdD, MSN, ACNS, BC, CNE \\ 3011 Evergreen Lane \\ Morgantown, WV 26505 \\ 304-367-4391 [Office] ..... 304-291-2625 [Home]
}

\title{
SUMMARY OF QUALIFICATIONS
}

Possess knowledge and experience in Nursing Education including:

- Lecture

- Clinical Supervision

- Direct Patient Care

- Course and Clinical Coordinator

Experienced Registered Staff Nurse in all aspects of Critical Care including:

- Adult Trauma

- Coronary and Intensive Care

- Thoracic Intensive Care

- Medical-Surgical Critical Care

Additional areas of experience include:

- Medical-Surgical Step-Down, Rehabilitation, and Camp Nursing

EDUCATION

Jan. 2006 - Dec. 2010

\section{West Virginia University}

Doctor of Education Degree

Dissertation Defense November 19, 2010

Date of Graduation, December 10, 2010

Aug. 1993 to May 1998

West Virginia University

Master of Science in Nursing

May 1988 to Aug. 1993

University of Pittsburgh at Johnstown

Bachelor of Science in Nursing

August 1985 to May 1988

Conemaugh Hospital School of Nursing

Diploma Registered Nurse 


\section{PROFESSIONAL EXPERIENCE}

Fairmont State University, 1201 Locust Avenue, Fairmont, WV 26554

Position: $\quad$ Associate Professor of Nursing, Tenured, August 2004 to Present Assistant Professor of Nursing, August 1998 to August 2004

Responsibilities include:

- Classroom and Clinical Instruction of students enrolled in the ADN Program Courses taught include:

- Nursing care of Adults I and II

- Contemporary Nursing Management

- Pharmacology I \& II

Clinical instruction includes Adult Health Nursing

Non-teaching faculty load includes:

- Student advisement/ Class advisement

- Mentoring New Faculty

- Departmental and University Committees

- Self-study Writing for NLNAC Accreditation

- Community Service

Emma Kaufman Camp, Morgantown, WV 26505

Position: Camp Registered Nurse - Summer Employment, June 1999-2009

Responsibilities include:

- Nursing care of school age children through adolescent, as well as care of the adult counselors and staff.

- Administer basic first aid

- Coordinate physician appointments in the health center

- Communicate with area pharmacies regarding prescriptions

- Administration of medications and injections to the diabetic child

- Perform routine wellness checks

Med Temporary Services, Johnstown, PA 15902

Position: Registered Staff Nurse - December 2001 to 2003

Responsibilities include:

- Direct patient care of the adult Medical-Surgical Rehabilitation client

- Provide care for 10-12 patients with multiple medical conditions including renal failure and dialysis, cardiac monitoring, and respiratory failure with ventilator management

West Virginia University Hospital, Morgantown, WV 26505

Position: $\quad$ Registered Staff and Charge Nurse

August 1993 to August 1998 (full-time)

Responsibilities included:

- Direct Patient Care/Adult Medical-Surgical Critical Care Units 
- Charge Nurse

- Coordinated staffing and patient assignments

- Assisted in the development of "Trauma Nurses Talk Tough Program." [This program involved educating high school students on safety and injury prevention during prom and graduation season.]

- Patient care/Adult Trauma/Neuro-Surgical/Orthopedic and Cardiac Units

Waynesburg College, Waynesburg, PA 15370

Position: $\quad$ Clinical Faculty, School of Nursing - Aug. 1994 to May 1998, Responsibilities included:

- Clinical Instruction of Adult Medical-Surgical, Cardiac, Peri-Operative, and Critical Care Nursing in the Baccalaureate Nursing Program

Conemaugh Medical Center, Johnstown, PA 15905

Position: $\quad$ Registered Staff and Charge Nurse - 1988 to 1993

Responsibilities included:

- Staff and Charge Nurse in Adult Medical-Surgical Trauma and Coronary Critical Care Units

- Cardio-Thoracic Surgery Patient Care and Education

- Patient Care/Post Anesthesia Care Unit

- Preceptor for new employees and nursing students

\section{RESEARCH}

- The Perceived Role Competencies and Qualifications of Newly Hired Novice and Experienced Nurse Educators in Prelicensure Registered Nurse Programs A Regional Study, Dissertation, 2010

- An Exploratory Study of Faculty Mentoring in Nursing Education, Unpublished Study. 2008

- A Comparison of Oral and Pulmonary Artery Core Body Temperatures of Critically Ill Patients With and Without Endotracheal Intubation: A Pilot Study, Unpublished Master's Paper, 1998

\section{PRESENTATIONS}

- Nurturing Nursing Educators, The Development of an Online Faculty Mentoring Program, Gateway to Innovation and Creativity in Nursing Education, Baltimore, Villanova, October 2010, Podium presentation

- $\quad$ Strategies to Enhance your Success on the CNE Examination, Poster. Drexel Nursing Education Institute, June 2010

- You Tube in the classroom. Moving Forward with Today's student, Poster, Drexel Nursing Education Institute, June 2010 
- An Exploratory Study of Faculty Mentoring in Nursing Education. Poster, Drexel University Nursing Education Conference, June 4, 2009

- Implementing Team Nursing and Delegation in the Clinical Setting. , Poster, Drexel University Nursing Education Institute presentation. Atlantic City, 2008

- Group Testing: A Powerful Cooperative Learning Strategy, Podium Presentation, Drexel University Nursing Education Conference, Philadelphia, Pa. June 2004

- Group Testing: A Powerful Cooperative Learning Strategy, Podium Presentation, New Horizons in Teaching and Learning, Fairmont State University, August 2004

\section{LICENSURE}

Professional Nurse

- Commonwealth of Pennsylvania, 1988 to Present

Department of Professional and Occupational Affairs

- West Virginia Board of Examiners, 1993 to Present

\section{HONORS}

- Fairmont State University Foundation Fellow Award, Nurturing Nurse Educators: The Development of a Faculty Mentoring Program, 2010

- West Virginia Center for Nursing Scholarship Recipient, 2008, 2009, 2010

- West Virginia League of Nursing Scholarship Recipient, 2009

- FSU School of Nursing, Departmental Award, Excellence In Advising -- Student Nurses Association, 1999

- Outstanding Team Performance, WVU Hospital, "Trauma Nurses Talk Tough Program"

- Sigma Theta Tau National Honor Society of Nursing, ETA Chapter University of Pittsburgh

- Cum Laude Bachelor of Science in Nursing, University of Pittsburgh at Johnstown

- Outstanding Scholar Award - Division of Nursing, University of Pittsburgh at Johnstown, 1993

\section{PROFESSIONAL MEMBERSHIPS}

- National League for Nursing

- Golden Key National Honor Society, West Virginia University

- Sigma Theta Tau Nursing Honorary

- West Virginia Nurses Association 


\section{CERTIFICATIONS}

June 30, 2009 to June 30, 2014

National League for Nursing, New York

Certified Nurse Educator

Dec. 2006 to Nov. 30, 2011

American Nurses Credentialing Center, Washington, D.C.

Certified Clinical Nurse Specialist, Medical-Surgical Nursing

2005 to 2008

American Association of Critical Care Nurses

Critical Care Nursing

\section{PROFESSIONAL ACTIVITIES}

- Chapter Reviewer, The Nurse Role in Diagnostic testing, LWW, 2010

- Textbook Reviewer and Test Item Writer, Pearson Education Co. 2009-2010

- Maintain Nursing Skills in Clinical Practice 2001-2009

- Unity Day for West Virginia Nurses Association, 2000-2006

- Participate in GEAR-UP, Fairmont State University, 2000-2006, Fairmont, WV

\section{PUBLIC SERVICE}

- Breast Cancer Run, Volunteer, 2010

- Mon General Hospital Flu Shot Clinic, 2008, 2009

- Mon General Hospital Health Fair, 2009

- Career Fair, St. Francis de Sales School, 2009

- Read Aloud St. Francis de Sales, 2007-2010

- Lymphoma and Leukemia Society Neighborhood Volunteer, 2008, 2009, 2010

- Lymphoma and Leukemia Society "Light the Night Walk" 2002-2005

- FGH Hospital Flu Shot Clinic 2003-2005

- St. Mary's Catholic Church Member

\section{WORKSHOPS and CONTINUING EDUCATION}

- Drexel University Nursing Education Institute 2010, June 22-24, 12.5 hours

- METI Medical Education Technologies Basic Education, April 10, 12 hours

- Gateway to Innovation and Creativity in Nursing Education, Oct 21-24, 12 hours 
- The Ultimate One-day Diabetes Course. March 22, PESI, 8 contact hours

- Test Item Writing. University of Kentucky, May 18, 8 contact hours

- Drexel University Nursing Education Institute, Arlington Va. June 4-7, 15.5 hours

- Review for Certification: CNE June 4, 2009 7.5 hours

- Villanova University Review for Certification in Nursing Education, June 12, 8 hours

2008

- Drexel University Pre-Conference Workshop, June 26, 4 hours

- Drexel University Nursing, June 27, 12 hours

- IV Therapy Principles and Practice, October 9, 9.2 hours

- METI 2 day Simulation Practice Workshop, December 18,10 hours

2007

- Integrated Course Design, General Model, FSU Opening Week January 8

- Give and Grow Rich, FSU Opening Week January 9

- Preventing a Crisis: Subclinical Signs of Impending Doom, May 22, 3 hours

- The Ultimate One-Day Cardiac Diagnostics \& Interventions, June 5, 6.26 hours

- Vista Boot Camp Training, January 9-13, FSU 40 hours

- WVNA Nurse's Unity day February 9, 2.0 contact hours

- Unity Day 2 February 2, 2 contact hours

- Faculty Development: April 28, 2006 Including Prioritizing Content, Teaching Strategies and Clinical Teaching

- Vista Boot Camp Training, June 5-9, 2006FSU 40 hours

- HIV and STD's: Prevention and Management June 13, 7.5 contact hours

- Med- Surg Nursing: Current Trends, Treatments, and Issues, August 24, 7.6

- Simulated Learning, October 13,1.0 contact hour

- The Sexual Assault Response Team Training, November 6, 4.0 contact hours 